\title{
Transient Maternal IL-6 boosts glutamatergic synapses and disrupts hippocampal connectivity in the offspring
}

Filippo Mirabella ${ }^{1,2}$, Genni Desiato ${ }^{2,7, \S}$, Sara Mancinelli2, ${ }^{2, \S}$, Giuliana Fossati ${ }^{2}$, Marco Rasile ${ }^{1}$, Raffaella Morini ${ }^{2}$, Marija Markicevic ${ }^{3}$, Christina Grimm ${ }^{3}$, Clara Amegandjin ${ }^{4,5}$, Alberto Termanini ${ }^{6}$, Clelia Peano ${ }^{7,8}$, Paolo Kunderfranco ${ }^{8}$, Graziella di Cristo ${ }^{4,5}$, Valerio Zerbi ${ }^{3,10}$, Simona Lodato ${ }^{1,2}$, Elisabetta Menna ${ }^{2,9}$, Michela Matteoli ${ }^{2,9, *}$ and Davide Pozzi ${ }^{1,2, *}$.

${ }^{1}$ Humanitas University, Department of Biomedical Science, Pieve Emanuele, Milan, 20090, Italy

${ }^{2}$ Humanitas Clinical and Research Center - IRCCS, Rozzano, Milan, 20089, Italy

${ }^{3}$ Neuroscience Center Zurich, ETH Zurich and University of Zurich, Zurich, 8057, Switzerland

${ }^{4}$ Department of Neurosciences, Université de Montréal, Montréal, Québec, Canada.

${ }^{5} \mathrm{CHU}$ Sainte-Justine Research Center, Montréal, Québec, Canada.

${ }^{6}$ Bioinformatic Unit, Humanitas Clinical and Research Center, Rozzano, Milan, 20089, Italy

${ }^{7}$ Institute of Genetic and Biomedical Research, UoS Milan, National Research Council, Rozzano, Milan, 20089, Italy

${ }^{8}$ Genomic Unit, Humanitas Clinical and Research Center, Rozzano, Milan, 20089, Italy

${ }^{9}$ Institute of Neuroscience - National Research Council, Milan, 20139, Italy

${ }^{10}$ Neural Control of Movement Lab, Department of Health Sciences and Technology, ETH Zürich, Zurich, 8057 Switzerland

${ }^{\S}$ These authors contributed equally to this work

${ }^{*}$ Correspondence should be addressed to DP (davide.pozzi@humanitasresearch.it) and MM (michela.matteoli@hunimed.eu)

\section{Summary}

Early prenatal inflammatory conditions are thought to represent a risk factor for different neurodevelopmental disorders, with long-term consequences on adult brain connectivity. Here we show that a transient IL-6 elevation, occurring at vulnerable stages of early neurodevelopment, directly impacts brain developmental trajectories through the aberrant enhancement of glutamatergic synapses and overall brain hyper-connectivity. The IL6-mediated boost of excitatory synapse density results from the neuronautonomous, genomic effect of the transcription factor STAT3 and causally involves the activation of RGS4 gene as a candidate downstream target. The STAT3/RGS4 pathway is also activated in neonatal brains as a consequence of maternal immune activation protocols mimicking a viral infection during pregnancy. By demonstrating that prenatal IL- 6 elevations result in aberrant synaptic and brain connectivity through the molecular players identified, we provide a mechanistic framework for the association between prenatal inflammatory events and brain neurodevelopmental disorders. 


\section{Keywords}

Neurodevelopmental Disorder, Synaptic development, IL-6, STAT3, RGS4, Pro-inflammatory cytokines, Neuroinflammation, Glutamatergic Transmission, Maternal Immune Activation, Brain Connectivity.

\section{Introduction}

The formation of synapses during the development of the central nervous system (CNS) represents a critical process which ensures a proper brain connectivity patterns at adult stages (Lu et al, 2009; Williams et al, 2010). The centrality of this process has been highlighted by the evidence that several neurodevelopmental disorders, including Autism Spectrum Disorders (ASD) (Bourgeron, 2009; Delorme et al, 2013) and Schizophrenia (Hall et al, 2015; Owen et al, 2016), are characterized by defects in the formation, maturation and maintenance of synaptic contacts (Melom \& Littleton, 2011; Penzes et al, 2011), resulting in altered brain development (Courchesne et al, 2007; Supekar et al, 2013)

The dynamic of synapse formation is a complex and hierarchically regulated event in which both intrinsic and extrinsic factors act together to ensure a proper brain connectivity (McAllister, 2007) and a correct excitatory/inhibitory (E/I) balance (Cline, 2005; Gatto \& Broadie, 2010). Beyond the highly specialized genetic program, which allows the precise temporal expression of neuronal genes involved in synaptogenesis (Shen \& Scheiffele, 2010), recent evidences highlighted the critical contribution of environmental factors in the modulation of synapse formation (Grabrucker, 2012). Among them, inflammatory states occurring at early stages of neuronal development have been recognized as the main environmental insult which may negatively affect the entire brain developmental trajectory. Indeed, epidemiological and experimental studies indicate a clear association between inflammation during pregnancy and risk of neurodevelopmental disorders in the progeny (Bergink et al, 2014; Knuesel et al, 2014; Li et al, 2009; Onore et al, 2012; Potvin et al, 2008). Although the underlying mechanisms are still unknown, soluble immune molecules released upon inflammatory states are thought to be key players in this process (Bauer et al, 2007; Deverman \& Patterson, 2009; McAfoose \& Baune, 2009).

A molecule widely engaged during inflammation is interleukine-6 (IL-6). IL-6 is a pleiotropic proinflammatory cytokine that exerts several actions on the mature nervous system (Balschun et al, 2004; Erta et al, 2012), modulating a plethora of brain processes including energy homeostasis (Timper et al, 2017; Wallenius et al, 2002), adult neurogenesis (Monje et al, 2003; Vallieres et al, 2002), and axonal regeneration upon neuronal damage (Cafferty et al, 2004; Leibinger et al, 2013a; Leibinger et al, 2013b; Pieraut et al, 2011). Besides these effects, the cytokine also plays key actions during brain development. Indeed, mice embryos prenatally 
bioRxiv preprint doi: https://doi.org/10.1101/202011.02.364356; this version posted November 2 , 2020. The copyright holder for this preprint (which was not certified by peer review) is the author/funder, who has granted bioRxiv a license to display the preprint in perpetuity. It is made available under aCC-BY-NC-ND 4.0 International license.

exposed to IL-6 display behavioral defects at adult stages (Choi et al, 2016; Shin Yim et al, 2017; Smith et al, 2007b), while a tight association between elevated IL-6 levels in the pregnant mother and altered brain connectivity and working memory in the newborns has been reported in humans (Rudolph et al, 2018; Spann et al, 2018). These evidences strongly suggest that an early IL-6 elevation can deeply affect neuronal development, leading to behavioral abnormalities. However, whether this phenomenon might be linked to a long-lasting alteration of synaptic formation is still undefined.

Here we describe an hippocampal pro-synaptogenic effect of IL-6 which specifically involves glutamatergic synapses. The increased formation of excitatory synapses persists at mature stages and is associated with brain hyper-connectivity. We also demonstrate that this process depends on the activation of Signal transducer and activator of transcription-3 (STAT3) and involves its downstream target gene Regulator of G protein Signaling 4 (RGS4). Therefore, a transient increase of IL-6, as a consequence of inflammatory processes occurring at early phases of neuronal development, is sufficient to disarrange the entire process of excitatory synaptogenesis resulting in an abnormal brain connectivity in the adulthood.

\section{Results:}

\section{Transient prenatal IL-6 elevation enhances hippocampal glutamatergic synapses in the adulthood}

We first aimed to assess whether transient prenatal IL-6 elevations impact the density of synaptic contacts in the offspring at postnatal stages. To this aim, a single intraperitoneal (i.p) injection of either $5 \mu \mathrm{g}$ of IL-6 (Choi et al, 2016; Gallagher et al, 2013; Smith et al, 2007b) or vehicle (as control), was administered to pregnant mice at gestational day 15 (GD15) (Figure S1A), when hippocampus is already formed (Urban \& Guillemot, 2014), the neurogenesis is peaking whereas synaptogenesis and astrogenesis have not started yet (Angevine, 1965; Finlay \& Darlington, 1995; Reemst et al, 2016).

The number of excitatory and inhibitory synaptic puncta was evaluated in the CA1 radiatum area of mice at postnatal day (P) 15 through immunofluorescence analysis of both glutamate (V-glut) and GABA (V-gat) vesicular transporters (Figure 1A). We found that the area of V-glut, but not V-gat, positive puncta was significantly enhanced in the hippocampus of mice exposed to IL-6 at prenatal stages (Figure 1B). To evaluate whether the selective increase of glutamatergic synaptic inputs was accompanied by functional changes, glutamatergic and GABAergic synaptic basal transmission were simultaneously evaluated at single cell level by whole cell patch-clamp recording of pyramidal neurons in the CA1 hippocampal region (Figure $1 \mathrm{C}$ ). We found a substantial increase in the frequency of miniature excitatory post synaptic currents (mEPSCs) in the hippocampi of mice prenatally exposed to IL-6 as compared to vehicle (Figure 1D), whereas miniature excitatory post synaptic currents (mIPSCs) were not altered (Figure 1E), resulting in an excitatory/inhibitory (E/I) imbalance of neurotransmission (Figure 1F) 
bioRxiv preprint doi: https://doi.org/10.1101/2020.11.02.364356; this version posted November 2,2020 . The copyright holder for this preprint (which was not certified by peer review) is the author/funder, who has granted bioRxiv a license to display the preprint in perpetuity. It is made available under aCC-BY-NC-ND 4.0 International license.

Since maternal IL-6 elevation during pregnancy triggers the activation of peripheral cells, immune molecules and gut microbiota in the mother (Choi et al, 2016; Kim et al, 2017; Shin Yim et al, 2017) which could indirectly be responsible for the increase of glutamatergic synapses, IL-6 or vehicle were injected intraventricularly (ICV) in the embryos at E15 (Figure 1G) to bypass any indirect signaling of the mother. Synapse quantitation in P15 offspring hippocampi (Figure $1 \mathrm{H}$ ) revealed that, similarly to results obtained upon intraperitoneal injection, ICV administration of IL-6 promotes the increase of glutamatergic synapses (Figure. 1I).

\section{Prenatal IL-6 elevation disrupts hippocampal functional connectivity in the adulthood}

The selective increase in excitatory, but not inhibitory, synapses in mice exposed to maternal IL-6 elevation was found to persist up to P30 (Figure S1B-C). An abnormal number of excitatory synapses and/or an altered E/I balance within local microcircuits, found in many models of neurodevelopmental disorders (Durand et al, 2007; Lee et al, 2015; Sala et al, 2001), is often associated with macroscale alterations in functional connectivity that can be detected with resting-state fMRI (Ajram et al, 2017; Filipello et al, 2018; Pagani et al, 2019; Zhou et al, 2019). Hence, we determined whether the transient maternal IL-6 elevation had an effect on brain connectivity in adulthood. We therefore acquired resting state-fMRI (rs-fMRI) scans in 16 mice (9 treated and 7 controls) at 14 weeks of age using a standardized pipelines for anesthesia control, data acquisition and preprocessing (Zerbi et al, 2015; Zerbi et al, 2018) (Figure 2A). To probe the existence of aberrant functional connections, the blood-oxygen-level-dependent (BOLD) time series were extracted from 165 regions of interest (ROIs) using the Allen's Common Coordinate Framework and their connectivity couplings were measured using regularized Pearson's correlation coefficients. Randomized permutation testing (5,000 permutations) revealed an overall hyper-connectivity phenotype of IL-6 mice compared to controls (Figure 2B). The spatial distribution of the hyper-connected edges was widespread (242 out of 2724 edges were identified as significantly hyper-connected at $p<0.05$ ) and the strongest contribution was given by hippocampal-midbrain, hippocampal-parietal, hippocampal-cortical subplate, prefrontal-parietal and somatomotor-thalamic connections among all (Figure $2 \mathrm{C}$ ). Only 36 edges (1.3\%) were found to be hypoconnected in the IL-6 group as compared to vehicle controls (Figure S1D).

Next, we examined whether the excessive excitatory neurotransmission by IL-6 exposure prompts large-scale resting-state network (RSN) reconfiguration. The connectivity strength within fifteen maximally-independent RSNs was measured using a dual regression approach as described elsewhere (Filippini et al, 2009) (for a complete list and spatial distribution of the networks please refer to our previous study (Zerbi et al, 2015)). Statistical analysis was conducted by comparing the connectivity-strength within all the voxels that constitute each RSNs. In the dorsal hippocampal network, the connectivity was significantly higher in IL-6 group compared to controls (Figure 2D,E). The temporal association network also showed moderate increases in 
connectivity in the IL-6 group, without reaching statistical significance $(p=0.09)$. Conversely, a reduction in connectivity approaching significance was seen in the primary and secondary somatosensory network $(p=0.066$ and $p=0.130$, respectively (Figure S1E). None of the other networks were affected. These data suggest that excitatory neurotransmission after IL-6 exposure can be detected with rs-fMRI in the form of an increased synchronicity, especially within elements of the hippocampal network. The structural integrity of major axonal bundles was quantified by extracting fractional anisotropy (FA) values from seven whitematter structures as described (Zerbi et al, 2013b; Zerbi et al, 2019). All white matter tracts did not exhibit significant differences between IL-6 mice and vehicle controls (Figure S1F), indicating that prenatal IL-6 does not compromise the macroscopic characteristics of anatomical connections but rather impairs their function. In support of this, no major anatomical alterations were detected by Nissl staining in the cortex or hippocampus of mice exposed to IL-6 at E15 (Figure 2SA). Furthermore, analysis of cortical lamination in brains at P30 using antibodies for layer-specific markers including Special AT-rich sequence binding protein 2 (SATB2), which specifically labels commissural excitatory neurons in all cortical layers (Alcamo et al, 2008) and NeuroD2, pan-glutamatergic cortical neurons, did not reveal any defect in cortical architecture nor lamination in any experimental conditions (Figure 2SB,C). These data indicate that IL-6 exposure does not significantly alter the overall architecture of the cerebral cortex in the offspring. In addition, the brain of mature offspring (P30) did not display signs of astrogliosis and inflammation, as indicated by the lack of difference in the number and expression of the Glial Fibrillary Acidic Protein (GFAP) protein, a marker of astrocytes, and by the absence of altered number and morphology of Iba1-positive cells, a marker of microglia (Figure 2SC,D). Thus prenatal exposure of IL-6 does not lead to a chronic inflammatory state, nor astrogliosis, in the adult offspring.

Given the central role played by the hippocampus in specific forms of learning and memory, a derangement of hippocampal synaptic functioning and connectivity might be associated with an impairment of hippocampal-dependent behavioral task. A panel of tests was then employed to evaluate the possible occurrence of behavioral abnormalities (Figure 2F-I). We found that the prenatal exposure to IL-6 does not impinge the mice performance in the open field, elevated plus maze and novel object recognition tests (Figure 2F-G), indicating that locomotor activity, anxiety-like behavior and episodic memory were not compromised. However, when assayed through novel object location test, mice prenatally exposed to IL-6 showed a significantly lower discrimination index (Figure 2I), indicating a specific impairment of spatial memory.

These data demonstrate that a transient prenatal exposure to IL-6, in our experimental paradigm, results in increased glutamatergic synaptic contacts and enhanced excitatory neurotransmission, which associate with altered hippocampal-related functional connectivity and behavior, in the absence of major morphological defects and inflammatory signs. 
bioRxiv preprint doi: https://doi.org/10.1101/2020.11.02.364356; this version posted November 2, 2020. The copyright holder for this preprint (which was not certified by peer review) is the author/funder, who has granted bioRxiv a license to display the preprint in perpetuity. It is made available under aCC-BY-NC-ND 4.0 International license.

The pro-inflammatory cytokine IL-6 selectively enhances glutamatergic synaptogenesis through a direct action on neurons

We next aimed to gain more insights into the cellular and molecular mechanisms responsible for the cytokine effect. To investigate whether IL-6 enhances the intrinsic capacity of neurons to promote glutamatergic synapse formation, E18 embryos exposed to either IL-6 or vehicle at E15 were collected and employed to establish primary cultures of hippocampal neurons (Figure $3 \mathrm{~A}$ ), where synapses develop according to a stereotypical sequence of events, from a stage preceding synapse formation (1-3 Days In Vitro; DIV) to a synaptically active mature phase (13-14 DIV) (Matteoli et al, 1995). After the in vitro development, mature cultured neurons obtained from IL-6-exposed embryos exhibited higher mEPSCs frequency, without changes in amplitude, if compared to vehicle-exposed cultures (Figure 3B), whereas mIPSCs were unaffected (Figure 3C). Thus, the effect of IL-6 is intrinsically sculpted in neurons, even after their isolation from the brain context.

To assess whether IL- 6 was effective in promoting synapse formation by acting specifically on neuronal cells, we used primary cultures of embryonic hippocampal neurons directly exposed to IL-6. Hippocampal cultures were incubated with different concentrations of IL-6 $(1,5$ and $10 \mathrm{ng} / \mathrm{ml})$ starting from 1 up to 14 DIV, refreshing IL- 6 every 3 days (Figure 3D), and the mEPSCs were evaluated at 14 DIV by patch clamp recordings (Figure 3E). The frequency of mEPSCs was significantly increased upon incubation with IL-6 at $10 \mathrm{ng} / \mathrm{ml}$, whereas mEPSCs amplitude was unchanged (Figure 3F). Passive membrane properties, including resting potential (Figure 3SA) and input resistance (Figure 3SB) were not altered by IL-6 treatment at $10 \mathrm{ng} / \mathrm{ml}$, thus indicating that the overall health state of neurons was not affected by the cytokine at this concentration. Henceforth, IL-6 was used at $10 \mathrm{ng} / \mathrm{ml}$ in cultured neurons. Given the presence of glial cells in cultures, to rule out the possible contribution of astrocytes to the enhanced excitatory neurotransmission, cultured neurons were grown in the presence of the anti-proliferative agent cytosine arabinoside (Ara-C) to obtain pure neuronal cultures (Figure 4SA). The increased frequency of mEPSCs observed upon chronic IL-6 treatment (Figure 4SB,C), demonstrated that astrocytes are not involved in the enhancement of excitatory neurotransmission. It is worth noting that, similar to what obtained in vivo, mIPSCs were not affected by the same IL-6 concentration effective in promoting glutamatergic synapses (Figure $3 \mathrm{H}$ ), which is indicative of an excitatory/inhibitory (E/I) imbalance due to excessive excitatory inputs also in vitro.

To directly address whether the increased glutamatergic basal transmission results from a higher number of excitatory synapses, glutamatergic synaptic density was investigated in both control and treated cultures by using antibodies against the presynaptic vesicular glutamate transporter-1 (V-glut-1) and postsynaptic density-95 (PSD-95) (Figure 3G, upper panel). IL-6-treated cultures displayed a significantly increased density of Vglut-1 and PSD-95 positive puncta per unit length of parent dendrite, as well as higher extent of 
colocalization between Vglut-1 and PSD-95, indicating a higher number of structurally mature synapses along the dendritic branches (Figure 3G, lower panels).

The increase in mEPSCs frequency might in principle result from different mechanisms, including enhanced release probability at presynaptic terminals. To exclude this possibility, short term plasticity was evaluated through paired recording measurements between synaptically connected neurons (Figure 4SD) (Maximov et al, 2007). Untreated neurons exhibited a paired pulse facilitation (PPF) at different interpulse intervals (Figure 4SE), with the paired pulse ratio progressively reducing as the interpulse intervals increased, as already described (Farisello et al, 2013; Nanou et al, 2016). Such trend was not significantly altered in neurons subjected to IL- 6 chronic treatment, thus excluding that IL-6 enhances presynaptic release probability (Figure S4E). Notably, the amplitude of post synaptic currents (EPSCS) evoked by a single action potential was significantly higher in neurons exposed to IL-6 treatment (Figure S4F), in line with the increase in glutamatergic inputs (Chao et al, 2007).

We also ruled out that the increase in glutamatergic synapses resulted from homeostatic compensatory mechanisms (e.g. synaptic scaling), as a consequence of reduced neuronal excitability upon IL-6 treatment (Vereyken et al, 2007; Wierenga et al, 2006). Indeed, electrically-evoked calcium transients recorded through single cell calcium imaging (Figure S4G,H) (Bedogni et al, 2016; Pozzi et al, 2013) showed a comparable neuronal excitability in control and IL6-treated cultures (Figure S4I). Finally, the lack of changes in the total number of cells, as well as in the ratio between astrocytes and neurons, in cultures chronically exposed to IL6 (Figure S4J-L) excluded a role for the cytokine in modulating the overall cellular components of the culture.

\section{A single pulse of IL- 6 at stages preceding synaptogenesis is sufficient to promote a long-lasting increase of glutamatergic synaptic transmission.}

The chronic treatment with IL- 6 in cultured neurons does not perfectly reflect the transient maternal IL- 6 elevation induced in vivo, where embryos were exposed to a single pulse of IL-6 (see Figure 1). Hence, to probe whether a shorter incubation with IL-6 was still effective in promoting glutamatergic transmission, neuronal cultures were incubated with the cytokine at restricted phases of early neuronal development (Figure 4A). IL-6 treatment performed at 1 and 4 DIV, was sufficient to increase mEPSC frequency (Figure 4B,C) and glutamatergic synapse density at 14 DIV (Figure 4D,E). Furthermore, we found that even a single pulse of IL-6, applied either before (1DIV) or during (4 DIV) the synaptogenesis process (Figure 4F), was sufficient to boost glutamatergic synaptic transmission (Figure 4G,H). Conversely, a single pulse of IL-6 at synaptically active mature stages (13 DIV) (Figure 4I) failed to increase glutamatergic transmission (Figure $4 \mathrm{~J}, \mathrm{~K})$. These results indicate that IL-6 does not affect synaptic transmission acutely and that a single, transient IL-6 elevation at stages preceding synapse formation promotes a long-lasting selective enhancement of glutamatergic synapses. To test the specificity of IL-6 to act as prosynaptogenic molecule, we extended our 
analysis to other proinflammatory cytokines, such as INF $\gamma$, TNF $\alpha$ and IL1 $\beta$, known to play a central role in inflammation. The cytokines were individually applied to neuronal cultures at 1 DIV and glutamatergic transmission was assessed at mature stages (Figure S5A). Unlike to IL-6, none of the proinflammatory cytokines tested was effective in enhancing excitatory transmission (Figure S5B), indicating specific action of IL-6 as prosynaptogenic molecule.

\section{STAT3 activity is required for the IL-6 dependent increase of glutamatergic synapses.}

To gain insights into the molecular underpinnings of the IL-6-mediated effect, we explored IL6-dependent signaling pathways involved in this process. Given the long-lasting effect produced by IL-6 on glutamatergic synapses, it is plausible that a transcriptional-dependent mechanism might be engaged. IL-6 is known to activate a cascade of molecular events converging on the activation of the transcription factor Signal Transducer and Activator of Transcription 3, STAT3 (Heinrich et al, 2003). This prompted us to investigate the involvement of STAT3 in our process. We found that both transcript and protein levels of STAT3 were enhanced in neuronal cultures upon short IL-6 treatment (Figure 5A-D). To note, IL6-mediated upregulation of STAT3 occurred also in AraC-treated cultures, indicating a neuronal-specific STAT3 activation (Figure 5C, D). Accordingly, STAT3 upregulation was tested in the embryonic hippocampi after $24 \mathrm{~h}$ from IL-6 i.p. injection (Figure 5E), thus confirming its modulation in vivo (Figure 5F,G).

STAT3 is known to undergo phosphorylation at two specific residues, Tyrosine-705 (Tyr-705) and Serine-727 (Ser-727). Whilst the phosphorylation of Tyr-705 is known to be IL-6-dependent (Wen et al, 1995), the phosphorylation at Ser-727 varies in different cell types according to the type of stimulation triggered (Chung et al, 1997a; Chung et al, 1997b; Lim \& Cao, 1999). Analysis of STAT3 phosphorylation after an acute IL-6 application in hippocampal neurons (Figure $5 \mathrm{H}$ ) revealed a transient increase of phosphorylation at Tyr-705 (Figure 5I), whilst Ser-727 remained unaltered (Figure 5J), indicating that IL-6 directly engages STAT3 activation.

To next assess the contribution of STAT3 activation on glutamatergic synaptogenesis, we took advantage of a pharmacological compound, Stattic, which selectively prevents STAT3 phosphorylation (Schust et al, 2006). Cultured neurons were transiently exposed to a single pulse of IL-6 (at 1 DIV, see scheme in Figure 4F) in the presence of either vehicle (as control) or $1 \mu \mathrm{M}$ Stattic. This concentration was effective in blocking STAT3 phosphorylation (Figure 6A,B), without affecting neuronal survival (Figure S5C) nor synaptic basal transmission (Figure S5D). Patch clamp analysis of glutamatergic basal transmission (Figure 6C) showed that the IL-6-dependent increase of mEPSC frequency (Figure 6D) was prevented by Stattic. Accordingly, the higher glutamatergic synaptic density (Figure 6E,F) induced by IL-6 does not occur in the presence of STAT3 inhibitor. Noteworthy, Stattic also prevented the increase of glutamatergic transmission induced by chronic treatment with IL-6 (Figure S6A-C), without affecting the overall increase of STAT3 protein level (Figure S6D), 
bioRxiv preprint doi: https://doi.org/10.1101/202011.02.364356; this version posted November 2 , 2020. The copyright holder for this preprint (which was not certified by peer review) is the author/funder, who has granted bioRxiv a license to display the preprint in perpetuity. It is made available under aCC-BY-NC-ND 4.0 International license.

indicating that the IL-6-mediated upregulation of the transcription factor is not self-sustained by STAT3 itself. Moreover, IL-6 treatment did not change the expression of a panel of pre- post-synaptic proteins, nor the expression of the transcription factor NFK $\beta$, involved in many immune-dependent processes (Figure S6E). Furthermore, the short application of IL-6, effective in enhancing excitatory synaptic transmission (Figure 3), did not result in a sustained upregulation of STAT3 protein at later stages (Figure 6SF-G), indicating that the transcription factor is only transiently induced by IL- 6 .

To univocally demonstrate that STAT3 activation per se is sufficient to boost glutamatergic synapses in a neuron-autonomous fashion, we took advantage of two STAT3 mutant forms: the mutant Y705F, in which the tyrosine 705 residue is replaced by phenylalanine, thus mimicking a constitutively unphosphorylated state of the protein (inactive form), and the mutant $\mathrm{Y705E}$, in which the tyrosine 705 residue is replaced by a glutamate, thus mimicking a constitutively phosphorylated state (active form). Both STAT3 phosphomutants were translated as fusion-proteins bearing a Myc-tag, and the synaptic density analysis was performed in sparse transfected neurons expressing the fusion proteins (Figure 6G). Analysis of PSD-95 positive puncta density in the transfected neurons showed that the phosphomimetic mutant Y705E, but not the Y705F, significantly increases both PSD-95 density and size (Figure 6H). These data indicate that STAT3 transient activation is required for the IL- 6 effect on glutamatergic synapses.

\section{IL-6 promotes glutamatergic synaptogenesis through a STAT3 dependent genomic effect involving RGS4} activity.

As a transcription factor, STAT3 is known to modify many cellular processes through genomic effects (Heinrich et al, 1998). However, a recent evidence reported a non-genomic effect of STAT3 in modulating synaptic plasticity (Nicolas et al, 2012). To assess whether STAT3 activation affects glutamatergic transmission via genomic or non-genomic mechanisms, the fungal metabolite Galiellalactone, a selective STAT3 inhibitor able to prevent STAT3 binding to DNA without affecting its phosphorylation (Weidler et al, 2000), was employed. The compound working concentration was selected through a luciferase reporter assay probing STAT3 genomic activity. $4 \mu \mathrm{M}$ Galiellalactone was identified as the effective concentration able to block STAT3 genomic activity (Figure 6I) interfering with neither synaptic basal transmission (Figure S7D) nor the IL-6 dependent STAT3 phosphorylation (Figure S7C), and with no effect on neuronal survival (Figure $S 7 A, B$ ) . Interestingly, this concentration was able to block the increase of mEPSC frequency upon IL-6 (Figure $6 \mathrm{~J}, \mathrm{~K})$, thus confirming that the pro-synaptogenic activity of IL-6 is mediated by the genomic effect induced by STAT3 activation.

In order to identify the molecular pathways involved in IL6-induced glutamatergic synaptogenesis, we investigated the overall transcriptional rearrangement induced by IL- 6 through STAT3 activation by 10X single cell transcriptomics (scRNA sequencing). We assessed the genome-wide expression profiling of 3,687 single 
bioRxiv preprint doi: https://doi.org/10.1101/2020.11.02.364356; this version posted November 2,2020 . The copyright holder for this preprint (which was not certified by peer review) is the author/funder, who has granted bioRxiv a license to display the preprint in perpetuity. It is made available under aCC-BY-NC-ND 4.0 International license.

cells isolated from cultured hippocampal neurons in control conditions or upon IL-6 application (ctrl: 1865; IL-6: 1822) at DIV5 (Figure 7A). The median number of genes detected per cell was 5,229 for IL6 and 4,714 for ctrl, and the median number of transcript (unique molecular identifiers, UMI) per cell was 22,011 and 17,572 respectively. Unsupervised clustering analysis was applied on our pooled dataset using Seurat $R$ package (Butler et al, 2018) at various resolution to computationally define cellular heterogeneity. The resolution tree of the clustering is reported in Figure S8A. The optimal cluster resolution (0.6) - selected based on cluster index stability and number of identified clusters - resulted in eight transcriptionally distinct populations were identified according to their gene transcriptional profile (Figure 7B-C). The clusters were represented in the two experimental conditions and substantially overlapped (Figure 7D), suggesting that changes in the transcriptional profiling within each single cluster, rather than modifications of the distinct cell identities, occurred upon IL6 treatment.

We, then, systematically classified the cells by comparing their transcriptional profiles to pre-existing signatures gene sets of endogenous neuronal and glial types (Cahoy et al, 2008; Cembrowski et al, 2016; Harris et al, 2018; Lein et al, 2007) (Supplementary Table 1), see materials and methods for details), to automatically evaluate their respective gene enrichment. We thus defined eight main transcriptionally distinct cell types reflecting the diversity of neuronal and non-neuronal classes found in the hippocampus (Cembrowski et al, 2016; Pelkey et al, 2017).

Based on this enrichment analysis, we found that three out of the eight clusters belonged to the astrocyte lineage $(c 2,7,8)$, expressing glial specific marker gene including Gfap and Aqp4 with one of them showing markers of cycling cells (c2) (Figure S8E and Supplementary Table 1). The clusters $c 0, c 3, c 4, c 5$ and $c 6$ display enrichment, instead, of neuronal-specific genes, among others, Snap25, Syp and Syt1, which are expressed in hippocampal neurons. Among these neuronal clusters, only one could be clearly ascribed to the GABAergic lineage (c6), expressing markers prototypical of cortical and hippocampal GABAergic neurons including GAD1 and S/c32a1(Figure S8B-D, and Supplementary Table 1) (Mancinelli \& Lodato, 2018). In terms of relative abundance of distinct cellular populations, the single cell sequencing data also provided evidence that our in vitro culture system support the development of the different classes, while, at large, respecting the ratio of excitatory and inhibitory neurons, and glial cells, which is appropriate for the developmental stage of the analysis (Lodato \& Arlotta, 2015; Mancinelli \& Lodato, 2018; Pelkey et al, 2017)

To further investigate the transcriptional changes induced by transient IL- 6 application, we performed differential expression analysis between IL-6-stimulated conditions compared to control. We identified 63 differentially expressed genes (Adjusted p-value cut-off of 0.05 and a logfc.threshold $=0.20$ ), with 55 being upregulated and 8 being downregulated upon IL6 treatment. Notably, as expected Stat3 gene expression was significantly upregulated ( $p$ value $\leq 0.05)$, but only in the neuronal clusters $(c 0, c 3)$, indicating a predominant activation of STAT3 in specific neuronal cell types upon IL-6 stimulation. Noteworthy, IL-6-mediated Stat3 
expression was not subjected to any significant modifications in either astrocyte or GABAergic neuron cluster (Figure 7E-F).

In order to identify possible Stat3 co-associated genes, we then combined an unbiased correlation analysis within neuronal clusters where Stat 3 was found significantly upregulated $(c 0 ; c 3)$, together with a differential analysis between IL-6-stimulated cultures and controls. Only four genes show significant correlation with Stat3 expression upon IL-6 treatment (Figure 7F, bottom table). Among them, the highest correlation (positive) was found between Stat3 and Rgs4 ( $r=0.31)$, indicating that in those clusters where Stat3 was upregulated, Rgs4 expression was concomitantly increased (Figure $7 \mathrm{G}, \mathrm{H}$ ), ranking at the top of significantly correlated genes. Interestingly, this gene was highly enriched in neuronal clusters (Figure $7 \mathrm{H}$ ). Furthermore, when we analyzed the promoter region of Rgs 4 through bioinformatics tools for transcription factor binding sites prediction (Khan et al, 2018; Sandelin et al, 2004), we found distinct putative sites containing Stat3 response elements predicted with relative profile score threshold $80 \%$ (Figure S8F). These results suggest that Rgs 4 could represent a downstream target gene of STAT3 upon IL-6 stimulation.

The data obtained through single-cell sequencing approach were then validated through qPCR quantitation of Rgs4 mRNA levels in primary cultured neurons upon acute IL-6 treatment. Rgs4 was significantly upregulated upon IL-6 treatment in a STAT3 dependent mechanism, as Galiellalactone was able to completely prevent the IL-6 mediated mRNA elevation (Figure 8A). STAT3 activity induced RGS4 transcriptional expression in a cell autonomous fashion. This was demonstrated by transfecting mouse N2A neuronal cell lines with different plasmids expressing either the active (STAT3-Y705E) or the inactive (STAT3-Y705F) form of STAT3 together with a plasmid encoding GFP as a report (Figure 8B). qPCR quantification of RGS4 mRNA expression in FACS-sorted $\mathrm{GFP}^{+}$cells, revealed that only the active form of STAT3 induces a significant enhancement of RGS4 expression (Figure 8C).

To next provide a causal link between RGS4 upregulation and the IL-6-mediated increase of glutamatergic synapses, we took advantage of the recently identified small-molecule CCG-63802, a selective RGS4 inhibitor (Blazer et al, 2010). Neuronal cultures were treated with IL-6 at 1 DIV (see scheme in Figure 4F) in the presence of either the RGS4 inhibitor or vehicle and the excitatory synaptic transmission was monitored at 14 DIV (Figure 8D). The inhibition of RGS4 completely prevented the IL-6-dependent enhancement of glutamatergic transmission (Figure 8E), thus demonstrating that STAT3 -dependent RGS4 elevation is required for the increase of glutamatergic synaptic contacts induced by IL-6.

Finally, to directly investigate the engagement of RGS4 genes in in vivo models of prenatal inflammation, pregnant mice were intraperitoneally injected at GD15 with either IL-6 or with Polyinosinic:polycytidylic acid (poly (I:C)), a synthetic analog of viral double-stranded RNA, a well-established model of Maternal Immune activation (MIA) (Choi et al, 2016; Corradini et al, 2017; Hsiao \& Patterson, 2011; Shin Yim et al, 2017; Smith 
bioRxiv preprint doi: https://doi.org/10.1101/2020.11.02.364356; this version posted November 2, 2020. The copyright holder for this preprint (which was not certified by peer review) is the author/funder, who has granted bioRxiv a license to display the preprint in perpetuity. It is made available under aCC-BY-NC-ND 4.0 International license.

et al, 2007a). Poly I:C was used at two different concentrations, $2 \mathrm{mg} / \mathrm{kg}$ or $20 \mathrm{mg} / \mathrm{kg}$, and the expression levels of STAT3 and RGS4 were evaluated after 24 hours from the injection in embryonic hippocampi (Figure 8F). In accordance with the result obtained upon IL-6 injection, the higher Poly I:C concentration was effective in promoting the upregulation of both STAT3 and RGS4 (Figure 8G), thus confirming the involvement of these two genes in MIA models.

\section{Discussion}

Synapse formation represents a fundamental key step in the brain developmental program which may be profoundly affected by genetic defects. However, environmental stressors occurring at this stage, among all inflammatory conditions, may have long-term effects on physiological trajectories, affecting brain connectivity and behavior in adulthood (Boulanger, 2009; Deverman \& Patterson, 2009). Although chronic inflammation is recognized to have detrimental consequences on many aspects of neuronal functioning (Glass et al, 2010; Kotas \& Medzhitov, 2015; Mandolesi et al, 2015; Najjar et al, 2013; Vezzani et al, 2011), inflammation associated with prenatal infections is likely to be an acute phenomenon (Benedusi et al, 2015; Garetto et al, 2016; Kallikourdis, 2018; Munoz-Suano et al, 2012), with a long-range impact on synaptogenesis which is completely unknown. This aspect has a crucial relevance given the clear association between prenatal immune activation and neurodevelopmental diseases, such as ASD and schizophrenia, occurring during childhood and adolescence (Boulanger-Bertolus et al, 2018; Estes \& McAllister, 2016; Knuesel et al, 2014).

In this study, using a combination of in vitro and in vivo models, we demonstrated that a transient elevation of IL-6 levels at early developmental stages is sufficient to exert a specific long-lasting effect on glutamatergic synaptogenesis, resulting in excessive density of excitatory inputs accompanied by enhanced synaptic basal transmission. The pro-synaptogenic effect of IL-6 occurs selectively in a specific developmental window characterized by the presence of postmitotic neurons where synaptic contacts are not formed yet, thereby representing a vulnerable period in which IL-6 is specifically able to enhance the intrinsic capacity of neurons to form glutamatergic synapses. Indeed, when applied at later stages of neuronal development the cytokine, we found no effect at glutamatergic synaptic transmission and, accordingly, it has been reported that acute application of comparable IL- 6 concentration on mature brain slices shifts the E/I balance through a reduction of GABAergic synaptic transmission without any alterations of glutamatergic inputs (Garcia-Oscos et al, 2012). These evidences highlight the capacity of IL- 6 to affect distinct subpopulations of neurons at specific developmental stages, resulting in different effects on neuronal functioning.

The increased number of glutamatergic contacts, together with the lack of effect on inhibitory synapses is indicative of an E/I imbalance produced by IL-6. A proper E/I ratio is a fundamental factor ensuring a correct brain functioning in adulthood (Bhatia et al, 2019; Deco et al, 2014; Jelitai et al, 2016), and represents a 
bioRxiv preprint doi: https://doi.org/10.1101/2020.11.02.364356; this version posted November 2, 2020. The copyright holder for this preprint (which was not certified by peer review) is the author/funder, who has granted bioRxiv a license to display the preprint in perpetuity. It is made available under aCC-BY-NC-ND 4.0 International license.

pathological feature of different neurodevelopmental disorders, such as ASD and schizophrenia (Lisman, 2012; Nelson \& Valakh, 2015; O'Donnell et al, 2017; Sohal \& Rubenstein, 2019). To note, several mouse models of neurodevelopment disorders characterized by an E/I imbalance (Durand et al, 2007; Lee et al, 2015; Sala et al, 2001) also display altered brain functional connectivity (Ajram et al, 2017; Filipello et al, 2018; Pagani et al, 2019; Zhou et al, 2019), so highlighting the association between these two main hallmarks in brain disorders. Interestingly, we found an overall hyper-connectivity in the brain of adult mice prenatally exposed to IL-6, with a particular involvement of the hippocampal and somatomotor-thalamic regions. The relevance of this finding is underlined by recent results obtained in humans showing a tight association between maternal IL-6 elevations during pregnancy and altered brain connectivity in the newborns (Rudolph et al, 2018; Spann et al, 2018). Hence, our finding that IL-6 exerts a pro-synaptogenic role on glutamatergic synapses, associated with altered brain connectivity, may represent a possible molecular underpinning of the IL-6 effect detected in humans.

It has been previously found that IL- 6 elevations in models of prenatal immune activation, engage other proinflammatory cytokines, such as IL-17, (Choi et al, 2016; Shin Yim et al, 2017) through the activation of maternal gut microbiota (Kim et al, 2017), which in turn leads to brain developmental defects (Choi et al, 2016; Shin Yim et al, 2017). Our evidence that the direct injection of IL-6 into the ventricles of the fetal brain at E15 increases the number of glutamatergic contacts in the adult offspring at P15, thus recapitulating the effects produced by maternal IL- 6 elevations, indicates that IL- 6 affects synapse formation directly in the embryos, without requiring the activation of other immune-related molecules in the mother. In line with this hypothesis, it is known that IL-6 can cross the placental barrier (Dahlgren et al, 2006), thus further supporting the notion that a maternal IL-6 elevation per se can directly reach the fetal brain thereby acting onto neurons.

Since the IL-6 receptor is expressed in the brain (Aniszewska et al, 2015; Gadient \& Otten, 1993; Gadient \& Otten, 1996; Rothaug et al, 2016) including in hippocampal neurons (Gadient \& Otten, 1994; Sawada et al, 1993; Vereyken et al, 2007), a possible direct action of the IL-6 onto neurons might be expected. We provided robust evidences demonstrating that the effect of IL- 6 on excitatory synapses was not ascribable to any indirect effect of the cytokine on brain cell types other than neurons. Indeed, IL- 6 treatment enhanced excitatory transmission in virtually pure neuronal cultures, devoid of astrocytes. Furthermore, we ruled out any possible mitogenic effect of IL-6 on glial cells. This latter result is not trivial, given the crucial role played by IL-6 and STAT3 in different brain tumors (Lee et al, 2010; Levison et al, 2000; Selmaj et al, 1990; Weissenberger et al, 2004; Yu et al, 2009). However, the mitogenic action of the cytokine is driven by a chronic inflammatory state (Jones \& Jenkins, 2018; Mantovani et al, 2008), whilst our paradigm relies on a transient activation of IL6-mediated signaling. Moreover, the cytokine did not promote any pro-survival effect on hippocampal neurons, as instead reported in other neuronal cell types, like catecholaminergic (Kushima et al, 1992); cholinergic (Hama et al, 1989) and retinal ganglion neurons (Mendonca Torres \& de 
Araujo, 2001). Also, IL-6 did not affect neuronal excitability thus excluding indirect homeostatic compensatory effects such as synaptic scaling. All these results support the view of a direct action of IL-6 onto neurons resulting in a pro-synaptogenic effect at excitatory synapses. Furthermore, the effect appears to be highly specific for this immune molecule, as other key proinflammatory cytokines activated upon inflammation (e.g. INF $\gamma$, TNF $\alpha$ and IL1 $\beta$ ), failed in promoting the enhancement of glutamatergic neurotransmission. IL- 6 thus plays a unique role in the control of excitatory synaptogenesis and probably brain connectivity.

The long-lasting effect produced by IL- 6 on glutamatergic synaptogenesis results from a transcriptional mechanism associated with a genomic rearrangement, and we identified the transcription factor STAT3 as a central molecular player underlying this effect. Although already studied in many different cellular context, including immune (Jiang et al, 2014; Maritano et al, 2004), cancer (Yu et al, 2009), neuronal progenitor (Gallagher et al, 2013) and in mature neurons (Fang et al, 2013; Leibinger et al, 2013a; Murase et al, 2012; Nicolas et al, 2012; Park et al, 2012), the direct role of STAT3 in neuronal synapse formation has never been investigated before. We show that STAT3 is both transcriptionally and functionally activated upon IL-6 elevation. To note, the IL6-dependent upregulation of the protein occurs transiently in a STAT3 independent manner, in contrast to immune cells in which STAT3 expression is autoregulated (Ichiba et al, 1998; Narimatsu et al, 2001). Importantly, STAT3 activation is causally linked with the increase of glutamatergic synapses and it promotes glutamatergic synaptogenesis in a cell autonomous fashion. We also demonstrate that the effect of STAT3 is mediated by transcriptional mechanisms (Heinrich et al, 1998), and does not rely on non-genomic effect as previously reported for synaptic plasticity (Nicolas et al, 2012).

It is worth noticing that STAT3 is significantly upregulated by IL-6 in two specific neuronal cell clusters, distinct from GABAergic neurons, thus indicating a predominant effect of the cytokine on bona-fide glutamatergic neurons, which likely explains the selective action of the cytokine at excitatory synapses.

One major accomplishment of our study is the identification of RGS4 as a STAT3 downstream neuronal gene, responsible for the boost of excitatory synapses through single cell transcriptomics. RGS4 belongs to a class of gene family composed by 30 different members involved in the regulation of G-coupled receptorassociated signaling through their role as GTPase-activator proteins (GAP) in modulating intracellular second messengers (Bansal et al, 2007; Berman et al, 1996a; Berman et al, 1996b; Hepler et al, 1997). RGS4 is the most abundant isoform in the CNS, being highly expressed in prefrontal cortex, hippocampus thalamus and striatum (Ni et al, 1999; Nomoto et al, 1997). Accordingly, the single cell analysis revealed a high enrichment of RGS4 in neuronal specific cluster genes. Although RGS4 role has been well studied in mature neurons, whereby it regulates multiple aspects of neuronal physiology including synaptic transmission and plasticity (Gerber et al, 2016), only few studies have investigated the possible involvement of RGS4 in neuronal 
development (Cheng et al, 2013; Pallaki et al, 2017). Furthermore, its transcriptional regulation is completely unknown. We provide evidences that RGS4 expression is dependent on STAT3 genomic activity and its activation is crucial for the IL6-mediated boost of excitatory synapses. Given the importance of G-protein signaling in neuronal development (Munno et al, 2003; Shelly et al, 2010), we propose RGS4 as a new player in the process of glutamatergic synaptogenesis, although its precise role in this phenomenon needs further investigations. We hypotheses that an early upregulation of the protein might modulate G-protein dependent intracellular signaling thus affecting the intrinsic capacity of neurons to form excitatory synapses. The role of RGS4 in neuronal development is of particular interest in view of its involvement in neurodevelopmental disorders. Indeed, polymorphisms in RGS4 gene (Chowdari et al, 2002; Shirts \& Nimgaonkar, 2004; Talkowski et al, 2006), and alterations of the protein levels (Dean et al, 2009; Erdely et al, 2006; Schwarz, 2018), were detected in patients affected by schizophrenia, thus making RGS4 one of the most promising candidate gene for this neurodevelopmental disorder (Levitt et al, 2006). It is now well established that autism and schizophrenia are two neurodevelopmental pathological conditions characterized by an aberrant synaptic connectivity (Frankle et al, 2003; Glausier \& Lewis, 2013; Konopaske et al, 2014; Penzes et al, 2011). Given the importance of maternal Immune activation as a risk factor in neurodevelopmental disorders (Bauman et al, 2014; Estes \& McAllister, 2016; Giovanoli et al, 2016; Lipina et al, 2013; Malkova et al, 2012; Missault et al, 2014), our findings that STAT3 and RGS4 expression are upregulated in the brain of embryos exposed to MIA represent a strong indication for a critical involvement of these two genes in inducing long-term consequences on synaptic density and brain connectivity upon prenatal inflammatory conditions.

Hence, our study provides a new piece of evidence about the complex cross-talk between immune and central nervous systems (Pozzi et al, 2018), unveiling the crucial contribution of two fundamental molecular neuronal players, STAT3 and RGS4, in abnormal synaptic formation and brain connectivity upon early IL6mediated inflammation. Given the current lack of pharmacological tools for the prevention of neurodevelopment disorders, these results represent a promising perspective in the identification of new druggable pathways for early interventional strategies.

\section{Acknowledgements}

We thank Prof. Valeria Poli, Department of Molecular Biotechnology and Health Sciences, University of Turin, Italy for kindly providing us all plasmids coding for the phosphomimetic mutants of STAT3; Dr Marinos Kallikourdis for Intellectual inputs and comments on the manuscript.

\section{Autor contribution}

F.M. performed and analyzed electrophysiological, biochemical and immunofluorescence experiments; G.D. Performed and analyzed qPCR experiments; G.F. performed in vitro immunofluorescence experiments and 
analysis; M.R. and F.M. performed the in vivo injections on pregnant mice; S.M. and S.L performed the intraventricular injections and immunofluorescence analysis; C.P. performed single cell sequencing experiment; P.K. and A.T. analyzed and interpreted the single cell sequencing data; R.M. performed the ex vivo electrophysiological recordings; Ma.M., C.G. and V.Z. functional connectivity experiments and data analysis; E.M. acquisition and analysis of immunofluorescence experiments; M.M., D.P., E.M., F.M., G.D., designed, analyzed and interpreted the data. M.M. and D.P. conceived the study and wrote the manuscript.

\section{Declaration of interests}

The authors declare that there is no conflict of interest regarding the publication of this article.

\section{Figure Legends:}

Figure 1. Transient prenatal exposure of embryos to IL-6 at E15 increases Glutamatergic synapses in the offspring at post-natal stages.

(A) Immunofluorescence analysis of Glutamatergic and GABAergic synapses identified as Vglut-1 (in green) or V-gat (in red) positive puncta respectively performed in the stratum radiatum of CA1 hippocampal region of offspring derived from Vehicle- (Vehicle) or IL-6 treated mother (IL-6). Scale bar $5 \mu \mathrm{m}$. Right panels, high magnification image relative to the dotted square.

(B) Quantitative analysis of Vglut-1 (vehicle $n=5$ mice; IL-6 $n=7$ mice. 3 independent experiments) and Vgat (vehicle $n=6$ mice; IL- $6 \mathrm{n}=7$ mice. 3 independent experiments) area in the two conditions. MannWhitney test. ${ }^{* *} p=0,0025$.

(C) Electrophysiological traces of mEPSCs and mIPSCs recorded in CA1 pyramidal hippocampal neurons in acute brain slices established from P15 offspring embryonically exposed to Vehicle or IL-6.

(D-E) Quantitative analysis of mEPSCs (vehicle $n=12$ cells, 4 mice; IL-6 $n=18$ cells, 5 mice. 3 independent experiments) and mIPSCs (vehicle $n=7$ cells, 3 mice; IL- $6 n=8$ cells, 3 mice. 3 independent experiments) frequency and amplitude. Mann-Whitney test ${ }^{* *} \mathrm{p}=0,0009$.

(F) quantitative analysis of E/I ratio calculated as ratio between mEPSCs and mIPSCs frequency recorded at single cell level. (vehicle $n=9$ cells, 3 mice; IL-6 $n=7$ cells, 3 mice. 3 independent experiments) MannWhitney test $* * p=0,0032$

(G) Schematic representation of the experimental procedure: intraventricular injection of vehicle or IL-6 (10ng/embryo) were performed in E15 embryos and the offspring were analyzed at post-natal day 15 by evaluating excitatory synapses. 
(H) Immunofluorescence analysis of Vglut-1 and V-gat positive puncta respectively performed in the stratum radiatum of CA1 hippocampal region of P15 offspring exposed to vehicle- (vehicle) or IL-6 via intraventricular injection. Scale bar $10 \mu \mathrm{m}$.

(I) Quantitative analysis of Vglut-1 area in CA1 hippocampal region in the two conditions. (vehicle $\mathrm{n}=7$ injected mice; IL-6 $\mathrm{n}=8$ injected mice). Mann-Whitney test. ${ }^{* * *} \mathrm{p}=0,0003$.

Figure 2: Offspring prenatally exposed to IL-6 show hyppocampal hyperconnettivity and altered spatial memory.

(A) Schematic of the experimental set-up for MRI recordings. Adult offspring from mothers exposed to IL-6 or Vehicle at GD15 underwent a single MRI session to record resting-state fMRI and diffusion tensor imaging, under light anesthesia (isoflurane $0.5 \%+$ medetomidine $0.1 \mathrm{mg} / \mathrm{kg} / \mathrm{h}$ ).

(B) Randomized non-parametric statistics of whole-brain functional connectome mapping indicates a shift toward hyper-connectivity in IL-6 mice

(C) Circos-plot showing the anatomical location of hyper-connected edges $(n=242)$ in IL-6 mice compared to vehicle-treated mice ( $p<0.05$, uncorrected). (Vehicle $n=9$ mice, IL-7 $n=7$ mice. Three independent experiments)

(D) Dual-regression analysis in 15 resting-state networks (RSNs) revels a significant increase in the Dorsal Hippocampal network strength in the IL-6 treated group compared to vehicle control mice $(p=0.017$, Bonferroni corrected).

(E) Multivariate ANOVA, Bonferroni corrected across 15 RSNs. Bar plots represent mean \pm SEM. $* *=p<0.01$.

(F-I) Behavioral evaluation of motor and cognitive functions.

(F-G) Open field (F): Quantification of distance travelled separately in the center and periphery, and total distance (in $\mathrm{cm}$ ) in an open field arena. Elevated plus maze (G): quantification of the percentage of time spent in the closed and open arms of plus maze arena. Two-way Anova with Sidak's multiple comparison Post hoc test. Vehicle $\mathrm{n}=13$ male mice, IL-6 $\mathrm{n}=7$ male mice, from 3 independent mothers.

(H-I) Discrimination index values in novel object recognition $(\mathrm{H})$ and in novel object location (I). Vehicle $\mathrm{n}=10$ male mice, IL- $6 \mathrm{n}=13$ male mice from 2 independent mothers. ${ }^{*} \mathrm{p}=0,0167$ Unpaired $\mathrm{t}$ test with Welch's correction. 
Figure 3. The proinflammatory cytokine IL-6 selectively increases Glutamatergic synaptogenesis in developing hippocampal cultures.

(A) Representative scheme of the experimental procedure: a single pulse of either vehicle (saline, as control)

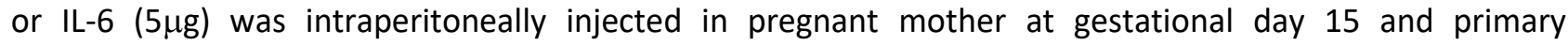
hippocampal neurons were established at E18. Cultured neurons were assayed at 14 DIV through patchclamp recording. (B) Quantitative analysis of mEPSCs frequency and amplitude in cultures established from either vehicle or IL-6 exposed embryos. (Vehicle $n=18$ cells, IL-6 $n=25$ cells. Three independent experiments). Mann-Whitney test. ${ }^{* * *} \mathrm{p}=0,0005$.

(C) Quantitative analysis of mIPSCs frequency and amplitude in control and upon IL-6 treatment cultures (Vehicle $n=14$ cells, IL-6 $n=18$ cells. Three independent experiments). Mann-Whitney test.

(D) Schematic representation of the experimental procedure. Different concentration of IL-6 were incubated throughout the in vitro development of hippocampal neurons, from 1 DIV up to 13 DIV, adding the cytokine every 3 days, and subsequently analyzed at 14 DIV.

(E) Representative traces of electrophysiological recordings of mEPSC performed in neuronal cultures at 14 days in vitro (DIV) upon chronic treatment with IL-6 at the indicated concentrations.

(F) Quantitative analysis of both frequency (left panel) and amplitude (right panel) of mEPSCs recorded at different concentration of IL-6. (Cells: Ctrl $n=27,1 n g / m I n=17,5 n g n=14,10 n g n=28$. Three independent experiments). One-way ANOVA on ranks followed by Dunn's multiple comparison test $* * * p=0,0005$, $* * p=0,0063, * p=0,0377$.

(G) Immunofluorescence analyses of glutamatergic synaptic contacts recognized using antibodies against post-synaptic (PSD 95, green) and presynaptic (Vglut1, blue) markers localized along dendritic processes (Beta III Tubulin, red) in control and after chronic treatment with IL-6 10ng/ml. Scale Bar $10 \mu \mathrm{m}$. Lower panels: bar graphs showing post-synaptic (left graph) pre-synaptic (central panel) and the colocalizing puncta density (right panel). (dendrites: ctrl $n=64$; IL-6 $n=70$. Four independent experiments). Mann-Whitney test. $* * * * p<$ $0.0001, * * * p=0.0002, * * * * p<0.0001$.

(H) Representative traces of electrophysiological recordings of mIPSC performed in neuronal cultures at 14 DIV upon chronic treatment with IL-6 at $10 \mathrm{ng} / \mathrm{ml}$. Lower panel: quantitative analysis of amplitude and frequency of mIPSCs (Cells: Ctrl n=22, IL-6 n=23. Three independent experiments). Mann-Whitney test.

Figure 4. A single IL-6 treatment at early stage of neuronal development is sufficient to increase Glutamatergic synapse at mature stages. 
(A) Schematic representation of the experimental procedure: IL-6 at $10 \mathrm{ng} / \mathrm{ml}$ was added at early stages of neuronal development at 1 and 4 DIV, and at 7 DIV the medium was replaced with fresh one. Neurons were assayed at 14 DIV.

(B) Electrophysiological traces of mEPSCs recorded in neuronal cultures at 14 DIV in control and upon a short (1-4 DIV) treatment with IL-6.

(C) Quantitative analysis of frequency and amplitude of mEPSCs in control condition and upon IL-6. (Cells: ctrl $\mathrm{n}=24, \mathrm{IL}-6 \mathrm{n}=22$. Three independent experiments). Mann-Whitney test. ${ }^{* * *} \mathrm{p}=0,0007$.

(D) Immunofluorescence analysis of glutamatergic synaptic density identified using pre-synaptic (Vglut-1, in blue) and post-synaptic (PSD-95, in green) markers along a dendritic branch stained with beta III tubulin, (in red). Scale bar, $10 \mu \mathrm{m}$.

(E) Quantitative analysis of PSD-95 puncta density (left panel), Vglut-1 puncta density (middle panel) and colocalizing puncta density (right panel) in both conditions. (Dendrites: $\operatorname{ctrl} n=133$, IL-6 153. Three independent experiments) Student's t-test. ${ }^{* * *} p=0,0002,{ }^{*}=p<0,0126, * * * * p<0,0001$.

(F) Schematic representation of the experimental procedure: a single exposure of IL-6 $10 \mathrm{ng} / \mathrm{ml}$ was performed at 1 DIV (Upper panel) or at 4 DIV (lower panel), and neurons were assayed at 14 DIV.

(G) Representative traces of mEPSCs recorded at 14 DIV in control condition and upon single IL-6 exposures at the indicated time points.

(H) Quantitative analysis of both frequency and amplitude of mEPSC at 14 DIV in the two conditions. (Cells: Ctrl $n=14$, IL6 1DIV n=14, IL6 4DIV n=19. Three independent experiments.). One-way ANOVA on ranks followed by Dunn's multiple comparison test. ${ }^{* *} \mathrm{p}=0,0011 ;{ }^{* * * *} \mathrm{p}<0,001$.

(I) Schematic representation of the experimental procedure: a single exposure of IL-6 $10 \mathrm{ng} / \mathrm{ml}$ was performed at 13 DIV, and neurons were assayed at 14 DIV.

(J) Representative traces of mEPSCs recorded at 14 DIV in control condition and upon single IL-6 exposures at later stage of development.

(K) Quantitative analysis of both frequency and amplitude of mEPSC in control and upon IL-6 treatment at later developmental stages. (Cells Ctrl $n=22, I L-6 n=22$. Three independent experiments) Mann-Whitney test.

Figure 5: IL-6 increases STAT3 levels both in vitro and in vivo in neurons and induces a selective phosphorylation at tyrosine 705 . 
(A) Schematic representation of the experimental procedure: IL- 6 at $10 \mathrm{ng} / \mathrm{ml}$ was added at 1 and 4 DIV, and at 6 DIV neurons were collected for the analysis.

(B) Quantitative qPCR of STAT3 mRNA levels in control and IL-6 treated cultures (four independent experiments). One sample t test. ${ }^{*} \mathrm{p}=0.008$.

(C) Western blot analysis of STAT3 protein levels in control and IL-6 treated neuronal cultures both in absence (with astrocytes, upper panel) or in the presence of Ara-C (no astrocytes, lower panel).

(D) Quantitative analysis of the optical density of STAT3 immunoreactive bands normalized by GAPDH level, in normal (left graphs) and in Ara-C treated cultures (right graphs). (Four independent experiments). One sample $t$ test. Ctrl cultures: ${ }^{*} p=0.0254 ;$ Ara-C cultures: ${ }^{*} p=0.04$.

(E) Representative scheme showing the experimental procedure: a single pulse of either vehicle (saline, as control) or IL-6 $(5 \mu \mathrm{g})$ was intraperitoneally injected in pregnant mothers at embryonic day 15 and the hippocampus of embryos were analyzed after 24 hours from the injection through immunofluorescence.

(F) Representative immunofluorescence of hippocampal regions stained with STAT3 (red) and Hoechst (blue), established from embryos at E16 exposed to vehicle or IL-6 at E15 via maternal intraperitoneal injection. (VZ: ventricular zone, HNE: hippocampal neuroepithelium, DNE: dentate neuroepithelium, $\mathrm{CH}$ : cortical hem) scale bar $250 \mu \mathrm{m}$. Inset panels: higher magnification of the selected area. Scale bar: $250 \mu \mathrm{m}$.

(G) Quantitative analysis of STAT3 mean intensity at hippocampal level in the two conditions (Vehicle $n=3$ embryos, IL-6 $\mathrm{n}=3$ embryos) Student's t-test. Data shown ad mean \pm SEM. ${ }^{* *} \mathrm{p}=0,0098$.

(H) Scheme of the experimental procedure: cultured neurons at 6 DIV were treated acutely with IL-6 and collected at different time points for western blot analysis.

(I-J) Time course analysis of STAT3 phosphorylation at tyrosine 705 and $(\mathrm{J})$ serine 727 upon acute (30 min) IL6 treatment of 6 DIV cultured neurons. Quantitative analysis of the optical density of STAT3 phosphorylation levels in tyrosine 705 (I, lower panel) and serine 727 (J, lower panel) normalized against the total amount of STAT3 (Four independent experiments). Wilcoxon Signed Rank Test. * $\mathrm{p}=0.0313$

Figure 6: STAT3 genomic activity is causally linked with the IL6-dependent increase of glutamatergic synapses. 
(A) Western Blot analysis of STAT3 phosphorylation in cultured neurons at 6 DIV acutely treated (30 min) with IL-6 in absence or presence of Stattic $1 \mu \mathrm{M}$

(B) Mean optical density quantification of STAT3 phosphorylation normalized on total STAT3 protein level. (three independent experiments). One sample $t$ test. ${ }^{*} p=0,0326$.

(C) Representative electrophysiological traces of mEPSCs recorded in cultured neurons at 14 DIV in control condition and upon a single application of IL-6 at 1 DIV (see scheme in figure $2 \mathrm{~F}$ ) in the presence of either vehicle or $1 \mu \mathrm{M}$ Stattic.

(D) Quantitative analysis of mEPSCs frequency and amplitude in the different conditions (Ctrl n=33 cells, IL-6 $\mathrm{n}=30$ cells, IL- 6 stattic $\mathrm{n}=19$ cells. Three independent experiments.) One-way ANOVA followed by Tukey's multiple comparisons test. ${ }^{* * * *}=p<0,001 ;{ }^{* *}=p<0,0065$.

(E) Immunofluorescence analysis of glutamatergic synaptic density evaluated in the same conditions through antibodies against pre- (Vglut1, blue) and post (PSD-95, red) synaptic markers along dendritic branches (beta III tubulin, in red). Scale bar $10 \mu \mathrm{m}$.

(F) Quantitative analysis of colocalizing puncta density in the different conditions. (Dendrites: Ctrl n=117, IL$6 n=130$, IL- $6+$ stattic $n=88$ ). One-way ANOVA on ranks followed by Dunn's multiple comparison test. ${ }^{* *} p$ $<0.0004 ; * * * \mathrm{p}<0.0001$.

(G) Representative images of hippocampal neurons expressing GFP together with: myc alone (upper panels), myc-flagged STAT3-phosphomutant Y705E (mimicking a constitutive phosphorylated state) (middle panels), myc-flagged STAT3-phosphomutant Y705F (mimicking a constitutive non-phosphorylated state) (lower panels). These neurons were stained with antibodies against myc (red), to visualize the mutant expression, and with PSD-95 (blue), to evaluate the density of post-synaptic puncta along the GFP-expressing (green) dendritic branches. High-magnification images on the right, arrows indicated PSD-95 positive puncta). Scale bar left panel $20 \mu \mathrm{m}$, right panel $10 \mu \mathrm{m}$.

(H) Quantitative analysis of PSD-95 positive puncta density and size in the three different conditions respect to control condition. (dendrites: $Y 705 E=33 ; Y 705 F=30 ; M Y C=35$. Three independent experiments) One-way ANOVA on ranks followed by Dunn's multiple comparison test. ${ }^{*} p=0,0258 ;{ }^{* *} p=0,0057$.

(I) STAT3 luciferase reporter assay performed in cultured neurons stimulated with IL-6 for 48 hours alone and in the presence of Galiellalactone 1 and $4 \mu \mathrm{M}$. (Five independent experiments) One sample t test. IL-6 ${ }^{*} \mathrm{p}=0,0353 ;$ IL-6 Gall*p=0,0122. 
(J) Representative electrophysiological traces of mEPSCs recorded in cultured neurons at 14 DIV in control condition and upon a single application of IL-6 at 1 DIV with either vehicle or Galiellalactone at 1 and $4 \mu \mathrm{M}$. (K) Quantitative analysis of mEPSCs frequency and amplitude in the indicated conditions. (Cells: Ctrl n=30, IL6 n=20, IL-6 Gall $\mu M \mathrm{n}=13$, IL-6 Gall4 $\mu \mathrm{M}$ n=20. Three independent experiments) One-way ANOVA on ranks followed by Dunn's multiple comparison test ${ }^{* * *} p=0,0008 ; * * * p<0,0001$.

Figure 7: Single cell transcriptional analysis of developing neurons reveals the upregulation of RGS4 gene in specific neuronal cluster cells upon IL-6 treatment.

(A) Schematic representation of the experimental workflow. Cultured neurons were incubated with IL-6 for a short period ( 1 and 4 DIV) and collected at 5 DIV for single cell sequencing analysis.

(B) Heat map showing the average expression value of Neuron and Astrocyte gene signatures (Lein et al, 2007) and manually-curated GABAergic signature across all cells belonging to cluster 0 to 7. Average expression scale is shown on the right.

(C) UMAP (uniform manifold approximation and projection) projection of all detected single cells. Each point depicts a single cell, colored according to cluster designation. $n=3,687$ individual cells. Clusters are labeled according to cell enrichment assessed by AUCell R Bioconductor package (see Supplementary Figure S8).

(D) UMAP projection of all detected single cells, colored according to experimental condition. Black points: control cells, red points: IL-6 treated cells.

(E) UMAP projection of all detected single cells, colored according to Stat3 gene expression level. Average expression scale is shown on the right. Left panel: control cells, right panel: IL-6 treated cells.

(F) Top: Expression distribution (violin plots) showing log-transformed, normalized expression levels of Stat3 gene, in all clusters grouped by cell type and coloured according to experimental condition. Black points: control cells, red points: IL-6 treated cells. *: $p$ value $\leq 0.05$, Wilcoxon Rank Sum test. Bottom: Table showing Pearson $r$ correlation value of genes significantly correlated with Stat3 gene expression level in cluster 0 and cluster 3 of IL- 6 treated cells, and significantly modulated after IL-6 treatment in cluster 0 and cluster 3.

(G) UMAP projection of all detected single cells, colored according to Rgs4 gene expression level. Average expression scale is shown on the right. Left panel: control cells, right panel: IL-6 treated cells.

(H) Expression distribution (violin plots) showing log-transformed, normalized expression levels of Rgs4 gene, in all clusters grouped by cell type and colored according to experimental condition. Black points: control cells, red points: IL-6 treated cells. *: $p$ value $\leq 0.05$, Wilcoxon Rank Sum test. 
Figure 8: RGS4 activity is required for the IL6-mediated effect on glutamatergic synapses and its upregulation occurs in the brain of embryos upon MIA model.

(A) qPCR analysis of RGS4 mRNA levels in cultured neurons at 6 DIV upon short IL-6 treatment (1 and 4 DIV as shown in the scheme of Figure 5A) with and without $4 \mathrm{mM}$ Galiellalactone normalized on GAPDH expression. (four independent experiments). One sample t Test *p=0,0389

(B) Schematic workflow: N2A cell lines were co-transfected with plasmids coding for the STAT3 phosphomutants Y705E and Y705F, together with GFP. After 24 hours GFP ${ }^{+}$-cells were FACS-sorted and assessed for RGS4 expression level through qPCR analysis.

(C) Quantitative analysis of RGS4 mRNA level normalized on GAPDH expression in the indicated conditions. (six independent experiments) One sample t test $* p=0,0411$

(D) Representative traces of mEPSCs recorded in cultured neurons at 14 DIV in control condition and upon a single application of IL- 6 at 1 DIV (see scheme in figure 2F) in the presence or absence of the RGS4 inhibitor CCG-63802.

(E) Quantitative analysis of mEPSCs frequency and amplitude in the indicated conditions. (Cells: ctrl n=23, IL$6 n=20$, IL-6 CCG n=25, CCG $n=15$. Three Independent experiments). One-way ANOVA on ranks followed by Dunn's multiple comparison test $* * p=0,0046 ; *^{*}=0,0391 ; * * *^{*}=0,0008$.

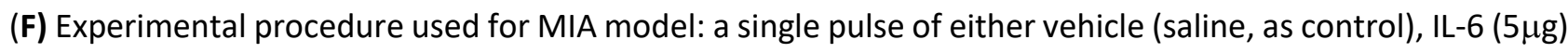
or Poly:IC (at 2 or $20 \mathrm{mg} / \mathrm{Kg}$ ) was intraperitoneally injected in pregnant mothers at embryonic day 15 and the hippocampus of embryos were analysed after 24 hours from the injection through qPCR analysis.

(G) Quantitative analysis of STAT3 and RGS4 expression normalized on GAPDH level in the hippocampi of embryos at the indicated conditions. (Vehicle $n=13$ mice, IL-6 n=19 mice, Polyl:C 2mg n=9 mice, Polyl:C 20mg $\mathrm{n}=19$ mice. Three Independent experiments). One-way ANOVA on ranks followed by Dunn's multiple comparison test. (STAT3 analysis: $* * * p=0,0001, *_{p}^{*}=0,0125 ; *_{p}=0,0394$. RGS4 analysis: $*_{p}=0,0238$; $* * p=0,0074)$. 


\section{STAR Methods:}

\section{EXPERIMENTAL MODELS AND SUBJECT DETAILS}

\section{Animals, MIA model and in utero intraventricular injection}

All experiments were performed using mice C57BL/6J (Charles River Laboratories) according the guidelines established by the European Community Council (Directive 2010/63/EU of September 22nd,2010) and were approved by the Institutional Animal Care and Use Committee (IACUC, permission number 467 and 565) of the Humanitas Research Hospital and by the Italian Ministry of Health. Mice were housed in a Specific Pathogen Free (SPF) facility under constant temperature $\left(22 \pm 1^{\circ} \mathrm{C}\right)$ and humidity $(50 \%)$ conditions with a 12 $\mathrm{h}$ light/dark cycle and were provided with food and water ad libitum. At gestational day 15, pregnant mothers were intraperitoneally (IP) injected with either $5 \mu \mathrm{g}$ of IL-6, polyinosinic:polycytidylic acid (Poly(I:C)) 2 or $20 \mathrm{mg} / \mathrm{kg}$, or laparotomy was performed to inject $1 \mathrm{ul}$ of IL- 6 at $10 \mathrm{ng} / \mu \mathrm{l}$ directly into the embryos lateral ventricles using the Nanoject II Auto-Nanoliter Injector (Drummond, cat.\# 3-000-204). Saline solution was used as a control of injection. Only male embryos and offspring were selected for the ex-vivo and in-vivo analysis.

\section{Primary cultures and cell lines:}

Primary hippocampal neurons were established from E18 C57BL/6 mice as previously described (Pozzi et al, 2013). Briefly, hippocampal regions were isolated from the brain in HBBS $1 X$ (Hank's Balanced Salt Solution) (Life technology), 1\% Pen/Strep, 10mM Hepes) and, after trypsinization, they were dissociated and plated onto $24 \mathrm{~mm}$-diameter round glass coverslips, previously coated with $0.1 \%$ Poly-L-Lysine (Sigma-Aldrich) in Borate buffer (50 mM Boric Acid, 15 mM Borax) pH 8.5. 80000 cells were seeded onto each coverslip. Cultures were grown in Neurobasal medium supplemented with $2 \%$ B27 and $1 \%$ Glutamax (Life Technology) at $37^{\circ} \mathrm{C}$ and $5 \% \mathrm{CO}_{2}$. Neurons were transfected with Lipofectamine 2000 (Life Technology) at 5 days in vitro (DIV) according to the manufacturer's protocol.

Neuro2a (N2A; ATCC ${ }^{\circledR}$ CCL-131 ${ }^{\mathrm{TM}}$ ) Neuroblastoma cell line was used to perform FACS experiments. N2A cells were cultured in complete DMEM medium (Life Technology) supplemented with 10\% FBS, $1 \%$ pen/strep; $1 \%$ Ultraglutamine (Life technologies) until reaching the sub-confluence and then seeded in $60 \mathrm{~mm}$-diameter round dishes at $5 \times 10^{\wedge 5}$ density.

\section{METHOD DETAILS}

\section{Drugs and Reagents:}


According to the type of experiment, the following reagents have been used: IL-6 (Peprotech), Poly(I:C) (Sigma-Aldrich), Galiellalactone (BioAustralis), CCG-63802 (Sigma-Aldrich), Stattic, Bicuculline, 6-Cyano-7nitroquinoxaline-2,3-dione (CNQX), Tetrodotoxin (TTX), D-2-amino-5-phosphonovalerate (APV) (Tocris Bioscience).

\section{Calcium imaging:}

Calcium imaging experiments were performed as previously described (Bedogni et al, 2016; Pozzi et al, 2013). Cultured neurons were loaded with the calcium sensitive dye Oregon Green 488 BAPTA 1-AM (Molecular Probes) for $1 \mathrm{~h}$ at $37^{\circ} \mathrm{C}$ in Neurobasal Medium and then imaged for calcium response. Electrical field stimulation was performed in $\mathrm{KRH}$ solution containing in mM: $125 \mathrm{NaCl} ; 5 \mathrm{KCl} ; 1,2 \mathrm{MgSO}$; 1,2 KH2PO4; 25 HEPES; 6 Glucose; $2 \mathrm{CaCl}$; pH 7,4.in the presence of CNQX $20 \mu \mathrm{M}$, APV $50 \mu \mathrm{M}$ and Bicuculline $20 \mu \mathrm{M}$ using a stimulation chamber (Warner Instruments, Hamden, CT). Electrical-evoked calcium transients were induced with a stimulus train of 40 stimuli (duration $1 \mathrm{msec}$; amplitude $90 \mathrm{~mA}$ ) at $20 \mathrm{~Hz}$ as previously reported (Pozzi 2013), using a train generation unit (Digitimer Ltd, DG2A) connected to a stimulus isolation unit (SIU-102; Warner Instruments, Hamden, CT). Recording chambers were placed on the stage of an IX-71 inverted microscope (Olympus, Hamburg, Germany) equipped with an EMCCD (electron-multiplying CCD) camera (Quantem 512×512, Photometrics). Illumination was obtained using a light-emitting diode LED (Cairn research, Optoled Lite), with a 20X objective. Regions of interest (ROIs) of about 15-pixel area were drawn on the cell cytoplasm of virtually all the cells in the recorded field. Time-lapse recording of calcium dynamics was performed with an acquisition rate of $5 \mathrm{~Hz}$ for 600 seconds and off-line analyzed with MetaFluor software (Molecular Devices). Calcium responses were measure as $\Delta \mathrm{F}$ (Fmax-F0) compared to the baseline (F0). All values were normalized to WT neurons at the same developmental stage within the same experiment. Cumulative data were then analyzed through Kolmogorov-Smirnov statistic to verify non-parametric distribution.

\section{Electrophysiology:}

Ex vivo acute hippocampal slices: C57BL6 male mice at P15 were deeply anesthetized with isofluorane inhalation and decapitated. Brains were removed and placed in ice-cold solution containing the following (in millimolar): $87 \mathrm{NaCl}, 21 \mathrm{NaHCO}, 1.25 \mathrm{NaH} 2 \mathrm{PO} 4,7 \mathrm{MgCl} 2,0.5 \mathrm{CaCl} 2,2.5 \mathrm{KCl}, 25 \mathrm{D}$-glucose, and 7 sucrose, equilibrated with $95 \% \mathrm{O} 2$ and $5 \% \mathrm{CO} 2(\mathrm{pH}$ 7.4). Coronal slices (300 $\mu \mathrm{m}$ thick) were cut with a VT1000S vibratome (Leica Microsystems) from medial Prefrontal Cortex (PFC). Slices were incubated at room temperature for at least $1 \mathrm{~h}$, in the same solution as above, before being transferred to the recording chamber. During experiments, slices were superfused at $2.0 \mathrm{~mL} / \mathrm{min}$ with artificial cerebrospinal fluid (ACSF) containing the following (in millimolar): $135 \mathrm{NaCl}, 21 \mathrm{NaHCO}, 0.6 \mathrm{CaCl} 2,3 \mathrm{KCl}, 1.25 \mathrm{NaH} 2 \mathrm{PO} 4,1.8 \mathrm{MgSO}$, and 10 D-glucose, aerated with 95\% $\mathrm{O} 2$ and 5\% CO2 (pH 7.4). Cells were examined with a BX51WI upright microscope (Olympus) equipped with a water immersion differential interference contrast (DIC) objective and an infrared (IR) camera (XM10r Olympus). Neurons were voltage (or current) clamped with a Multiclamp 
bioRxiv preprint doi: https://doi.org/10.1101/2020.11.02.364356; this version posted November 2, 2020. The copyright holder for this preprint (which was not certified by peer review) is the author/funder, who has granted bioRxiv a license to display the preprint in perpetuity. It is made available under aCC-BY-NC-ND 4.0 International license.

700B patch-clamp amplifier (Molecular Devices, Union City, CA) at room temperature. Low-resistance micropipettes (2-3 M $\Omega$ ) were pulled from borosilicate. The cell capacitance and series resistance were always compensated. Experiments in which series resistance did not remain below $10 \mathrm{M} \Omega$ (typically 5--8 $\mathrm{M} \Omega$ ) were discarded. Input resistance was generally close to 100-200 M . Signals were low-pass filtered at $2 \mathrm{kHz}$, sampled at $10 \mathrm{kHz}$ and analyzed with Digidata 1440A (Molecular Devices). Recordings were made from cortical layer $V$ pyramidal neurons. Excitatory and inhibitory synaptic basal transmission were recorded at $70 \mathrm{mV}$ and $+10 \mathrm{mV}$ respectively in the presence of $1 \mu \mathrm{M} \mathrm{TTX}$, using the following pipette internal solution (in mM): 138 Cs-gluconate, 2 NaCl,10 HEPES, 4 EGTA, 0.3 Tris-GTP and 4 Mg-ATP (pH 7.2).

In vitro primary hippocampal neurons: Patch-clamp recordings were performed in an extracellular solution with the following composition (in $\mathrm{mM}$ ): $130 \mathrm{NaCl}, 5 \mathrm{KCl}, 1.2 \mathrm{KH}_{2} \mathrm{PO}_{4}, 1.2 \mathrm{MgSO}_{4}, 2 \mathrm{CaCl}_{2}, 25 \mathrm{HEPES}$, and 6 Glucose, $\mathrm{pH} 7.4$, with glass pipettes of 4-6 $\mathrm{M} \Omega$ as recording electrodes. mEPSCs were recorded in the presence of bicucullin $(20 \mu \mathrm{M})$, APV $(50 \mu \mathrm{M})$ and tetrodotoxin (TTX; $1 \mathrm{mM})$ using the following internal solution (in mM): $135 \mathrm{~K}$-gluconate, $5 \mathrm{KCl}, \mathrm{MgCl}_{2}, 10$ HEPES, 1 EGTA, 2 ATP, $0.5 \mathrm{GTP}, \mathrm{pH}$ 7.4. mIPSCs were recorded in the presence of 6-cyano-7-nitroquinoxaline-2,3-dione (CNQX; $20 \mu \mathrm{M}),(2 \mathrm{R})$-amino-5phosphonovaleric acid (APV; $50 \mu \mathrm{M})$ and TTX (1 mM) using the following internal solution (in $\mathrm{mM}$ ): $68 \mathrm{~K}$ gluconate, $68 \mathrm{KCl}, 2 \mathrm{MgSO}_{4}, 20 \mathrm{HEPES}, 2 \mathrm{ATP}, 0.5 \mathrm{GTP}$, pH 7.2. Both mEPSCs and mIPSCs were recorded at $70 \mathrm{mV}$ as holding potential. Short term plasticity was evaluated through paired whole-cell recording as previously described (Liu et al, 2014; Maximov et al, 2007) using the following internal solution (in mM): 135 K-gluconate, $5 \mathrm{KCl}, \mathrm{MgCl}_{2}$, $10 \mathrm{HEPES}, 1 \mathrm{EGTA}, 2 \mathrm{ATP}, 0.5 \mathrm{GTP}$, and $10 \mathrm{QX}-314$, pH 7.4. Presynaptic stimulation was achieved through a bipolar electrode (FHC, Concentric bipolar electrode Cat\# CBAEC75) placed at 100$150 \mathrm{~mm}$ from the recorded neuron with 0,9 mA, $1 \mathrm{msec}$ current injection through a stimulus isolation unit (SIU-102; Warner Instruments, Hamden, CT). Electrical signals were amplified by a Multiclamp 200 B (Axon instruments), filtered at $5 \mathrm{kHz}$, digitized at $20 \mathrm{kHz}$ with a DIGIDATA 1440 and stored with pClamp 10 (Axon instruments). The resting potential was calculated at $\mathrm{l}=0$ in current clamp configuration, whereas input resistance was calculated in voltage clamp configuration by using the slope of the I/V relationship of the steady state current measured at different hyperpolarizing voltage steps (from -100 to $-70 \mathrm{mV}$ ). Only cells with an access resistance $<20 \mathrm{M} \Omega$ were considered for the analysis of mEPSCs and mIPSCs, and $<10 \mathrm{M} \Omega$ for the analysis of short-term plasticity. Access resistance was continuously monitored during the experiment and those cells in which access resistance was changed of more than $10 \%$ were rejected. The analysis of both mEPSC and mIPSC were performed with Mini analysis (Synaptosoft Inc., Fort Lee, NJ, USA) whereas the analysis of short-term plasticity was performed with Clampfit (Axon instruments).

\section{Biochemistry}

For total protein extraction, samples were homogenized using the following lysis buffer composed by $1 \%$ sodium dodecyl sulphate (SDS), 10mM Hepes at pH 7.4 and 2 mM EGTA and protein concentration was 
bioRxiv preprint doi: https://doi.org/10.1101/2020.11.02.364356; this version posted November 2, 2020. The copyright holder for this preprint (which was not certified by peer review) is the author/funder, who has granted bioRxiv a license to display the preprint in perpetuity. It is made available under aCC-BY-NC-ND 4.0 International license.

estimated using Bicinchoninic Acid Assay (BCA) kit (Thermo Fischer Scientific) as $20 \mu \mathrm{g}$. Proteins were loaded with 2x Loading Buffer (100 mM Tris-HCl at pH 6.8; 4\% SDS; 20\% Glycerol; 200 mM 2-Mercaptoethanol, 2 mg Bromophenol-Blue) and fractionated by SDS-PAGE, then transferred to a nitrocellulose membrane using a transfer apparatus according to the manufacturer's protocols (Bio-Rad). Membranes were stained with the following primary antibodies: mouse anti-STAT3 (Cell Signalling, 1:1000), rabbit anti-STAT3 P-Tyrosine 705 (Cell Signalling, 1:1000), mouse anti-STAT3 P-Serine 727 (Cell Signalling, 1:1000), rabbit anti-GAPDH (Synaptic System, 1:4000), mouse anti-PSD95 (UC Davis/NIH NeuroMab Facility, CA; 1:1000), guinea pig anti-vGLUT1 (Synaptic System, 1:1000), rabbit anti-Shank2/3 (Synaptic System, 1:1000), mouse anti-GAP43 (Millipore, 1:1000), rabbit anti-NFKB (Cell Signalling; 1:1000), rabbit anti-SNAP25 (Synaptic System, 1:1000), mouse antip65 (Cell Signalling; 1:1000). Immunodetection was performed with Clarity ${ }^{\mathrm{TM}}$ Western ECL Substrate (Bio Rab) and analyzed through Chemidoc apparatus via ImageLab software (Bio-Rab).

\section{Immunofluorescence analysis:}

Hippocampal slices: Mice at P15 and P30 were deeply anesthetized with chloral hydrate $(4 \% ; 1 \mathrm{ml} / 100 \mathrm{~g}$ body weight, i.p.) and transcardially perfused with $4 \%$ paraformaldehyde (PFA). Post-fixed brains were collected and immunohistochemistry was performed on $50-\mu \mathrm{m}$ hippocampal coronal sections with specific primary antibodies followed by incubation with the secondary antibodies. The following primary antibodies were used: guinea pig anti-vGLUT1 (1:1500; Synaptic Systems); mouse anti-V-gat (Synaptic Systems, 1:1000), rabbit anti-IBA (WAKO, 1:200), mouse anti-GFAP (Sigma-Aldrich, 1:400), guinea pig anti-NeuN (Synaptic System, 1:500), mouse anti-SATB2 (AbCam,1:100), rabbit anti-NeuroD2 (AbCam, 1:1500). Embryos' brains (EB) were collected at GD16, 24 hours post mother injection, and post-fixed with PFA 4\% for 16 hours. EB were

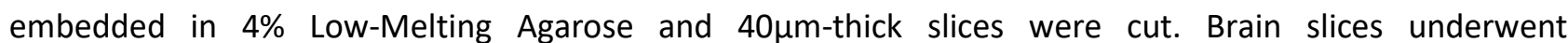
immunofluorescence staining against mouse anti-STAT3 (Cell Signalling, 1:1000). Secondary antibodies conjugated with Alexa-488, Alexa-555, or Alexa-633 fluorophores (Invitrogen) were used. All slices were counterstained with Hoechst-33342 (ThermoFisher) and mounted with Fluorsave (Calbiochem, San Diego, CA, USA).

In vitro primary hippocampal neurons: Neuronal cultures were fixed in $4 \% \mathrm{PFA}, 4 \%$ sucrose, $20 \mathrm{mM} \mathrm{NaOH}$ and $5 \mathrm{mM} \mathrm{MgCl} 2$ in PBS, $\mathrm{pH} 7.4$, for 8 minutes at room temperature (RT). Cultures were permeabilized and non-specific binding sites of proteins blocked with Goat Serum Dilution Buffer (GSDB; 15 \% goat serum, 0.3 \% Triton $\mathrm{X}-100,450 \mathrm{mM} \mathrm{NaCl}, 20 \mathrm{mM}$ phosphate buffer, $\mathrm{pH}$ 7.4) for 30 minutes. The following primary antibodies were used: guinea pig anti-vGLUT1 (Synaptic Systems, 1:1000), mouse anti-PSD95 (UC Davis/NIH NeuroMab Facility, CA, 1:800), mouse anti-ßeta III Tubulin (Promega Corporation, 1:800), rabbit anti-tubulin (Sigma-Aldrich, 1:80), rabbit anti-MAP2 (Millipore, 1:1000), mouse anti STAT3 (Cell Signalling, 1:1000). Secondary antibodies conjugated with Alexa-488, Alexa-555, or Alexa-633 fluorophores (Invitrogen) were used. Images were acquired using a Leica SP8I confocal microscope equipped with an ACS APO 40x oil 
immersion objective. Whole brain images were taken with DMi8 inverted light microscope equipped with ACS APO 10x dry objective (Leica Microsystems, Solms,Germany). Image analyses were performed using Bitplane Imaris 7.4 software (Bitplane AG, Zurich, Switzerland) and Fiji-ImageJ software (NIH,Bethesda, MD, USA).

\section{Magnetic resonance imaging}

$\mathrm{N}=16$ mice (9 IL-6 and 7 vehicle control) underwent MRI to study the functional connectivity and white matter integrity of the entire brain. During the imaging sessions, the experimenters were blinded to the group. Data collection was performed on a Biospec 70/16 small animal MRI system (Bruker BioSpin) equipped with a cryogenic quadrature surface coil (Bruker BioSpin). For the detection of rs-fMRI we used a standard echoecho gradient echo imaging sequence (GE-EPI, repetition time $T R=1 \mathrm{~s}$, echo time $T E=15 \mathrm{~ms}$, resolution in the plane RES $=0.22 \times 0,2 \mathrm{~mm}^{2}$, number of slices NS $=20$, slice thickness ST $=0.4 \mathrm{~mm}$, slice spacing SS $=0.1$ $\mathrm{mm}, 900$ volumes, sampling time $=15 \mathrm{~min}$ ). In addition, diffusion-weighted images (DWI) were used to evaluate the structural integrity of the white matter (EPI spin echo multishot sequence, 4 segments, TR $=2$ $\mathrm{s}, \mathrm{TE}=22 \mathrm{~ms}, \mathrm{RES}=0.2 \times 0.2 \mathrm{~mm}^{2}, \mathrm{NS}=28, \mathrm{ST}=0.4 \mathrm{~mm}, \mathrm{SS}=0 \mathrm{~mm}$, values $\mathrm{b}=0-1000 \mathrm{~s} / \mathrm{mm} 2$, coding 94 directions, acquisition time $=9 \mathrm{~min})$.

During MRI, the degree of anesthesia and the physiological parameters of the mouse were monitored according to a defined protocol to obtain a reliable measure of functional connectivity (Grandjean et al, 2014; Zerbi et al, 2015). Briefly, anesthesia was initiated with $4 \%$ isoflurane and the animals were intubated endotracheally and the tail vein was cannulated. The mice were placed on a compatible MRI base and artificially ventilated with 80 breaths / $\mathrm{min}, 1: 4 \mathrm{O} 2$ / air ratio and $1.8 \mathrm{ml} / \mathrm{h}$ (CWE) flow. A bolus injection of medetomidine $0.04 \mathrm{mg} / \mathrm{kg}$ and pancuronium bromide $0.05 \mathrm{mg} / \mathrm{kg}$ was given and isoflurane was reduced to $1 \%$. After 5 minutes, an infusion of medetomidine at $0.09 \mathrm{mg} / \mathrm{kg} / \mathrm{h}$ and pancuronium bromide at 0.15 $\mathrm{mg} / \mathrm{kg} / \mathrm{h}$ were administered and the isoflurane was further reduced to $0.5 \%$. The temperature of the animals was monitored using a rectal thermometer probe and kept in the cradle at $36.5^{\circ} \mathrm{C} \pm 0.5$ during measurements with a water heating system.

\section{Resting-state fMRI.}

The datasets were preprocessed using an existing pipeline to eliminate unwanted time-series confusion, according to the guidelines of the Human Connectome project adapted to the mouse (Zerbi et al, 2015). In short, each rs-fMRI data set was entered into MELODIC (Multivariate Exploratory Linear Optimized Decomposition of Independent Components; (Beckmann \& Smith, 2004)) to perform an independent component analysis (ICA, number of components set to 60). This included the correction and regression of head movement and in-plane smoothing with a $0.3 \times 0.3 \mathrm{~mm}$ kernel. We used FSL-FIX for the removal of the 
variance of artifact components. The artifact-corrected data sets were then band-pass filtered (0.01-0.25 Hz), normalized in a GE-EPI study-specific template, and then to the Allen Common Coordinate Framework Version (CCF, v3) with Advanced Normalization Tools (ANTs v2.1, http://picsl.upenn.edu/software/ants/).

\section{Diffusion MRI}

For diffusion MRI, the preprocessing steps consisted of individual realignment of the diffusion images, followed by eddy current correction and tensor estimation as in (Zerbi et al, 2013a). From the eigenvalues of the diffusion tensor, fractional anisotropy (FA), mean diffusivity (MD), and first eigenvalue $(\lambda 1)$ maps were calculated. The resulting volumes were spatially normalized to the Allen CCF template using linear affine and nonlinear elastic transformations in ANTs and thereafter FA, MD, and $\lambda 1$ values were extracted from seven major white matter structures: anterior commissure, fimbria, corpus callosum, fornix, cingulum, internal capsule, and cerebral peduncle.

\section{Behavioural studies :}

Animals were kept under a light-dark cycle (12 light-12 dark) in a temperature and humidity controlled room. Room lights were low during all procedures. A camera was mounted above the arena and object exploration was tracked using a computer running the Smart Software (Panlab, Harvard Apparatus). Only males were used in these studies.

\section{Open Field Analysis:}

For the open field, each subject was gently placed in the centre of the open field and allowed to explore freely all the arena for $10 \mathrm{~min}$. At the end, the animal was removed and the arena cleaned with $70 \%$ ethanol and dried before testing the next animal. Locomotor activity was indexed as the distance spent in centre, periphery and total distance travelled.

\section{Elevated plus maze:}

The Elevated Plus Maze (EPM) was conducted as previously described (Hagenbuch et al, 2006). Mice were allowed to freely explore the entire apparatus for $5 \mathrm{~min}$. The percentage of time spent in the arms was scored as measure of anxiety-related behavior. The arm entry was defined as having all four paws into the arm of the EPM.

\section{Object location Recognition and Novel Object Recognition test:}

The test was performed in the open-field apparatus. This test was used to assess short-time memory retention. Between trials, the objects and the box were cleaned with $70 \%$ ethanol. Mice were first habitued to an open field chamber by allowing free exploration of an empty chamber for $5 \mathrm{~min}$. The Oject location and 
Novel object recognition test included three sessions. In the first session, two identical objects were placed in the testing arena and each mouse was allowed to explore the objects for 10 minutes to facilitate the familiarization. These objects presented similar textures, colors and sizes. One hour later, one of the identical objects was displaced and the mouse was placed back into the chamber and allowed to explore objects for 10 min (Object location Recognition phase). Lastly,1 hour later, the mouse was returned for $10 \mathrm{~min}$ in the chamber where a novel object replaced one of the 2 identical familiar objects (Novel Object Recognition Phase). The amount of time the mouse spent physically investigating each of the objects was manually determined for all the trials and was used to calculate the discrimination index.

\section{Nissl staining}

Brains were perfused with 4\% PFA and $50 \mu \mathrm{m}$ thick coronal slices were obtained at the vibratome. Slices were mounted on charged coverslips and let dry overnight. They were then re-hydrated with an alcohol scale from $100 \%$ to water and subsequently stained for 5 minutes in a $0.1 \%$ cresyl violet solution. Afterwards, slices were differentiated again in alcohol 95\% for 5 minutes according to the intensity of the staining, de-hydrated in alcohol $100 \%$ and a subsequently fixed with a xylene-based medium. Images were taken at BX61VS Olympus microscope using a 10x/0,40 UPlanSApo objective.

\section{Luciferase assay}

To monitor the transcriptional activity of STAT3 cultured neurons were transduced using Cignal Lenti STAT3 reporter Kit (Qiagen) at 3 DIV and exposed to IL-6 and Galiellalactone for 48 hours at 10 DIV. Neurons were then processed according to manufacturer's instructions and Firefly luciferase activity was detected with Luciferase assay system (Promega) and Synergy H2 (Biotek).

\section{Quantitative RT-PCR}

Cultured neurons were homogenized prior to RNA extraction in $500 \mu \mathrm{l}$ of TRI-reagent (Zymo research). Total RNA was isolated using the RNA Direct-Zol ${ }^{\mathrm{TM}}$ MiniPrep Isolation Kit (Zymo research) according to the manufacturer's guidelines. The RNA was eluted in $25 \mu \mathrm{L}$ DNase/RNAse-free water, quantified using NANOdrop 2000c spectrophotometer (Thermo Fisher Scientific) for RNA concentration and 260/280 nm optical density ratios. Reverse transcription was performed using $1 \mu \mathrm{g}$ RNA with a High Capacity cDNA RT kit (Applied Biosystems). Quantitative real-time polymerase chain reaction (qRT-PCR) was performed with Sybr Green detection kit (SensiFAST SYBR Lo-ROX, Bioline) with RT-PCR Viia7 software system (Applied Biosystems) in a final volume of $10 \mu \mathrm{l}$. Each gene was subjected to at least duplicate measurements and data analyses were performed with the comparative $\Delta \Delta C_{T}$ method. The RNA levels were normalized against gapdh and actin3 as indicated. The following Sybr oligos were used: gapdh Fw: TTCCAGAGGGGCCATCCACAG, Rv: 
GGTCACCAGGGCTGCCATTTG; actin Fw: GCCATCCTGCGTTCTGGA, Rv: GCTCTTCTCCAGGGAGGA; Rgs4 Fw: GTCGGAATACAGCGAGGAGAAC, Rv: GGAAGGATTGGTCAGGTCAAGATAG; Stat3 Fw: CCATGCTGAGCATCGAGCAGCTGACA; Rv: TCA CACAGATGAACTTGGTCTTCAGG.

\section{Fluorescence Activated Cell Sorting (FACS) analysis}

The day after plating N2A were co-transfected according to three experimental conditions with the following plasmids: 1) pCDNA 3.1 EGFP; 2) pCDNA 3.1 EGFP + pCDNA 3.1 myc 768-STAT3 Y795E; 3) pCDNA 3.1 EGFP + pCDNA 3.1 myc 768-STAT3 Y705F and maintained for 6 hours in the transfection medium. After 24 hours, they were gently detached with Accutase solution (Sigma-Aldrich) for 3 minutes at $37^{\circ} \mathrm{C}$, centrifuged at 500 rcf for 10 minutes and then sorted out by means of BD FACS Melody ${ }^{\mathrm{TM}}$ cell sorter (BD, Biosciences). GFP positive (+) and GFP negative (-) cells were collected for each condition, lysed with TRI-Reagent and subsequently processed for total RNA extraction and qRT-PCR.

\section{Single cell sequencing:}

Hippocampal neurons untreated and treated with IL-6 $(10 \mathrm{ng} / \mathrm{ml}$ at 1 DIV and 4 DIV) were collected at 5 DIV using Accutase solution (Sigma-Aldrich) and resuspended in $1 \mathrm{ml}$ of PBS -/- with 0.04\% BSA (Sigma Aldrich), centrifuged at $450 \mathrm{rcf}$ for $7 \mathrm{~min}$ and washed twice with PBS-/- with 0.04\% BSA. After the second wash, cells were resuspended in $30 \mathrm{ul}$ and counted with an automatic cell counter to get a precise estimation of total number of cells recovered. $\sim 5,000$ cells were loaded into one channel of the Single Cell Chip A for each sample using the Single Cell 3' v2 single cell reagent kit (10X Genomics) for Gel bead Emulsion generation into the Chromium system. Following capture and lysis, cDNA was synthesized and amplified for 14 cycles following the manufacturer's protocol (10X Genomics). $50 \mathrm{ng}$ of the amplified cDNA were then used for each sample to construct Illumina sequencing libraries. Sequencing was performed on the NextSeq500 Illumina sequencing platform following 10x Genomics instruction for reads generation.

\section{Single cell mapping and clustering}

Raw sequencing data (bcl-files) were converted to fastq files with Illumina bcl2fastq tool, integrated into the CellRanger (10X Genomics) suite (version 2.1.1). The CellRanger analysis pipeline was used to generate a digital gene expression matrix staring from raw data. Pre-build mouse genome (version mm10-1.2.0) was used as genome reference. CellRanger count module was used to map reads with default settings setting and sequence length set to $r 1$-length $=26$ and $--r 2$-length $=50$. At least 90,000 reads per cell were produced. The 
raw digital gene expression matrix (UMI counts per gene per cell) was imported in R https://www.Rproject.org/ version 3.5.2 using Seurat R package (version Seurat_2.3.4) (Butler et al, 2018). Briefly, UMI counts per gene per cell for each biological replicate was imported in Seurat. Initial quality control in each biological replicate was assessed, by filtering out cells meeting any of the following criteria: less than 200 or more than 10,000 unique genes expressed, more than 50,000 UMIs, or more than $15.0 \%$ of reads mapping to mitochondria. Data was normalized through a global-scaling method, converted by a scale factor $(10,000$ by default) and log-transformed. Scaling the data and removing unwanted sources of variation was applied through ScaleData Seurat function. Detection of variable genes across the single cells in each sample was performed. The resulting gene list was used to perform a canonical correlation analysis (CCA) using the first 30 canonical vectors. After aligning subspaces, clustering was performed through FindClusters function, using the first 20 dimensions. Uniform Manifold Approximation and Projection (UMAP) dimensional reduction was computed with RunUMAP function.

Clusters enrichment was determined by running the AUCell Bioconductor R Package v1.2.4 (Aibar et al, 2017) with default parameters.

AUCell evaluates each cell individually. Genes are ranked from highest to lowest expression value. The top $5 \%$ of the genes in the ranking are used to calculate the "Area Under the Curve" (AUC) value for the gene-set (signature) of interest. The AUC estimates the proportion of genes in the signature that are highly expressed within the cell. The distribution of AUC values across all the cells allows exploring the relative expression of the signature: cells expressing more genes from the gene-set will have values higher than cells expressing fewer.

To determine clusters of cells that are more likely of the cell type according to the gene signature, cells are split into two groups: cells that pass the assignment threshold (cells where the gene-set is defined as "active"), and cells that don't (cells where the gene-set is defined as "non-active"). The assignment threshold was calculated automatically by AUCell by examining the AUC distribution.

Clusters enrichment was determined by running the AUCell Bioconductor R Package v1.2.4 (Aibar et al, 2017) with default parameters. Three gene-sets were considered: two included in the AUCell package: neurons and astrocytes from (Cahoy et al, 2008; Cembrowski et al, 2016; Lein et al, 2007), one manually-curated GABAergic gene signature from (Harris et al, 2018) and proliferating cells from (Kowalczyk et al, 2015; Tirosh et al, 2016).

A Complete list of gene signatures used for identifying each cluster was added in Table 1. Cells that pass the assignment threshold are colored in shades of pink-red while cells that don't are colored in black-blue in Supplementary Fig. 8.

\section{Promoter sequence analysis.}


bioRxiv preprint doi: https://doi org/10.1101/2020.11.02 364356; this version posted November 2,2020 . The copyright holder for this preprint (which was not certified by peer review) is the author/funder, who has granted bioRxiv a license to display the preprint in perpetuity. It is made available under aCC-BY-NC-ND 4.0 International license.

The bioinformatic prediction for transcription factor binding sites in RGS4 promoter region was performed using JASPAR database (http://jaspar.genereg.net/) (Khan et al, 2018; Sandelin et al, 2004)

\section{Single cell markers identification and differential expression}

We identified markers specific to each cluster using FindAllMarkers Seurat function with the following settings (only.pos=TRUE, min.pct=0.05, thresh.use $=0.05$ ). We defined a gene to be a cluster-specific marker if it was differentially up-regulated in a specific cluster (Wilcoxon test), as compared to each of the remaining clusters. To identify differentially expressed genes within the same cluster in different experimental conditions and between different clusters in the same experimental condition, we used MAST R package (Finak et al, Genome Biology, 2015) implemented in Seurat FindMarkers function with an FDR cut-off of 0.05 and a logfc.threshold $=0.20$.

\section{QUANTIFICATION AND STATISTICAL ANALYSIS}

The numerical data shown in the figures are presented as means \pm SEM. The normal distribution of experimental data was assessed using Kolmogorov Smirnov and Shapiro-Wilk normality tests. If not specifically indicated, to compare two normally distributed sample groups, the Student's unpaired two-tailed t-test was used. To compare two sample groups that were not normally distributed, we used MannWhitney's non-parametric test. To compare more than two normally distributed sample groups, we used one ANOVA, followed by Tukey's multiple comparisons test. To compare more than two groups that were not normally distributed, we used one One-way ANOVA on ranks followed by Dunn's multiple comparison test. One sample t test or Wilcoxon Signed Rank Test were used in some experiments to analyze normally distributed or not normally distributed data set, respectively. Statistical analysis was performed by using SigmaPlot (Systat), GraphPad (Prism) or OriginPro (OriginLab) software.

\section{DATA AND CODE AVAILABILITY}

The scRNA-seq data, together with global mapping statistics, has been deposited in GEO under accession code GEO: GSE130803 


\section{References}

Aibar S, Gonzalez-Blas CB, Moerman T, Huynh-Thu VA, Imrichova H, Hulselmans G, Rambow F, Marine JC, Geurts P, Aerts J, van den Oord J, Atak ZK, Wouters J, Aerts S (2017) SCENIC: single-cell regulatory network inference and clustering. Nature methods 14, 1083-1086

Ajram LA, Horder J, Mendez MA, Galanopoulos A, Brennan LP, Wichers RH, Robertson DM, Murphy CM, Zinkstok J, Ivin G, Heasman M, Meek D, Tricklebank MD, Barker GJ, Lythgoe DJ, Edden RAE, Williams SC, Murphy DGM, McAlonan GM (2017) Shifting brain inhibitory balance and connectivity of the prefrontal cortex of adults with autism spectrum disorder. Translational psychiatry 7, e1137

Alcamo EA, Chirivella L, Dautzenberg M, Dobreva G, Farinas I, Grosschedl R, McConnell SK (2008) Satb2 regulates callosal projection neuron identity in the developing cerebral cortex. Neuron 57, 364-377

Angevine JB, Jr. (1965) Time of neuron origin in the hippocampal region. An autoradiographic study in the mouse. Experimental neurology Supplement, Suppl 2:1-70

Aniszewska A, Chlodzinska N, Bartkowska K, Winnicka MM, Turlejski K, Djavadian RL (2015) The expression of interleukin- 6 and its receptor in various brain regions and their roles in exploratory behavior and stress responses. Journal of neuroimmunology 284, 1-9

Balschun D, Wetzel W, Del Rey A, Pitossi F, Schneider H, Zuschratter W, Besedovsky HO (2004) Interleukin-6: a cytokine to forget. FASEB journal : official publication of the Federation of American Societies for Experimental Biology 18, 1788-1790

Bansal G, Druey KM, Xie Z (2007) R4 RGS proteins: regulation of G-protein signaling and beyond. Pharmacology \& therapeutics 116, 473-495

Bauer S, Kerr BJ, Patterson PH (2007) The neuropoietic cytokine family in development, plasticity, disease and injury. Nature reviews Neuroscience 8, 221-232

Bauman MD, losif AM, Smith SE, Bregere C, Amaral DG, Patterson PH (2014) Activation of the maternal immune system during pregnancy alters behavioral development of rhesus monkey offspring. Biological psychiatry 75, 332-341 
Beckmann CF, Smith SM (2004) Probabilistic independent component analysis for functional magnetic resonance imaging. IEEE transactions on medical imaging 23, 137-152

Bedogni F, Cobolli Gigli C, Pozzi D, Rossi RL, Scaramuzza L, Rossetti G, Pagani M, Kilstrup-Nielsen C, Matteoli M, Landsberger N (2016) Defects During Mecp2 Null Embryonic Cortex Development Precede the Onset of Overt Neurological Symptoms. Cerebral cortex 26, 2517-2529

Benedusi V, Martini E, Kallikourdis M, Villa A, Meda C, Maggi A (2015) Ovariectomy shortens the life span of female mice. Oncotarget 6, 10801-10811

Bergink V, Gibney SM, Drexhage HA (2014) Autoimmunity, inflammation, and psychosis: a search for peripheral markers. Biological psychiatry 75, 324-331

Berman DM, Kozasa T, Gilman AG (1996a) The GTPase-activating protein RGS4 stabilizes the transition state for nucleotide hydrolysis. The Journal of biological chemistry 271, 27209-27212

Berman DM, Wilkie TM, Gilman AG (1996b) GAIP and RGS4 are GTPase-activating proteins for the Gi subfamily of $\mathrm{G}$ protein alpha subunits. Cell $86,445-452$

Bhatia A, Moza S, Bhalla US (2019) Precise excitation-inhibition balance controls gain and timing in the hippocampus. elife 8

Blazer LL, Roman DL, Chung A, Larsen MJ, Greedy BM, Husbands SM, Neubig RR (2010) Reversible, allosteric small-molecule inhibitors of regulator of $\mathrm{G}$ protein signaling proteins. Molecular pharmacology $78,524-533$

Boulanger-Bertolus J, Pancaro C, Mashour GA (2018) Increasing Role of Maternal Immune Activation in Neurodevelopmental Disorders. Frontiers in behavioral neuroscience 12, 230

Boulanger LM (2009) Immune proteins in brain development and synaptic plasticity. Neuron 64, 93-109

Bourgeron T (2009) A synaptic trek to autism. Current opinion in neurobiology 19, 231-234

Butler A, Hoffman P, Smibert P, Papalexi E, Satija R (2018) Integrating single-cell transcriptomic data across different conditions, technologies, and species. Nature biotechnology 36, 411-420

Cafferty WB, Gardiner NJ, Das P, Qiu J, McMahon SB, Thompson SW (2004) Conditioning injury-induced spinal axon regeneration fails in interleukin- 6 knock-out mice. The Journal of neuroscience : the official journal of the Society for Neuroscience 24, 4432-4443

Cahoy JD, Emery B, Kaushal A, Foo LC, Zamanian JL, Christopherson KS, Xing Y, Lubischer JL, Krieg PA, Krupenko SA, Thompson WJ, Barres BA (2008) A transcriptome database for astrocytes, neurons, and oligodendrocytes: a new resource for understanding brain development and function. The Journal of neuroscience : the official journal of the Society for Neuroscience 28, 264-278 
Cembrowski MS, Wang L, Sugino K, Shields BC, Spruston N (2016) Hipposeq: a comprehensive RNA-seq database of gene expression in hippocampal principal neurons. eLife 5, e14997

Chao HT, Zoghbi HY, Rosenmund C (2007) MeCP2 controls excitatory synaptic strength by regulating glutamatergic synapse number. Neuron $56,58-65$

Cheng YC, Scotting PJ, Hsu LS, Lin SJ, Shih HY, Hsieh FY, Wu HL, Tsao CL, Shen CJ (2013) Zebrafish rgs4 is essential for motility and axonogenesis mediated by Akt signaling. Cellular and molecular life sciences : CMLS 70, 935-950

Choi GB, Yim YS, Wong H, Kim S, Kim H, Kim SV, Hoeffer CA, Littman DR, Huh JR (2016) The maternal interleukin-17a pathway in mice promotes autism-like phenotypes in offspring. Science 351, 933-939

Chowdari KV, Mirnics K, Semwal P, Wood J, Lawrence E, Bhatia T, Deshpande SN, B KT, Ferrell RE, Middleton FA, Devlin B, Levitt P, Lewis DA, Nimgaonkar VL (2002) Association and linkage analyses of RGS4 polymorphisms in schizophrenia. Human molecular genetics 11, 1373-1380

Chung CD, Liao J, Liu B, Rao X, Jay P, Berta P, Shuai K (1997a) Specific inhibition of Stat3 signal transduction by PIAS3. Science $278,1803-1805$

Chung J, Uchida E, Grammer TC, Blenis J (1997b) STAT3 serine phosphorylation by ERK-dependent and independent pathways negatively modulates its tyrosine phosphorylation. Molecular and cellular biology 17, $6508-6516$

Cline H (2005) Synaptogenesis: a balancing act between excitation and inhibition. Current biology : CB 15, R203-205

Corradini I, Focchi E, Rasile M, Morini R, Desiato G, Tomasoni R, Lizier M, Ghirardini E, Fesce R, Morone D, Barajon I, Antonucci F, Pozzi D, Matteoli M (2017) Maternal Immune Activation Delays Excitatory-toInhibitory Gamma-Aminobutyric Acid Switch in Offspring. Biological psychiatry

Courchesne E, Pierce K, Schumann CM, Redcay E, Buckwalter JA, Kennedy DP, Morgan J (2007) Mapping early brain development in autism. Neuron 56, 399-413

Dahlgren J, Samuelsson AM, Jansson T, Holmang A (2006) Interleukin-6 in the maternal circulation reaches the rat fetus in mid-gestation. Pediatric research 60, 147-151

Dean B, Boer S, Gibbons A, Money T, Scarr E (2009) Recent advances in postmortem pathology and neurochemistry in schizophrenia. Current opinion in psychiatry 22, 154-160 
Deco G, Ponce-Alvarez A, Hagmann P, Romani GL, Mantini D, Corbetta M (2014) How local excitationinhibition ratio impacts the whole brain dynamics. The Journal of neuroscience : the official journal of the Society for Neuroscience 34, 7886-7898

Delorme R, Ey E, Toro R, Leboyer M, Gillberg C, Bourgeron T (2013) Progress toward treatments for synaptic defects in autism. Nature medicine 19, 685-694

Deverman BE, Patterson PH (2009) Cytokines and CNS development. Neuron 64, 61-78

Durand CM, Betancur C, Boeckers TM, Bockmann J, Chaste P, Fauchereau F, Nygren G, Rastam M, Gillberg IC, Anckarsater H, Sponheim E, Goubran-Botros H, Delorme R, Chabane N, Mouren-Simeoni MC, de Mas P, Bieth E, Roge B, Heron D, Burglen L, Gillberg C, Leboyer M, Bourgeron T (2007) Mutations in the gene encoding the synaptic scaffolding protein SHANK3 are associated with autism spectrum disorders. Nature genetics $39,25-$ 27

Erdely HA, Tamminga CA, Roberts RC, Vogel MW (2006) Regional alterations in RGS4 protein in schizophrenia. Synapse 59, 472-479

Erta M, Quintana A, Hidalgo J (2012) Interleukin-6, a major cytokine in the central nervous system. International journal of biological sciences 8, 1254-1266

Estes ML, McAllister AK (2016) Maternal immune activation: Implications for neuropsychiatric disorders. Science 353, 772-777

Fang XX, Jiang XL, Han XH, Peng YP, Qiu YH (2013) Neuroprotection of interleukin-6 against NMDA-induced neurotoxicity is mediated by JAK/STAT3, MAPK/ERK, and PI3K/AKT signaling pathways. Cellular and molecular neurobiology 33, 241-251

Farisello P, Boido D, Nieus T, Medrihan L, Cesca F, Valtorta F, Baldelli P, Benfenati F (2013) Synaptic and extrasynaptic origin of the excitation/inhibition imbalance in the hippocampus of synapsin I/II/III knockout mice. Cerebral cortex 23, 581-593

Filipello F, Morini R, Corradini I, Zerbi V, Canzi A, Michalski B, Erreni M, Markicevic M, Starvaggi-Cucuzza C, Otero K, Piccio L, Cignarella F, Perrucci F, Tamborini M, Genua M, Rajendran L, Menna E, Vetrano S, Fahnestock M, Paolicelli RC, Matteoli M (2018) The Microglial Innate Immune Receptor TREM2 Is Required for Synapse Elimination and Normal Brain Connectivity. Immunity 48, 979-991 e978

Filippini N, MacIntosh BJ, Hough MG, Goodwin GM, Frisoni GB, Smith SM, Matthews PM, Beckmann CF, Mackay CE (2009) Distinct patterns of brain activity in young carriers of the APOE-epsilon4 allele. Proceedings of the National Academy of Sciences of the United States of America 106, 7209-7214

Finlay BL, Darlington RB (1995) Linked regularities in the development and evolution of mammalian brains. Science 268, 1578-1584 
Frankle WG, Lerma J, Laruelle M (2003) The synaptic hypothesis of schizophrenia. Neuron 39, 205-216

Gadient RA, Otten U (1993) Differential expression of interleukin-6 (IL-6) and interleukin-6 receptor (IL-6R) mRNAs in rat hypothalamus. Neuroscience letters 153, 13-16

Gadient RA, Otten U (1994) Expression of interleukin-6 (IL-6) and interleukin-6 receptor (IL-6R) mRNAs in rat brain during postnatal development. Brain research 637, 10-14

Gadient RA, Otten U (1996) Postnatal expression of interleukin-6 (IL-6) and IL-6 receptor (IL-6R) mRNAs in rat sympathetic and sensory ganglia. Brain research 724, $41-46$

Gallagher D, Norman AA, Woodard CL, Yang G, Gauthier-Fisher A, Fujitani M, Vessey JP, Cancino GI, Sachewsky N, Woltjen K, Fatt MP, Morshead CM, Kaplan DR, Miller FD (2013) Transient maternal IL-6 mediates long-lasting changes in neural stem cell pools by deregulating an endogenous self-renewal pathway. Cell stem cell 13, 564-576

Garcia-Oscos F, Salgado H, Hall S, Thomas F, Farmer GE, Bermeo J, Galindo LC, Ramirez RD, D'Mello S, RoseJohn S, Atzori M (2012) The stress-induced cytokine interleukin-6 decreases the inhibition/excitation ratio in the rat temporal cortex via trans-signaling. Biological psychiatry 71, 574-582

Garetto S, Sardi C, Martini E, Roselli G, Morone D, Angioni R, Cianciotti BC, Trovato AE, Franchina DG, Castino GF, Vignali D, Erreni M, Marchesi F, Rumio C, Kallikourdis M (2016) Tailored chemokine receptor modification improves homing of adoptive therapy T cells in a spontaneous tumor model. Oncotarget 7, 43010-43026

Gatto CL, Broadie K (2010) Genetic controls balancing excitatory and inhibitory synaptogenesis in neurodevelopmental disorder models. Frontiers in synaptic neuroscience 2, 4

Gerber KJ, Squires KE, Hepler JR (2016) Roles for Regulator of G Protein Signaling Proteins in Synaptic Signaling and Plasticity. Molecular pharmacology 89, 273-286

Giovanoli S, Engler H, Engler A, Richetto J, Feldon J, Riva MA, Schedlowski M, Meyer U (2016) Preventive effects of minocycline in a neurodevelopmental two-hit model with relevance to schizophrenia. Translational psychiatry 6, e772

Glass CK, Saijo K, Winner B, Marchetto MC, Gage FH (2010) Mechanisms underlying inflammation in neurodegeneration. Cell 140, 918-934

Glausier JR, Lewis DA (2013) Dendritic spine pathology in schizophrenia. Neuroscience 251, 90-107

Grabrucker AM (2012) Environmental factors in autism. Frontiers in psychiatry 3, 118 
Grandjean J, Schroeter A, Batata I, Rudin M (2014) Optimization of anesthesia protocol for resting-state fMRI in mice based on differential effects of anesthetics on functional connectivity patterns. Neurolmage $102 \mathrm{Pt}$ $2,838-847$

Hagenbuch N, Feldon J, Yee BK (2006) Use of the elevated plus-maze test with opaque or transparent walls in the detection of mouse strain differences and the anxiolytic effects of diazepam. Behavioural pharmacology 17, 31-41

Hall J, Trent S, Thomas KL, O'Donovan MC, Owen MJ (2015) Genetic risk for schizophrenia: convergence on synaptic pathways involved in plasticity. Biological psychiatry 77, 52-58

Hama T, Miyamoto M, Tsukui H, Nishio C, Hatanaka H (1989) Interleukin-6 as a neurotrophic factor for promoting the survival of cultured basal forebrain cholinergic neurons from postnatal rats. Neuroscience letters 104, 340-344

Harris KD, Hochgerner H, Skene NG, Magno L, Katona L, Bengtsson Gonzales C, Somogyi P, Kessaris N, Linnarsson S, Hjerling-Leffler J (2018) Classes and continua of hippocampal CA1 inhibitory neurons revealed by single-cell transcriptomics. PLoS biology 16, e2006387

Heinrich PC, Behrmann I, Haan S, Hermanns HM, Muller-Newen G, Schaper F (2003) Principles of interleukin (IL)-6-type cytokine signalling and its regulation. The Biochemical journal 374, 1-20

Heinrich PC, Behrmann I, Muller-Newen G, Schaper F, Graeve L (1998) Interleukin-6-type cytokine signalling through the gp130/Jak/STAT pathway. The Biochemical journal 334 ( Pt 2), 297-314

Hepler JR, Berman DM, Gilman AG, Kozasa T (1997) RGS4 and GAIP are GTPase-activating proteins for Gq alpha and block activation of phospholipase $\mathrm{C}$ beta by gamma-thio-GTP-Gq alpha. Proceedings of the National Academy of Sciences of the United States of America 94, 428-432

Hsiao EY, Patterson PH (2011) Activation of the maternal immune system induces endocrine changes in the placenta via IL-6. Brain, behavior, and immunity 25, 604-615

Ichiba M, Nakajima K, Yamanaka Y, Kiuchi N, Hirano T (1998) Autoregulation of the Stat3 gene through cooperation with a cAMP-responsive element-binding protein. The Journal of biological chemistry 273, 61326138

Jelitai M, Puggioni P, Ishikawa T, Rinaldi A, Duguid I (2016) Dendritic excitation-inhibition balance shapes cerebellar output during motor behaviour. Nature communications 7,13722

Jiang S, Li C, McRae G, Lykken E, Sevilla J, Liu SQ, Wan Y, Li QJ (2014) MeCP2 reinforces STAT3 signaling and the generation of effector CD4+ T cells by promoting miR-124-mediated suppression of SOCS5. Science signaling 7, ra25 
Jones SA, Jenkins BJ (2018) Recent insights into targeting the IL-6 cytokine family in inflammatory diseases and cancer. Nature reviews Immunology 18, 773-789

Kallikourdis M (2018) T cell responses to tumor: how dominant assumptions on immune activity led to a neglect of pathological functions, and how evolutionary considerations can help identify testable hypotheses for improving immunotherapy. Cancer immunology, immunotherapy : CII 67, 989-998

Khan A, Fornes O, Stigliani A, Gheorghe M, Castro-Mondragon JA, van der Lee R, Bessy A, Cheneby J, Kulkarni SR, Tan G, Baranasic D, Arenillas DJ, Sandelin A, Vandepoele K, Lenhard B, Ballester B, Wasserman WW, Parcy F, Mathelier A (2018) JASPAR 2018: update of the open-access database of transcription factor binding profiles and its web framework. Nucleic acids research 46, D1284

Kim S, Kim H, Yim YS, Ha S, Atarashi K, Tan TG, Longman RS, Honda K, Littman DR, Choi GB, Huh JR (2017) Maternal gut bacteria promote neurodevelopmental abnormalities in mouse offspring. Nature 549, 528-532

Knuesel I, Chicha L, Britschgi M, Schobel SA, Bodmer M, Hellings JA, Toovey S, Prinssen EP (2014) Maternal immune activation and abnormal brain development across CNS disorders. Nature reviews Neurology 10, $643-660$

Konopaske GT, Lange N, Coyle JT, Benes FM (2014) Prefrontal cortical dendritic spine pathology in schizophrenia and bipolar disorder. JAMA psychiatry 71, 1323-1331

Kotas ME, Medzhitov R (2015) Homeostasis, inflammation, and disease susceptibility. Cell 160, 816-827

Kowalczyk MS, Tirosh I, HeckI D, Rao TN, Dixit A, Haas BJ, Schneider RK, Wagers AJ, Ebert BL, Regev A (2015) Single-cell RNA-seq reveals changes in cell cycle and differentiation programs upon aging of hematopoietic stem cells. Genome research 25, 1860-1872

Kushima Y, Hama T, Hatanaka H (1992) Interleukin-6 as a neurotrophic factor for promoting the survival of cultured catecholaminergic neurons in a chemically defined medium from fetal and postnatal rat midbrains. Neuroscience research $13,267-280$

Lee H, Deng J, Kujawski M, Yang C, Liu Y, Herrmann A, Kortylewski M, Horne D, Somlo G, Forman S, Jove R, Yu H (2010) STAT3-induced S1PR1 expression is crucial for persistent STAT3 activation in tumors. Nature medicine 16, 1421-1428

Lee J, Chung C, Ha S, Lee D, Kim DY, Kim H, Kim E (2015) Shank3-mutant mice lacking exon 9 show altered excitation/inhibition balance, enhanced rearing, and spatial memory deficit. Frontiers in cellular neuroscience 9,94

Leibinger M, Andreadaki A, Diekmann H, Fischer D (2013a) Neuronal STAT3 activation is essential for CNTFand inflammatory stimulation-induced CNS axon regeneration. Cell death \& disease 4, e805 
Leibinger M, Muller A, Gobrecht P, Diekmann H, Andreadaki A, Fischer D (2013b) Interleukin-6 contributes to CNS axon regeneration upon inflammatory stimulation. Cell death \& disease 4, e609

Lein ES, Hawrylycz MJ, Ao N, Ayres M, Bensinger A, Bernard A, Boe AF, Boguski MS, Brockway KS, Byrnes EJ, Chen L, Chen L, Chen TM, Chin MC, Chong J, Crook BE, Czaplinska A, Dang CN, Datta S, Dee NR, Desaki AL, Desta T, Diep E, Dolbeare TA, Donelan MJ, Dong HW, Dougherty JG, Duncan BJ, Ebbert AJ, Eichele G, Estin LK, Faber C, Facer BA, Fields R, Fischer SR, Fliss TP, Frensley C, Gates SN, Glattfelder KJ, Halverson KR, Hart MR, Hohmann JG, Howell MP, Jeung DP, Johnson RA, Karr PT, Kawal R, Kidney JM, Knapik RH, Kuan CL, Lake JH, Laramee AR, Larsen KD, Lau C, Lemon TA, Liang AJ, Liu Y, Luong LT, Michaels J, Morgan JJ, Morgan RJ, Mortrud MT, Mosqueda NF, Ng LL, Ng R, Orta GJ, Overly CC, Pak TH, Parry SE, Pathak SD, Pearson OC, Puchalski RB, Riley ZL, Rockett HR, Rowland SA, Royall JJ, Ruiz MJ, Sarno NR, Schaffnit K, Shapovalova NV, Sivisay T, Slaughterbeck CR, Smith SC, Smith KA, Smith BI, Sodt AJ, Stewart NN, Stumpf KR, Sunkin SM, Sutram M, Tam A, Teemer CD, Thaller C, Thompson CL, Varnam LR, Visel A, Whitlock RM, Wohnoutka PE, Wolkey CK, Wong VY, Wood M, Yaylaoglu MB, Young RC, Youngstrom BL, Yuan XF, Zhang B, Zwingman TA, Jones AR (2007) Genome-wide atlas of gene expression in the adult mouse brain. Nature 445, 168-176

Levison SW, Jiang FJ, Stoltzfus OK, Ducceschi MH (2000) IL-6-type cytokines enhance epidermal growth factor-stimulated astrocyte proliferation. Glia 32, 328-337

Levitt P, Ebert P, Mirnics K, Nimgaonkar VL, Lewis DA (2006) Making the case for a candidate vulnerability gene in schizophrenia: Convergent evidence for regulator of G-protein signaling 4 (RGS4). Biological psychiatry 60, 534-537

Li X, Chauhan A, Sheikh AM, Patil S, Chauhan V, Li XM, Ji L, Brown T, Malik M (2009) Elevated immune response in the brain of autistic patients. Journal of neuroimmunology 207, 111-116

Lim CP, Cao X (1999) Serine phosphorylation and negative regulation of Stat3 by JNK. The Journal of biological chemistry 274, 31055-31061

Lipina TV, Zai C, Hlousek D, Roder JC, Wong AH (2013) Maternal immune activation during gestation interacts with Disc1 point mutation to exacerbate schizophrenia-related behaviors in mice. The Journal of neuroscience : the official journal of the Society for Neuroscience 33, 7654-7666

Lisman J (2012) Excitation, inhibition, local oscillations, or large-scale loops: what causes the symptoms of schizophrenia? Current opinion in neurobiology 22, 537-544

Liu H, Bai H, Hui E, Yang L, Evans CS, Wang Z, Kwon SE, Chapman ER (2014) Synaptotagmin 7 functions as a $\mathrm{Ca2+-sensor} \mathrm{for} \mathrm{synaptic} \mathrm{vesicle} \mathrm{replenishment.}$

Lodato S, Arlotta P (2015) Generating neuronal diversity in the mammalian cerebral cortex. Annual review of cell and developmental biology 31, 699-720

Lu B, Wang KH, Nose A (2009) Molecular mechanisms underlying neural circuit formation. Current opinion in neurobiology 19, 162-167 
Malkova NV, Yu CZ, Hsiao EY, Moore MJ, Patterson PH (2012) Maternal immune activation yields offspring displaying mouse versions of the three core symptoms of autism. Brain, behavior, and immunity 26, 607-616

Mancinelli S, Lodato S (2018) Decoding neuronal diversity in the developing cerebral cortex: from single cells to functional networks. Current opinion in neurobiology 53, 146-155

Mandolesi G, Gentile A, Musella A, Fresegna D, De Vito F, Bullitta S, Sepman H, Marfia GA, Centonze D (2015) Synaptopathy connects inflammation and neurodegeneration in multiple sclerosis. Nature reviews Neurology $11,711-724$

Mantovani A, Allavena P, Sica A, Balkwill F (2008) Cancer-related inflammation. Nature 454, 436-444

Maritano D, Sugrue ML, Tininini S, Dewilde S, Strobl B, Fu X, Murray-Tait V, Chiarle R, Poli V (2004) The STAT3 isoforms alpha and beta have unique and specific functions. Nature immunology 5, 401-409

Matteoli M, Verderio C, Krawzeski K, Mundigl O, Coco S, Fumagalli G, De Camilli P (1995) Mechanisms of synaptogenesis in hippocampal neurons in primary culture. Journal of physiology, Paris 89, 51-55

Maximov A, Pang ZP, Tervo DG, Sudhof TC (2007) Monitoring synaptic transmission in primary neuronal cultures using local extracellular stimulation. Journal of neuroscience methods $161,75-87$

McAfoose J, Baune BT (2009) Evidence for a cytokine model of cognitive function. Neuroscience and biobehavioral reviews 33, 355-366

McAllister AK (2007) Dynamic aspects of CNS synapse formation. Annual review of neuroscience 30, 425-450

Melom JE, Littleton JT (2011) Synapse development in health and disease. Current opinion in genetics \& development 21, 256-261

Mendonca Torres PM, de Araujo EG (2001) Interleukin-6 increases the survival of retinal ganglion cells in vitro. Journal of neuroimmunology 117, 43-50

Missault S, Van den Eynde K, Vanden Berghe W, Fransen E, Weeren A, Timmermans JP, Kumar-Singh S, Dedeurwaerdere $S$ (2014) The risk for behavioural deficits is determined by the maternal immune response to prenatal immune challenge in a neurodevelopmental model. Brain, behavior, and immunity 42, 138-146

Monje ML, Toda H, Palmer TD (2003) Inflammatory blockade restores adult hippocampal neurogenesis. Science 302, 1760-1765

Munno DW, Prince DJ, Syed NI (2003) Synapse number and synaptic efficacy are regulated by presynaptic CAMP and protein kinase A. The Journal of neuroscience : the official journal of the Society for Neuroscience 23, 4146-4155 
Munoz-Suano A, Kallikourdis M, Sarris M, Betz AG (2012) Regulatory T cells protect from autoimmune arthritis during pregnancy. Journal of autoimmunity 38, J103-108

Murase S, Kim E, Lin L, Hoffman DA, McKay RD (2012) Loss of signal transducer and activator of transcription 3 (STAT3) signaling during elevated activity causes vulnerability in hippocampal neurons. The Journal of neuroscience : the official journal of the Society for Neuroscience 32, 15511-15520

Najjar S, Pearlman DM, Alper K, Najjar A, Devinsky O (2013) Neuroinflammation and psychiatric illness. Journal of neuroinflammation 10, 43

Nanou E, Sullivan JM, Scheuer T, Catterall WA (2016) Calcium sensor regulation of the CaV2.1 Ca2+ channel contributes to short-term synaptic plasticity in hippocampal neurons. Proceedings of the National Academy of Sciences of the United States of America 113, 1062-1067

Narimatsu M, Maeda H, Itoh S, Atsumi T, Ohtani T, Nishida K, Itoh M, Kamimura D, Park SJ, Mizuno K, Miyazaki J, Hibi M, Ishihara K, Nakajima K, Hirano T (2001) Tissue-specific autoregulation of the stat3 gene and its role in interleukin-6-induced survival signals in T cells. Molecular and cellular biology 21, 6615-6625

Nelson SB, Valakh V (2015) Excitatory/Inhibitory Balance and Circuit Homeostasis in Autism Spectrum Disorders. Neuron 87, 684-698

Ni YG, Gold SJ, Iredale PA, Terwilliger RZ, Duman RS, Nestler EJ (1999) Region-specific regulation of RGS4 (Regulator of G-protein-signaling protein type 4) in brain by stress and glucocorticoids: in vivo and in vitro studies. The Journal of neuroscience : the official journal of the Society for Neuroscience 19, 3674-3680

Nicolas CS, Peineau S, Amici M, Csaba Z, Fafouri A, Javalet C, Collett VJ, Hildebrandt L, Seaton G, Choi SL, Sim SE, Bradley C, Lee K, Zhuo M, Kaang BK, Gressens P, Dournaud P, Fitzjohn SM, Bortolotto ZA, Cho K, Collingridge GL (2012) The Jak/STAT pathway is involved in synaptic plasticity. Neuron 73, 374-390

Nomoto S, Adachi K, Yang LX, Hirata Y, Muraguchi S, Kiuchi K (1997) Distribution of RGS4 mRNA in mouse brain shown by in situ hybridization. Biochemical and biophysical research communications 241, 281-287

O'Donnell C, Goncalves JT, Portera-Cailliau C, Sejnowski TJ (2017) Beyond excitation/inhibition imbalance in multidimensional models of neural circuit changes in brain disorders. eLife 6

Onore C, Careaga M, Ashwood P (2012) The role of immune dysfunction in the pathophysiology of autism. Brain, behavior, and immunity 26, 383-392 
Pagani M, Bertero A, Liska A, Galbusera A, Sabbioni M, Barsotti N, Colenbier N, Marinazzo D, Scattoni ML, Pasqualetti M, Gozzi A (2019) Deletion of Autism Risk Gene Shank3 Disrupts Prefrontal Connectivity. The Journal of neuroscience : the official journal of the Society for Neuroscience 39, 5299-5310

Pallaki P, Georganta EM, Serafimidis I, Papakonstantinou MP, Papanikolaou V, Koutloglou S, Papadimitriou E, Agalou A, Tserga A, Simeonof A, Thomaidou D, Gaitanou M, Georgoussi Z (2017) A novel regulatory role of RGS4 in STAT5B activation, neurite outgrowth and neuronal differentiation. Neuropharmacology 117, 408421

Park KW, Nozell SE, Benveniste EN (2012) Protective role of STAT3 in NMDA and glutamate-induced neuronal death: negative regulatory effect of SOCS3. PloS one 7, e50874

Pelkey KA, Chittajallu R, Craig MT, Tricoire L, Wester JC, McBain CJ (2017) Hippocampal GABAergic Inhibitory Interneurons. Physiological reviews 97, 1619-1747

Penzes P, Cahill ME, Jones KA, VanLeeuwen JE, Woolfrey KM (2011) Dendritic spine pathology in neuropsychiatric disorders. Nature neuroscience 14, 285-293

Pieraut S, Lucas O, Sangari S, Sar C, Boudes M, Bouffi C, Noel D, Scamps F (2011) An autocrine neuronal interleukin-6 loop mediates chloride accumulation and NKCC1 phosphorylation in axotomized sensory neurons. The Journal of neuroscience : the official journal of the Society for Neuroscience 31, 13516-13526

Potvin S, Stip E, Sepehry AA, Gendron A, Bah R, Kouassi E (2008) Inflammatory cytokine alterations in schizophrenia: a systematic quantitative review. Biological psychiatry $63,801-808$

Pozzi D, Lignani G, Ferrea E, Contestabile A, Paonessa F, D'Alessandro R, Lippiello P, Boido D, Fassio A, Meldolesi J, Valtorta F, Benfenati F, Baldelli P (2013) REST/NRSF-mediated intrinsic homeostasis protects neuronal networks from hyperexcitability. The EMBO journal 32, 2994-3007

Pozzi D, Menna E, Canzi A, Desiato G, Mantovani C, Matteoli M (2018) The Communication Between the Immune and Nervous Systems: The Role of IL-1beta in Synaptopathies. Frontiers in molecular neuroscience 11,111

Reemst K, Noctor SC, Lucassen PJ, Hol EM (2016) The Indispensable Roles of Microglia and Astrocytes during Brain Development. Frontiers in human neuroscience 10, 566

Rothaug M, Becker-Pauly C, Rose-John S (2016) The role of interleukin-6 signaling in nervous tissue. Biochimica et biophysica acta 1863, 1218-1227

Rudolph MD, Graham AM, Feczko E, Miranda-Dominguez O, Rasmussen JM, Nardos R, Entringer S, Wadhwa PD, Buss C, Fair DA (2018) Maternal IL-6 during pregnancy can be estimated from newborn brain connectivity and predicts future working memory in offspring. Nature neuroscience $21,765-772$ 
Sala C, Piech V, Wilson NR, Passafaro M, Liu G, Sheng M (2001) Regulation of dendritic spine morphology and synaptic function by Shank and Homer. Neuron 31, 115-130

Sandelin A, Alkema W, Engstrom P, Wasserman WW, Lenhard B (2004) JASPAR: an open-access database for eukaryotic transcription factor binding profiles. Nucleic acids research 32, D91-94

Sawada M, Itoh Y, Suzumura A, Marunouchi T (1993) Expression of cytokine receptors in cultured neuronal and glial cells. Neuroscience letters 160, 131-134

Schust J, Sperl B, Hollis A, Mayer TU, Berg T (2006) Stattic: a small-molecule inhibitor of STAT3 activation and dimerization. Chemistry \& biology 13, 1235-1242

Schwarz E (2018) A gene-based review of RGS4 as a putative risk gene for psychiatric illness. American journal of medical genetics Part B, Neuropsychiatric genetics : the official publication of the International Society of Psychiatric Genetics 177, 267-273

Selmaj KW, Farooq M, Norton WT, Raine CS, Brosnan CF (1990) Proliferation of astrocytes in vitro in response to cytokines. A primary role for tumor necrosis factor. Journal of immunology 144, 129-135

Shelly M, Lim BK, Cancedda L, Heilshorn SC, Gao H, Poo MM (2010) Local and long-range reciprocal regulation of cAMP and cGMP in axon/dendrite formation. Science 327, 547-552

Shen K, Scheiffele P (2010) Genetics and cell biology of building specific synaptic connectivity. Annual review of neuroscience $33,473-507$

Shin Yim Y, Park A, Berrios J, Lafourcade M, Pascual LM, Soares N, Yeon Kim J, Kim S, Kim H, Waisman A, Littman DR, Wickersham IR, Harnett MT, Huh JR, Choi GB (2017) Reversing behavioural abnormalities in mice exposed to maternal inflammation. Nature $549,482-487$

Shirts BH, Nimgaonkar V (2004) The genes for schizophrenia: finally a breakthrough? Current psychiatry reports $6,303-312$

Smith SE, Li J, Garbett K, Mirnics K, Patterson PH (2007a) Maternal immune activation alters fetal brain development through interleukin-6. The Journal of neuroscience : the official journal of the Society for Neuroscience 27, 10695-10702

Smith SEP, Li J, Garbett K, Mirnics K, Patterson PH (2007b) Maternal immune activation alters fetal brain development through interleukin-6. Journal of Neuroscience 27, 10695-10702

Sohal VS, Rubenstein JLR (2019) Excitation-inhibition balance as a framework for investigating mechanisms in neuropsychiatric disorders. Molecular psychiatry 
Spann MN, Monk C, Scheinost D, Peterson BS (2018) Maternal Immune Activation During the Third Trimester Is Associated with Neonatal Functional Connectivity of the Salience Network and Fetal to Toddler Behavior. The Journal of neuroscience : the official journal of the Society for Neuroscience 38, 2877-2886

Supekar K, Uddin LQ, Khouzam A, Phillips J, Gaillard WD, Kenworthy LE, Yerys BE, Vaidya CJ, Menon V (2013) Brain hyperconnectivity in children with autism and its links to social deficits. Cell reports 5, 738-747

Talkowski ME, Seltman H, Bassett AS, Brzustowicz LM, Chen X, Chowdari KV, Collier DA, Cordeiro Q, Corvin AP, Deshpande SN, Egan MF, Gill M, Kendler KS, Kirov G, Heston LL, Levitt P, Lewis DA, Li T, Mirnics K, Morris DW, Norton N, O'Donovan MC, Owen MJ, Richard C, Semwal P, Sobell JL, St Clair D, Straub RE, Thelma BK, Vallada H, Weinberger DR, Williams NM, Wood J, Zhang F, Devlin B, Nimgaonkar VL (2006) Evaluation of a susceptibility gene for schizophrenia: genotype based meta-analysis of RGS4 polymorphisms from thirteen independent samples. Biological psychiatry 60, 152-162

Timper K, Denson JL, Steculorum SM, Heilinger C, Engstrom-Ruud L, Wunderlich CM, Rose-John S, Wunderlich FT, Bruning JC (2017) IL-6 Improves Energy and Glucose Homeostasis in Obesity via Enhanced Central IL-6 trans-Signaling. Cell reports 19, 267-280

Tirosh I, Izar B, Prakadan SM, Wadsworth MH, 2nd, Treacy D, Trombetta JJ, Rotem A, Rodman C, Lian C, Murphy G, Fallahi-Sichani M, Dutton-Regester K, Lin JR, Cohen O, Shah P, Lu D, Genshaft AS, Hughes TK, Ziegler CG, Kazer SW, Gaillard A, Kolb KE, Villani AC, Johannessen CM, Andreev AY, Van Allen EM, Bertagnolli M, Sorger PK, Sullivan RJ, Flaherty KT, Frederick DT, Jane-Valbuena J, Yoon CH, Rozenblatt-Rosen O, Shalek AK, Regev A, Garraway LA (2016) Dissecting the multicellular ecosystem of metastatic melanoma by singlecell RNA-seq. Science 352, 189-196

Urban N, Guillemot F (2014) Neurogenesis in the embryonic and adult brain: same regulators, different roles. Frontiers in cellular neuroscience 8, 396

Vallieres L, Campbell IL, Gage FH, Sawchenko PE (2002) Reduced hippocampal neurogenesis in adult transgenic mice with chronic astrocytic production of interleukin-6. The Journal of neuroscience : the official journal of the Society for Neuroscience 22, 486-492

Vereyken EJ, Bajova H, Chow S, de Graan PN, Gruol DL (2007) Chronic interleukin-6 alters the level of synaptic proteins in hippocampus in culture and in vivo. The European journal of neuroscience 25, 3605-3616

Vezzani A, French J, Bartfai T, Baram TZ (2011) The role of inflammation in epilepsy. Nature reviews Neurology 7, 31-40

Wallenius V, Wallenius K, Ahren B, Rudling M, Carlsten H, Dickson SL, Ohlsson C, Jansson JO (2002) Interleukin-6-deficient mice develop mature-onset obesity. Nature medicine 8, 75-79

Weidler M, Rether J, Anke T, Erkel G (2000) Inhibition of interleukin- 6 signaling by galiellalactone. FEBS letters 484, 1-6 
Weissenberger J, Loeffler S, Kappeler A, Kopf M, Lukes A, Afanasieva TA, Aguzzi A, Weis J (2004) IL-6 is required for glioma development in a mouse model. Oncogene 23, 3308-3316

Wen Z, Zhong Z, Darnell JE, Jr. (1995) Maximal activation of transcription by Stat1 and Stat3 requires both tyrosine and serine phosphorylation. Cell 82, 241-250

Wierenga CJ, Walsh MF, Turrigiano GG (2006) Temporal regulation of the expression locus of homeostatic plasticity. Journal of neurophysiology 96, 2127-2133

Williams ME, de Wit J, Ghosh A (2010) Molecular mechanisms of synaptic specificity in developing neural circuits. Neuron $68,9-18$

Yu H, Pardoll D, Jove R (2009) STATs in cancer inflammation and immunity: a leading role for STAT3. Nature reviews Cancer 9, 798-809

Zerbi V, Grandjean J, Rudin M, Wenderoth N (2015) Mapping the mouse brain with rs-fMRI: An optimized pipeline for functional network identification. Neurolmage 123, 11-21

Zerbi V, lelacqua GD, Markicevic M, Haberl MG, Ellisman MH, A AB, Frick A, Rudin M, Wenderoth N (2018) Dysfunctional Autism Risk Genes Cause Circuit-Specific Connectivity Deficits With Distinct Developmental Trajectories. Cerebral cortex 28, 2495-2506

Zerbi V, Jansen D, Dederen PJ, Veltien A, Hamans B, Liu Y, Heerschap A, Kiliaan AJ (2013a) Microvascular cerebral blood volume changes in aging APP(swe)/PS1(dE9) AD mouse model: a voxel-wise approach. Brain structure \& function $218,1085-1098$

Zerbi V, Kleinnijenhuis M, Fang X, Jansen D, Veltien A, Van Asten J, Timmer N, Dederen PJ, Kiliaan AJ, Heerschap A (2013b) Gray and white matter degeneration revealed by diffusion in an Alzheimer mouse model. Neurobiology of aging 34, 1440-1450

Zerbi V, Markicevic M, Gasparini F, Schroeter A, Rudin M, Wenderoth N (2019) Inhibiting mGluR5 activity by AFQ056/Mavoglurant rescues circuit-specific functional connectivity in Fmr1 knockout mice. Neurolmage 191, 392-402

Zhou Y, Sharma J, Ke Q, Landman R, Yuan J, Chen H, Hayden DS, Fisher JW, 3rd, Jiang M, Menegas W, Aida T, Yan T, Zou Y, Xu D, Parmar S, Hyman JB, Fanucci-Kiss A, Meisner O, Wang D, Huang Y, Li Y, Bai Y, Ji W, Lai X, Li W, Huang L, Lu Z, Wang L, Anteraper SA, Sur M, Zhou H, Xiang AP, Desimone R, Feng G, Yang S (2019) Atypical behaviour and connectivity in SHANK3-mutant macaques. Nature 570, 326-331 
bioRxiv preprint doi: https://doi.org/10.1101/2020.11.02.364356; this version posted Navember 2, 2020. The copyright holder for this preprint (which was not certified by peer review) is the author/funder, who has granted bioAxdjuatticense tordisplay the preprimt in GD15

PO perpetyity. It is madedvalt

IL-6

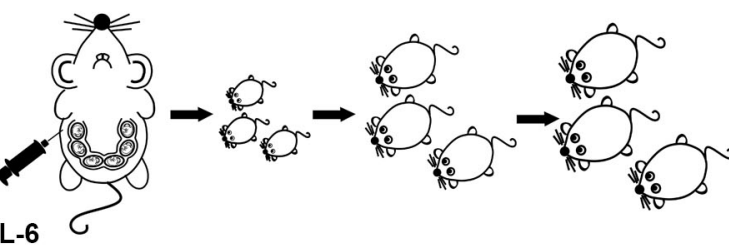

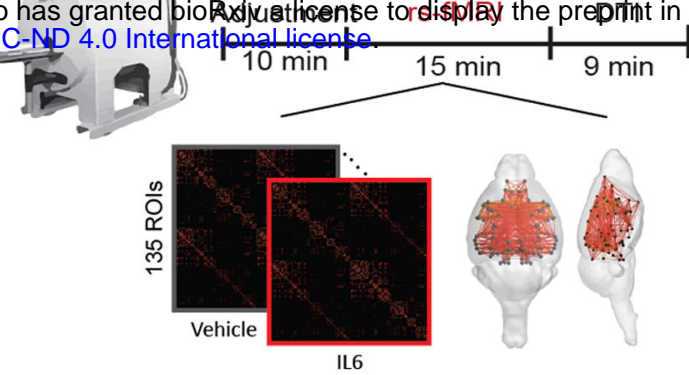

injection

isoflurane $(0.5 \%)+$ medetomidine $(0.1 \mathrm{mg} / \mathrm{kg} / \mathrm{h})$

Vehicle > IL-6

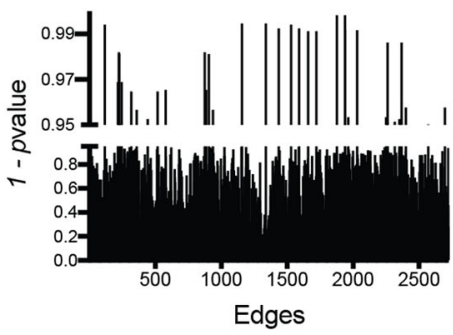

IL-6 > Vehicle

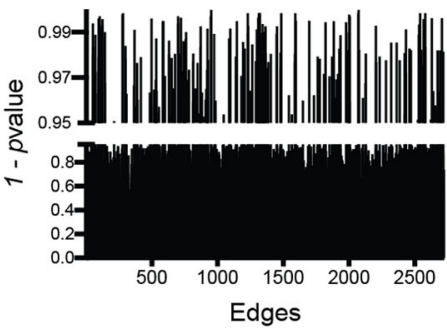

Dorsal Hippocampal Network: Vehicle (average)
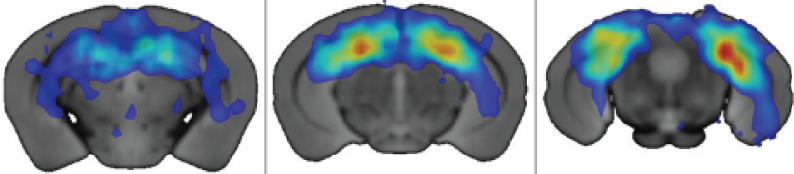

Dorsal Hippocampal Network: IL-6 (average)
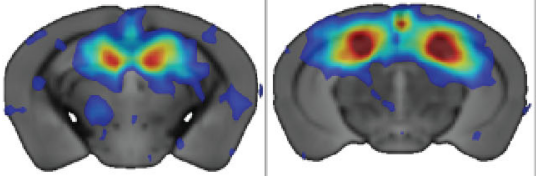

$-2.18$

$-2.70$

$-3.16$

Distance from Bregma $(\mathrm{mm})$
C

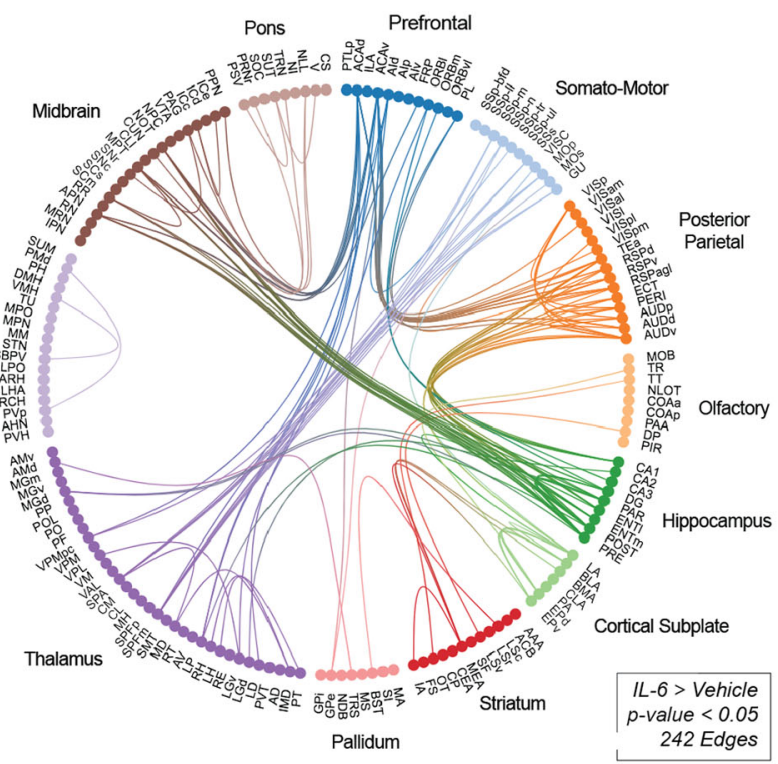

\section{F Open Fleld}

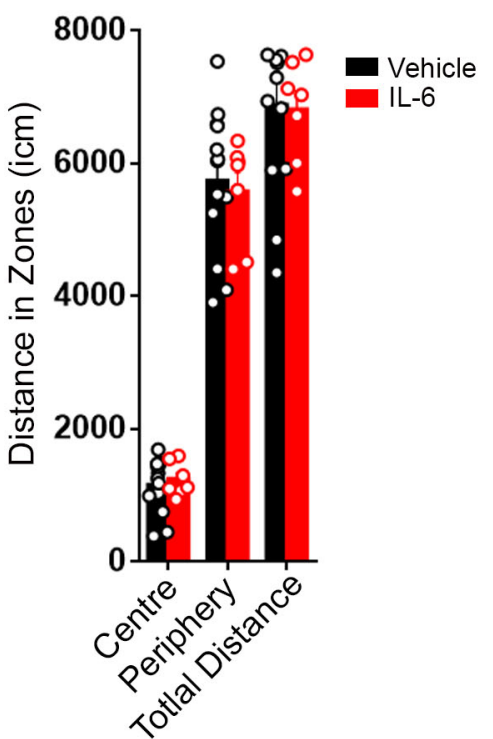

\section{G Elevated Plus Maze}

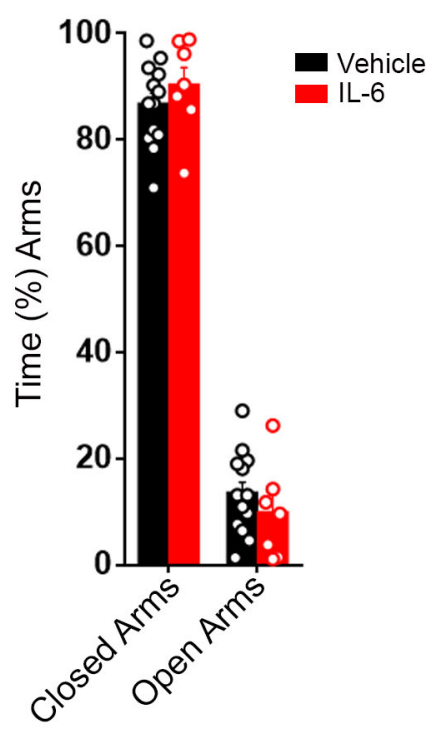

H Novel Object Recognition

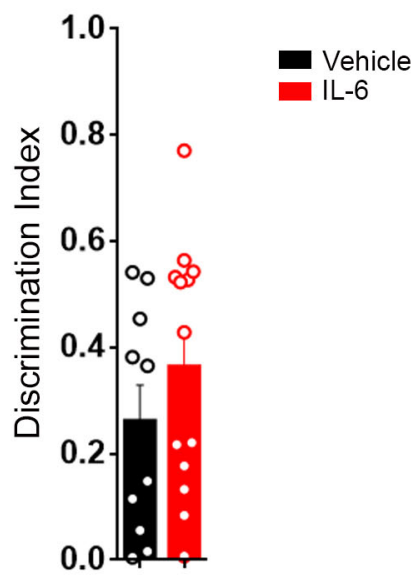

I Novel Object Location

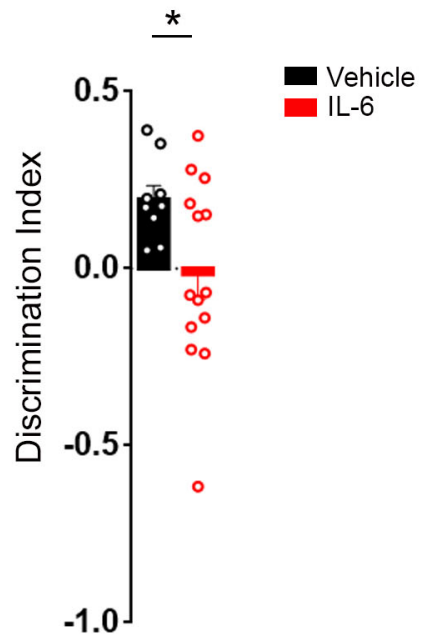




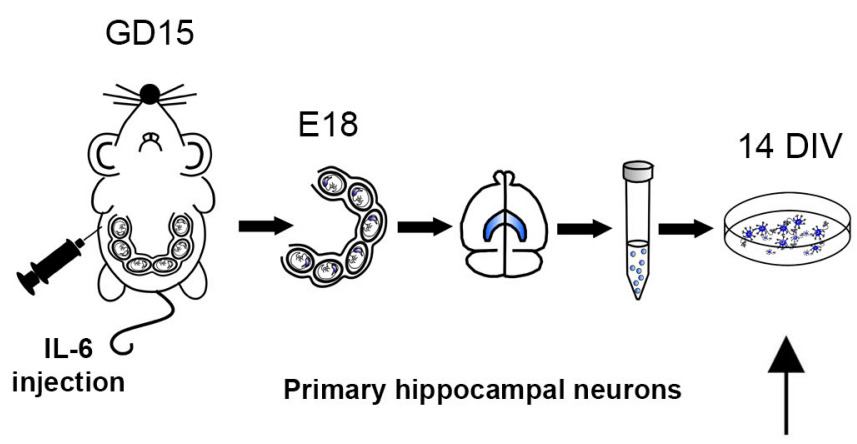

Analysis
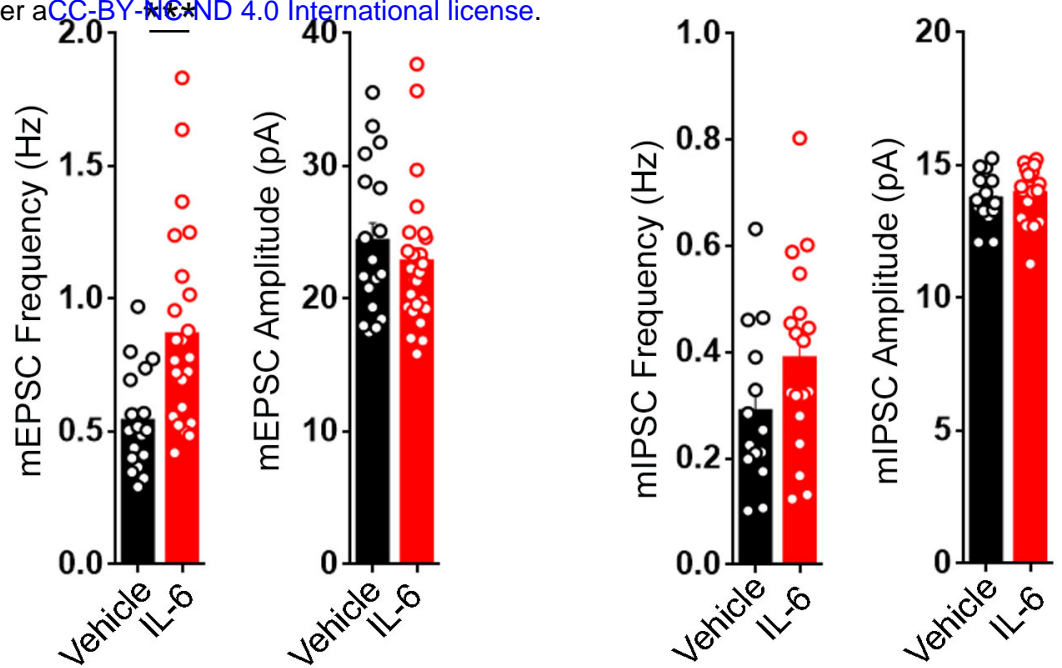

$\mathbf{E}$

$1 \mathrm{ng} / \mathrm{ml}$

$5 \mathrm{ng} / \mathrm{ml}$

Primary hippocampal neurons

Analysis

$10 \mathrm{ng} / \mathrm{ml}$

$20 \mathrm{pA} \underset{4 \mathrm{sec}}{\bigsqcup}$
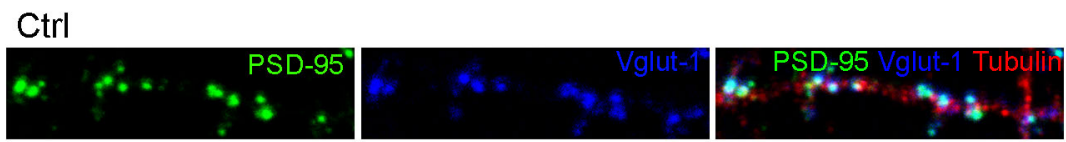

IL-6
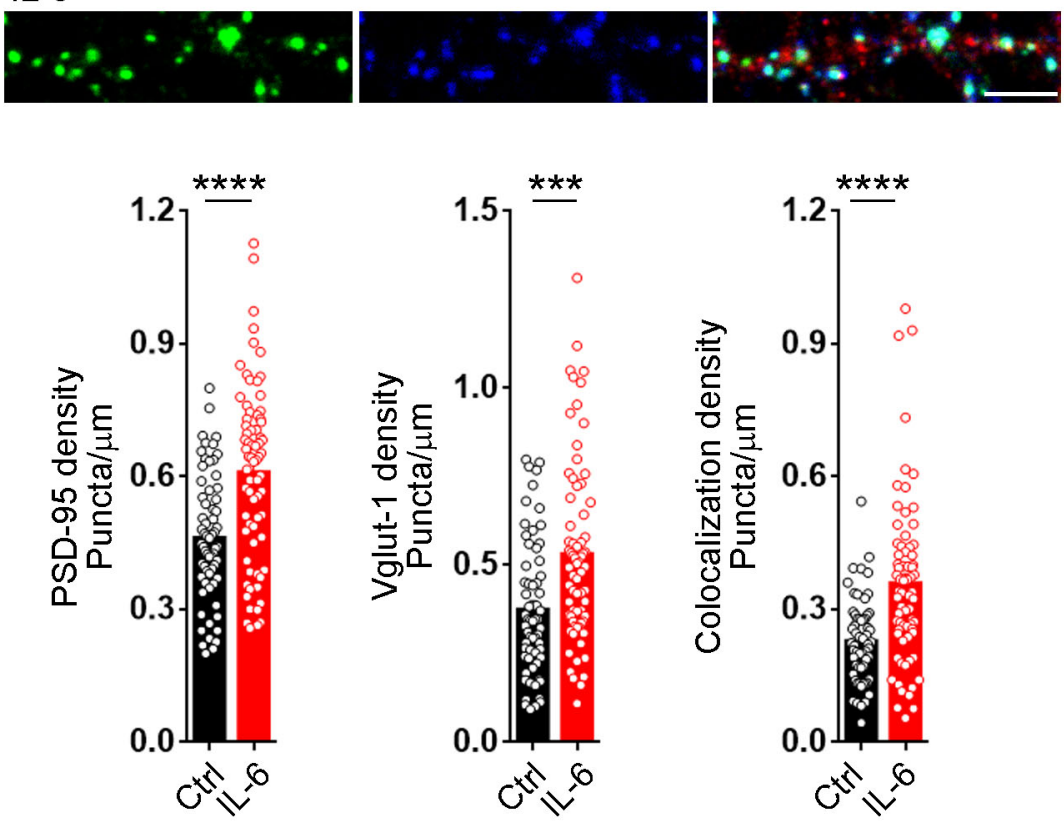

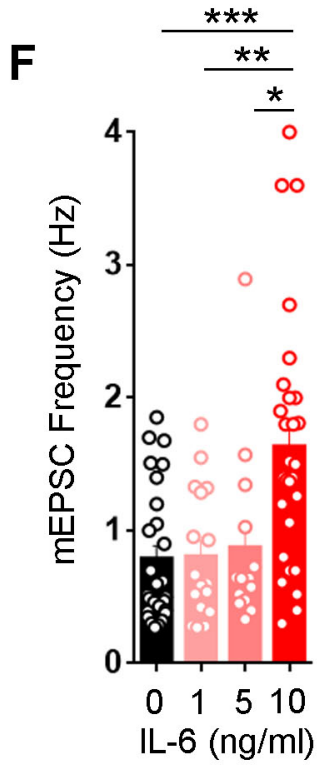

H

IL-6

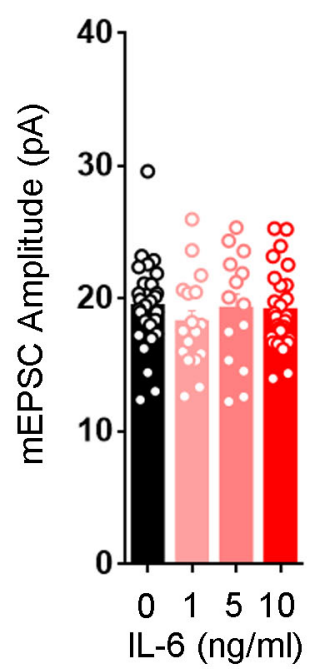

Ctrl $0 \mathrm{pA} \bigsqcup_{4 \mathrm{sec}}$
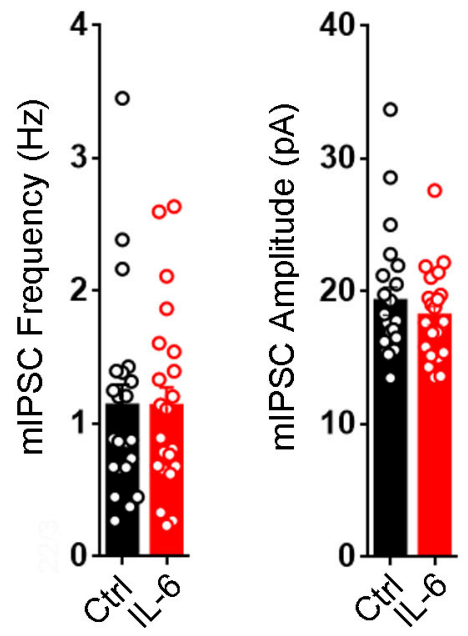
A

PrimakiqRixiv prenrint delifattps://doi.org/10.1101/2020.11.02.364356; this version posted November 2, 2020. The6ppyright holder for this

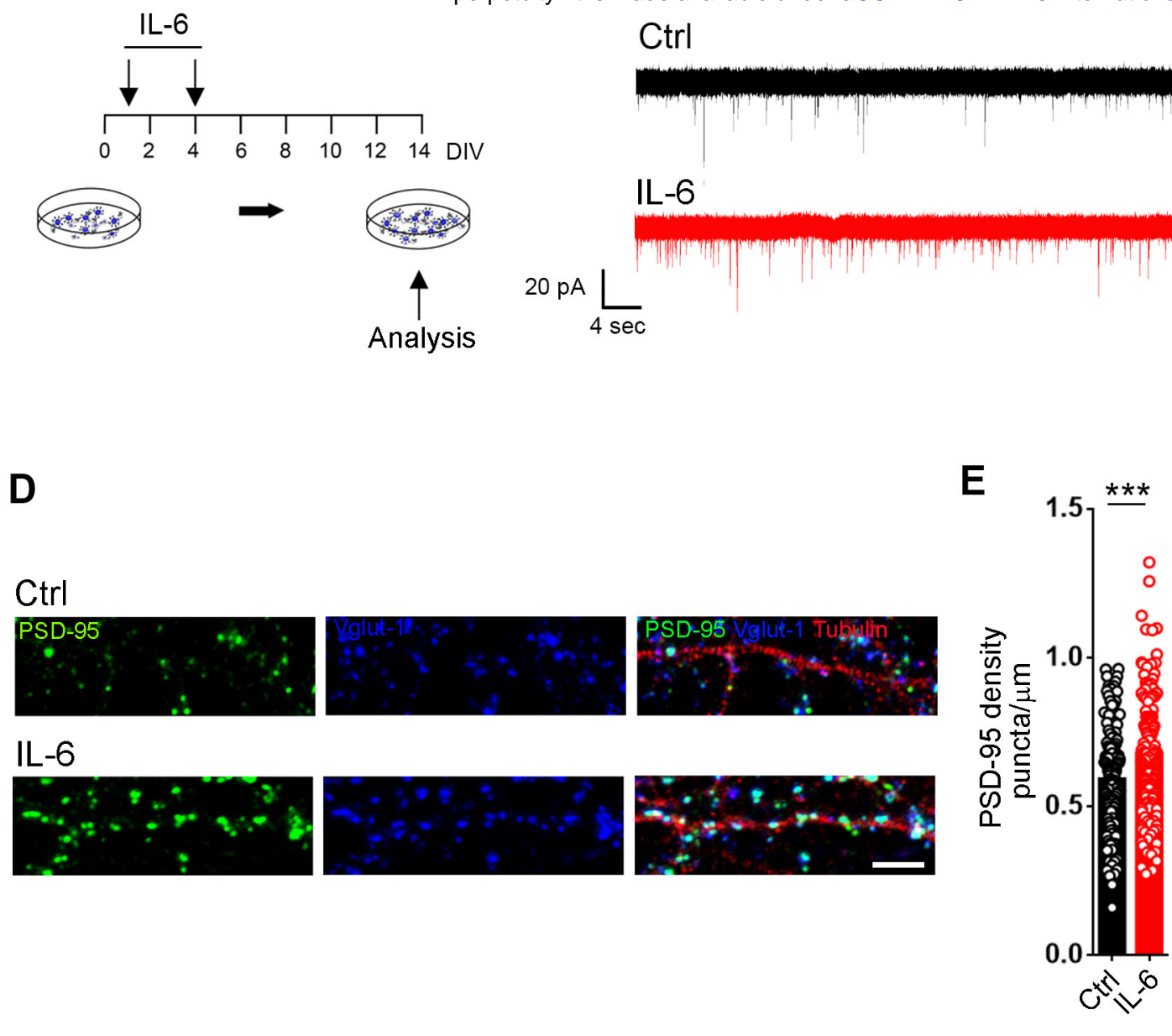
perpetuity. It is made available under aCC-BY-NC-ND 4.0 International licens
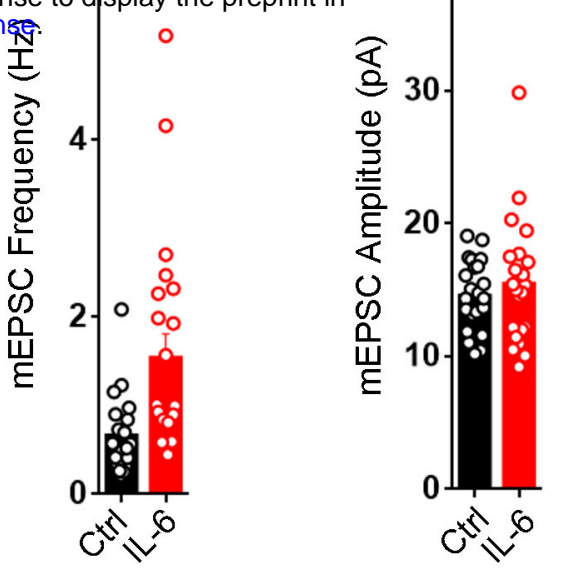

$\mathbf{F}$
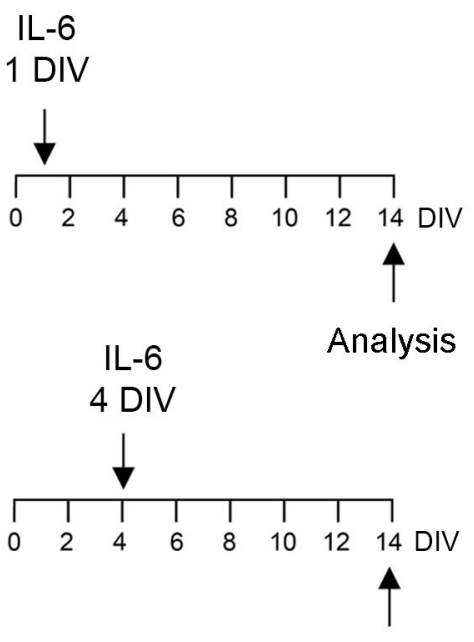

Analysis

IL-6

13 DIV

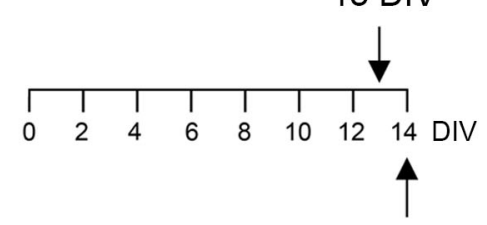

Analysis
$\mathbf{G}$

Ctrl

\section{IL-6 1 DIV}

\section{IL-6 4 DIV}

$$
20 \mathrm{pA} \underset{4 \mathrm{sec}}{\longleftarrow}
$$

\section{J}

\section{Ctrl}

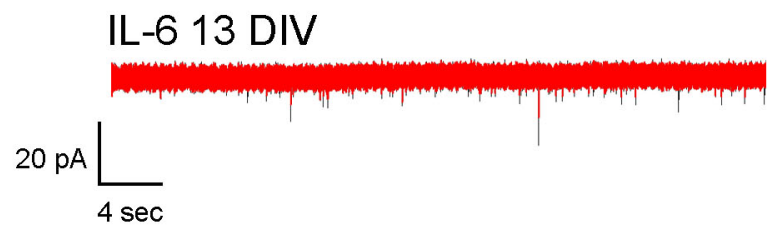

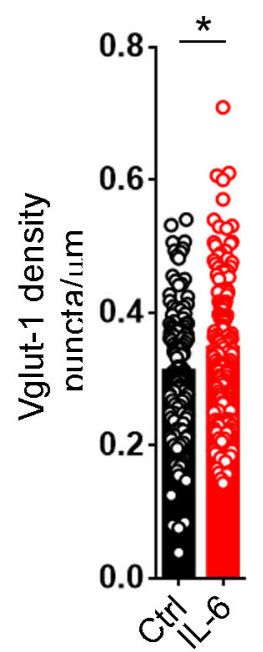

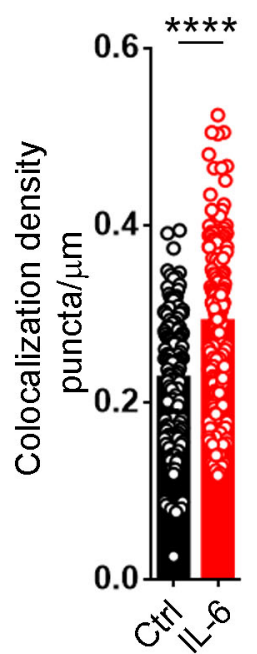

H
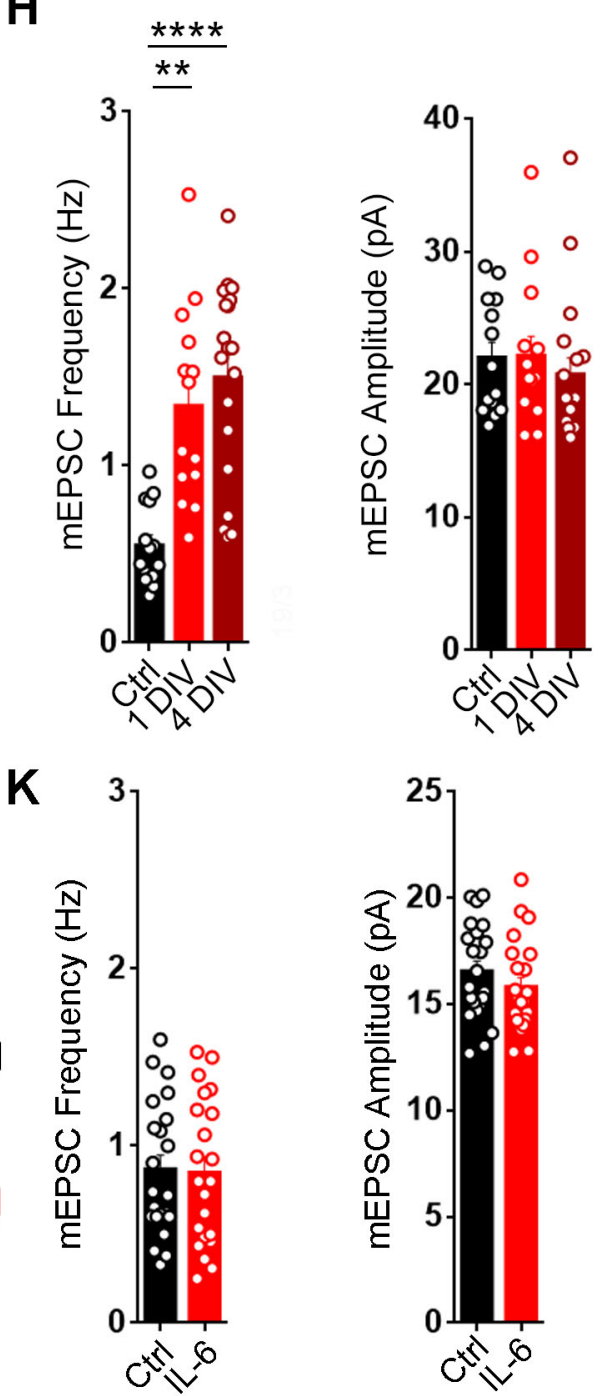

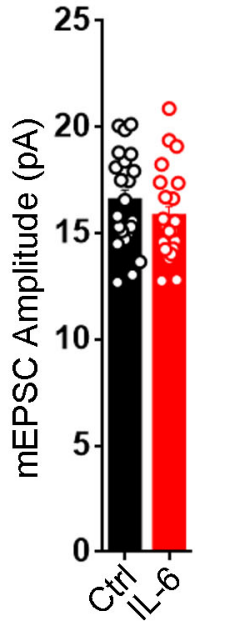




\section{STAT3 mRNA level}

\section{STAT3 protein level}

A

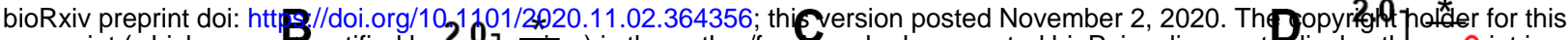
preprint (which was notcertified by feen review) is the author/funder, who has granted bioRxiv a license to display the preprint in perpetuity. It is made available under aCC-BY-NC_ND 4.0 Internatipn-3 license.

Primary hippocampal neurons
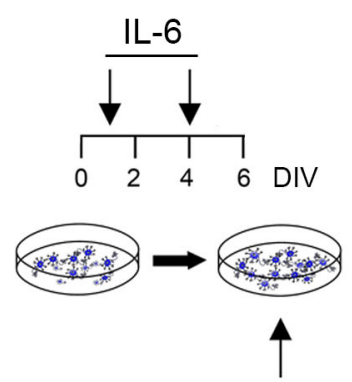

Analysis
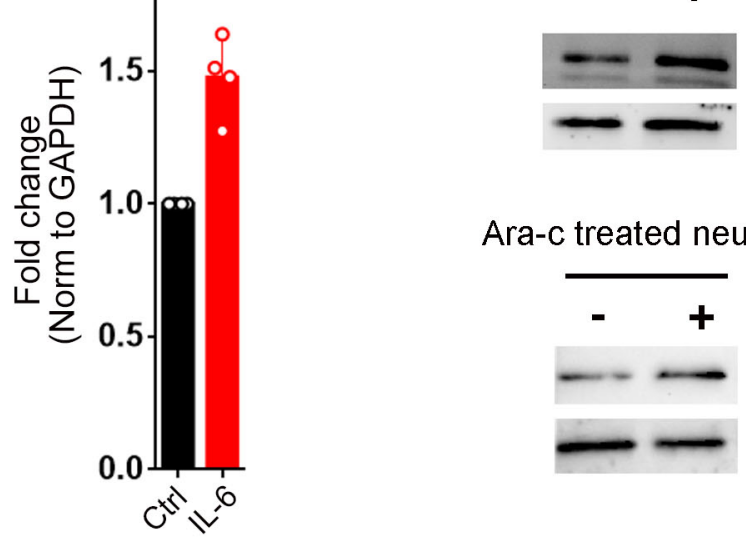

STAT3

GAPDH

Ara-c treated neurons

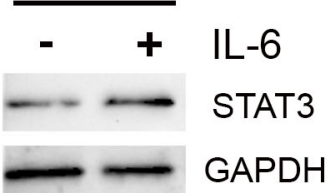

$\mathbf{F}$

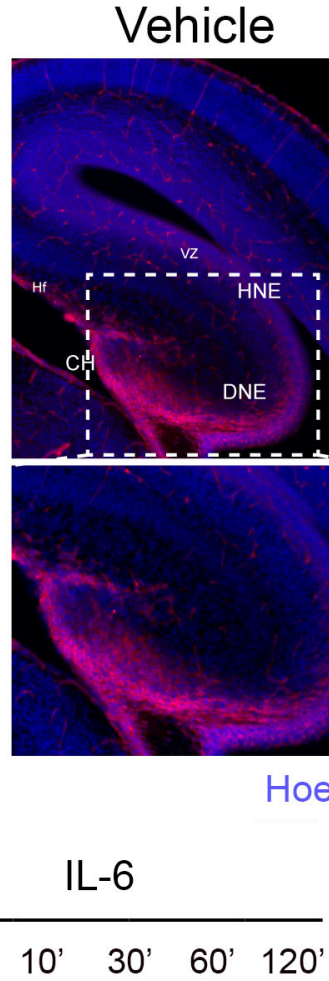

P-STAT3

Tyr705

STAT3 Tot

E16
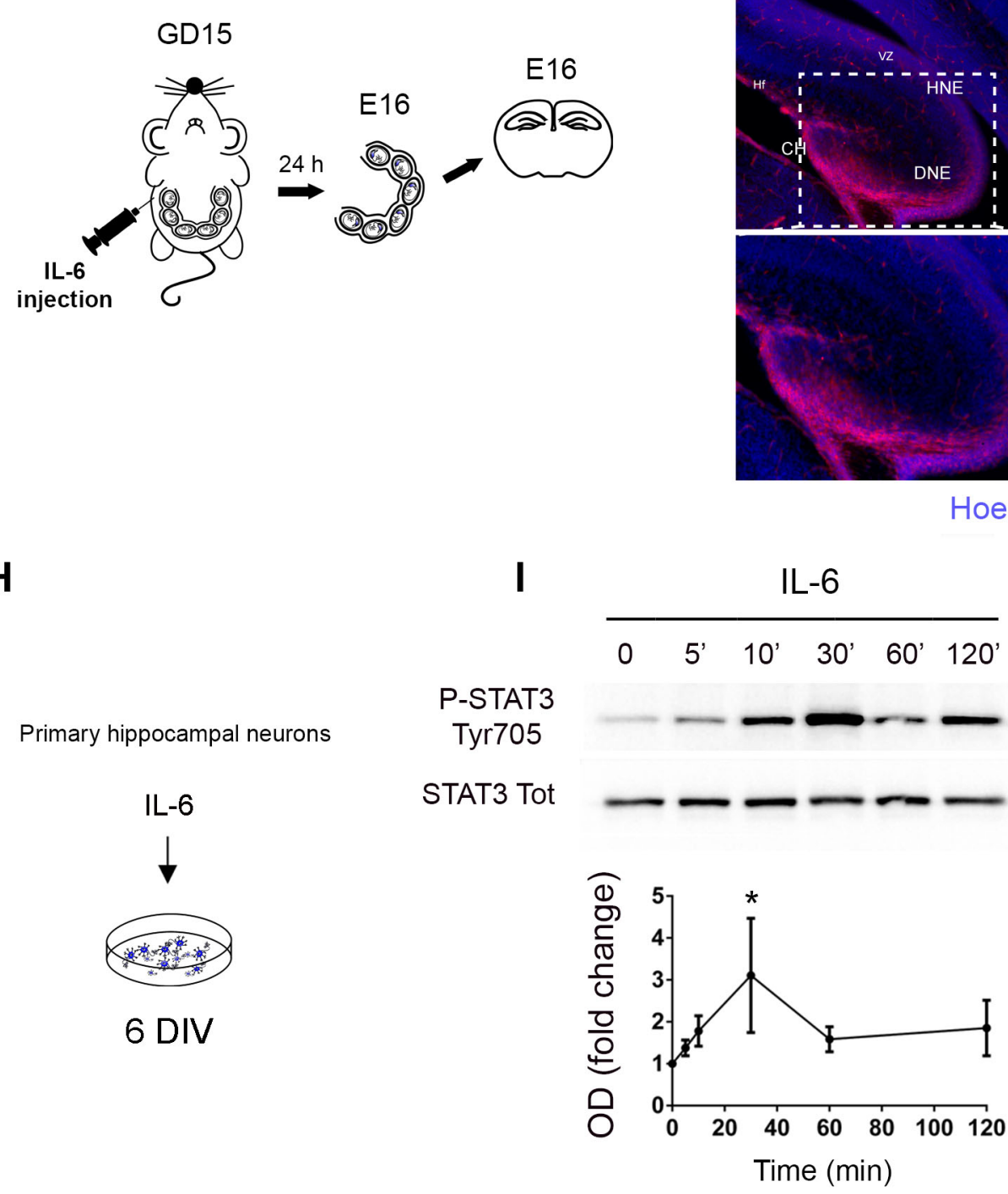
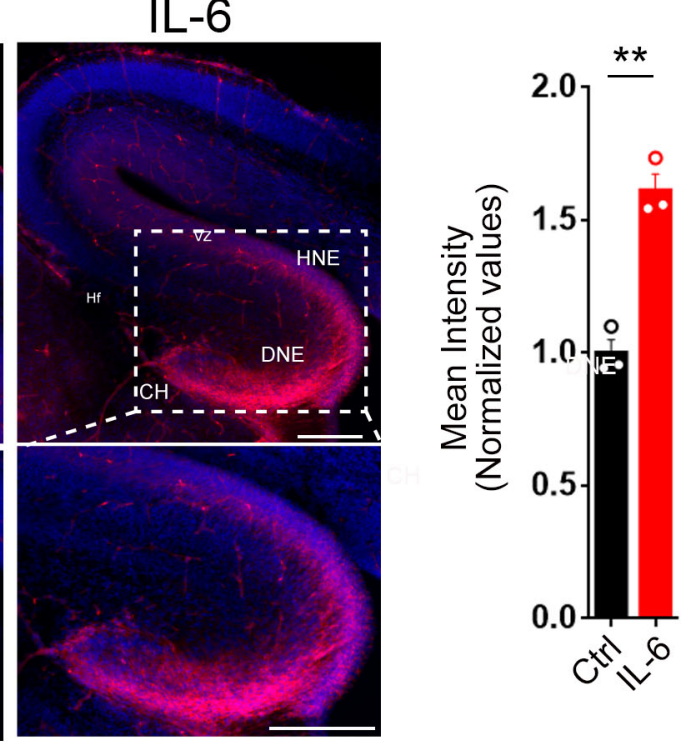

G

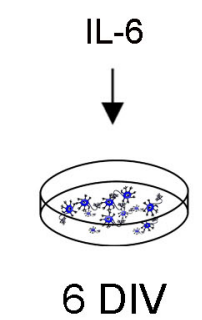

6 DIV

H

Primary hippocampal neurons
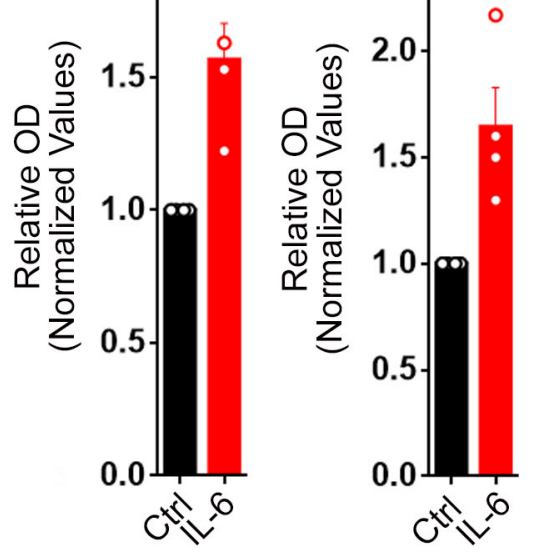

Ara-c

Hoechst STAT3

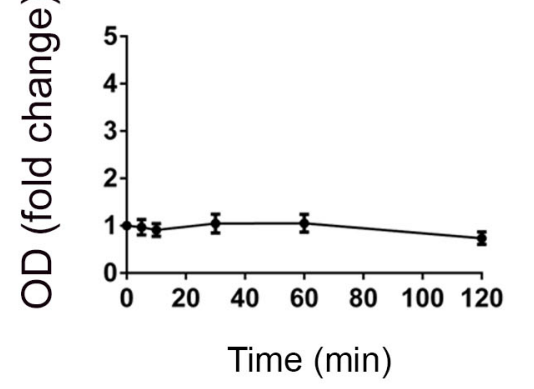

Mirabella et al., Fig 5 


\section{A}

B preprint (which was not certified by peer leview) is the author/funder, who has granted bioRxiv a license to display thêfreprint in

IL-6

Stattic

P-Tyr 705

STAT-3

total
Ctrl

\section{IL-6 + Vehicle}

IL-6 + Stattic

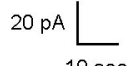

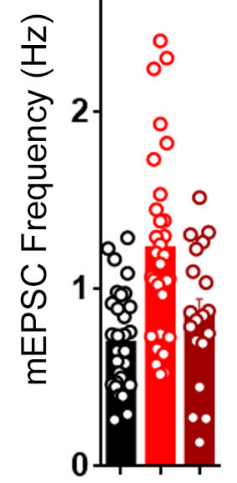

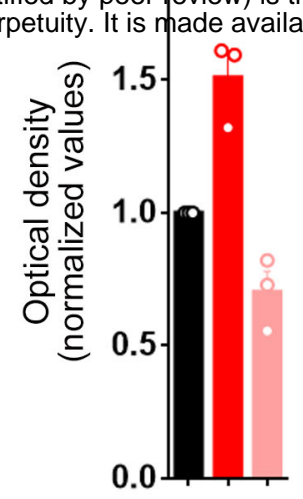

IL-6 - + +

Stattic - - +

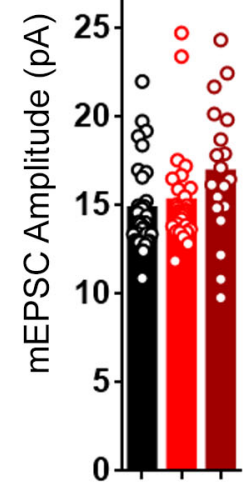

IL6 - + + IL6 - + +

Stattic - - + Stattic - - +

F
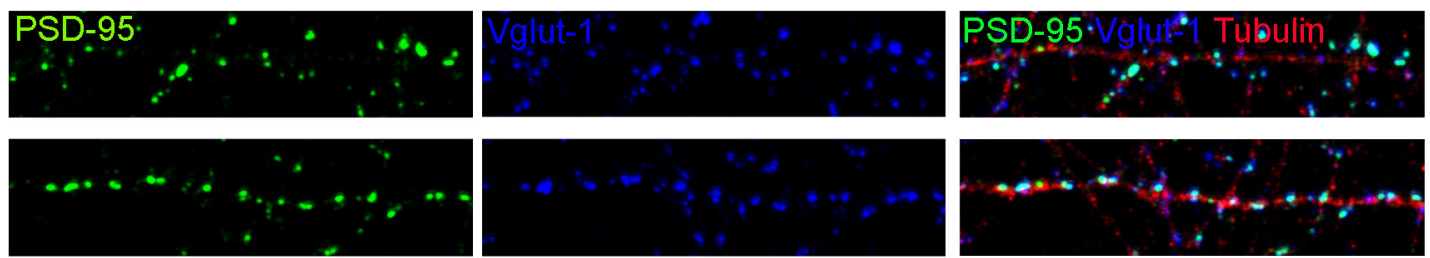

IL $-6+$
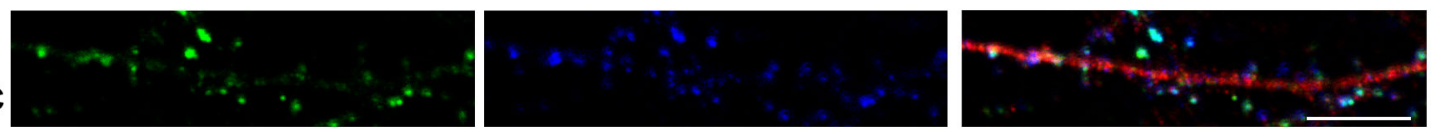

G

GFP

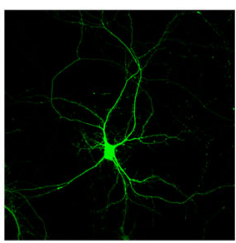

STAT3

Y705E

STAT3 Y705F
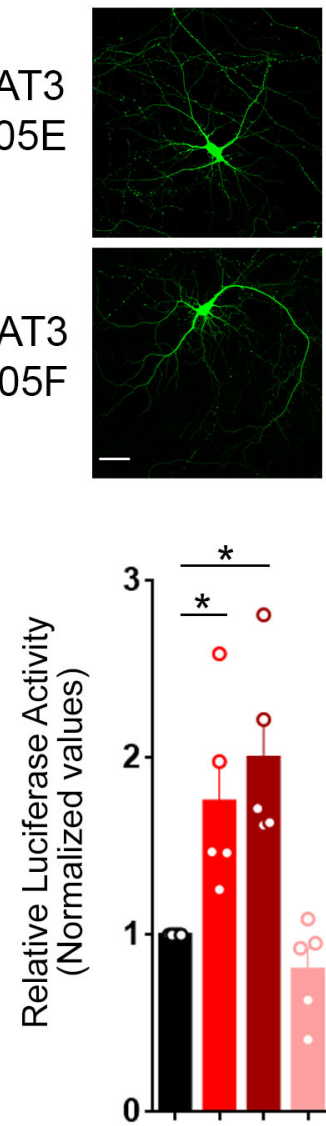

IL $-6-+++$

Gall $(\mu \mathrm{M})$ - 14
Myc

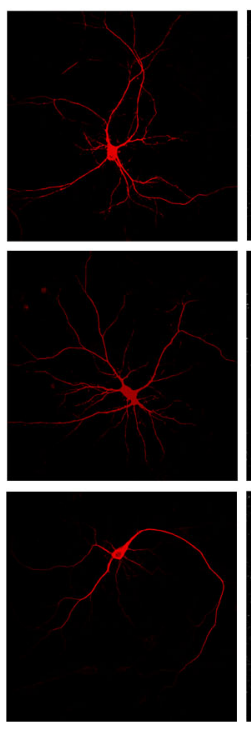

J

Ctrl

IL-6 + Vehicle

IL-6 $1 \mu \mathrm{M}$ Galiellalactone

IL-6 $4 \mu \mathrm{M}$ Galiellalactone $20 \mathrm{pA}$

Merge

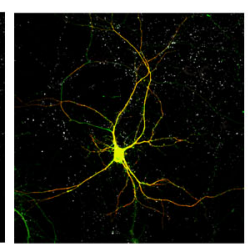

GFP/Myc/PSD-95
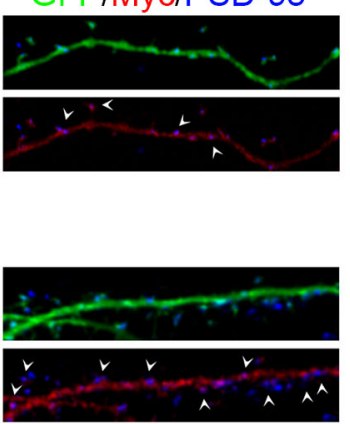

H

IL $6-++$

Stattic - - +
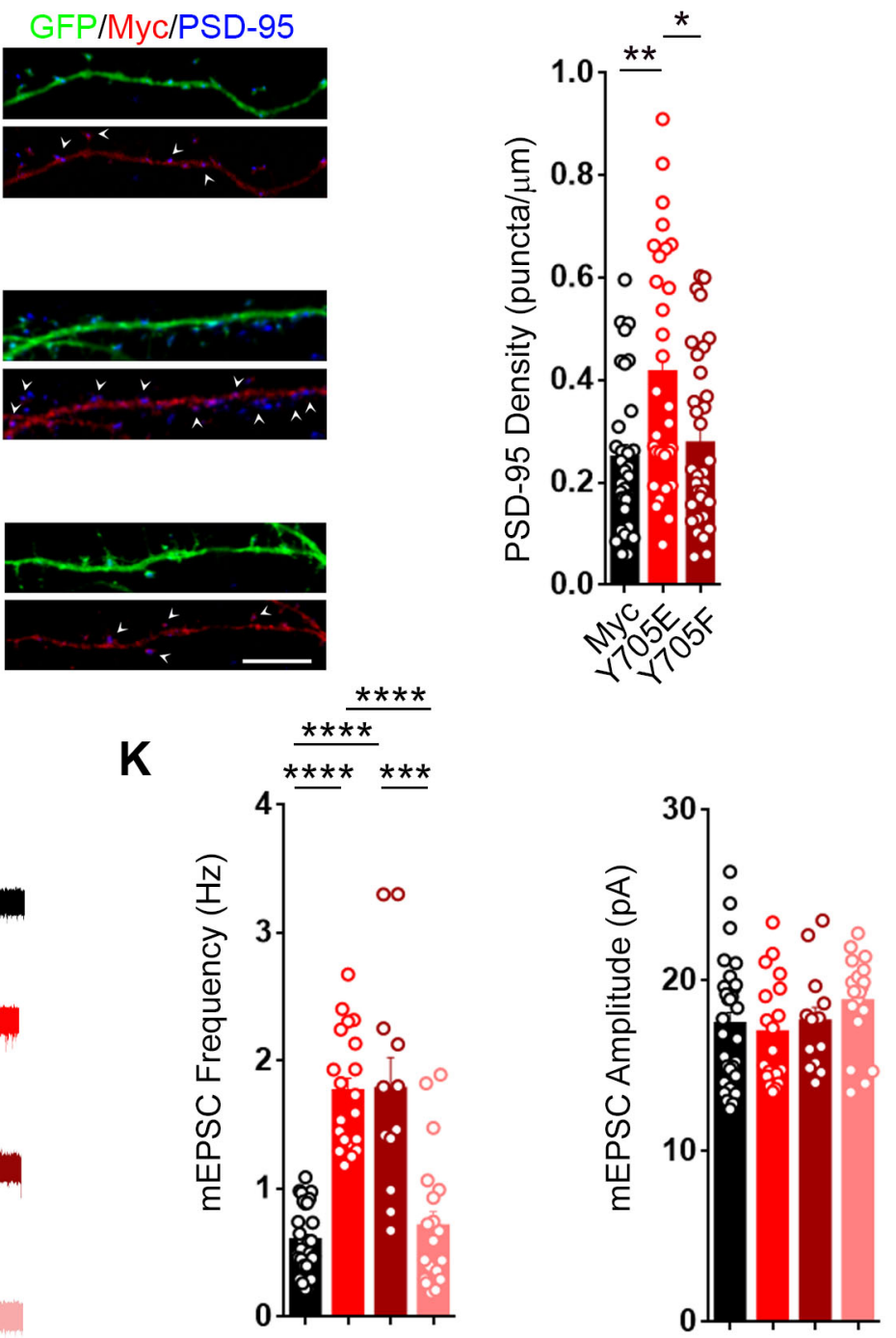
Mirabella et al., Fig 6

IL -6 - + + +

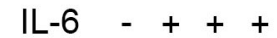

Gall (mM) - - 14 


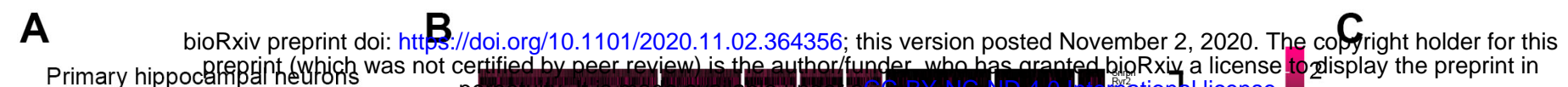
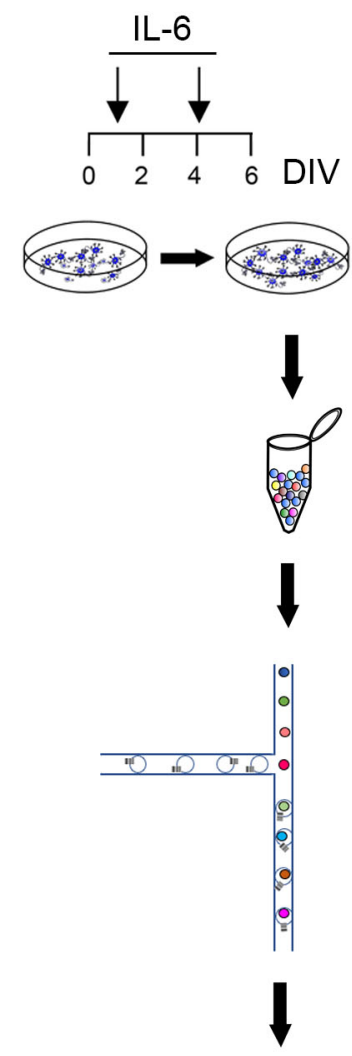

$10 \mathrm{X}$

Single-Seq

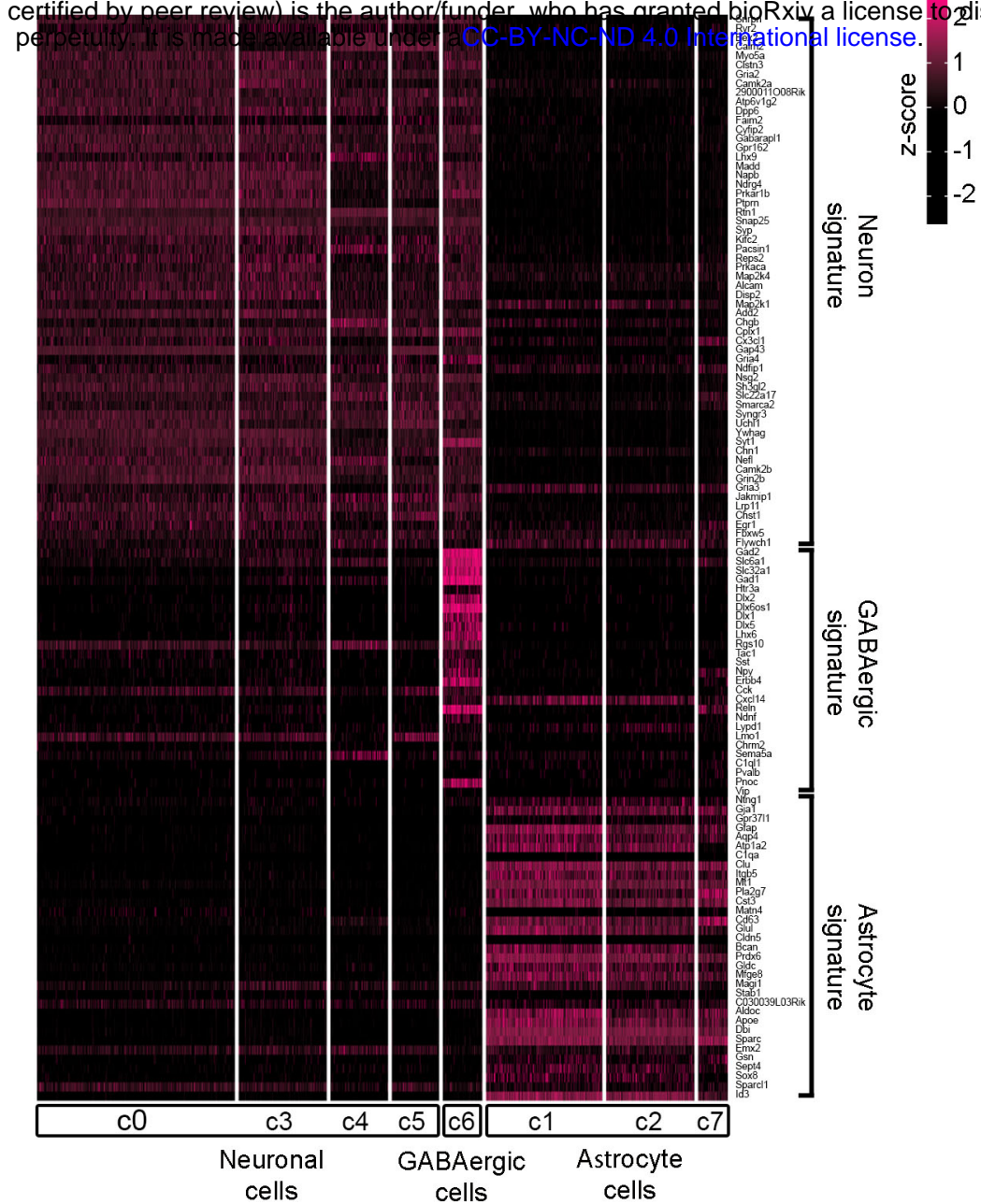

GABA neurons (c6)

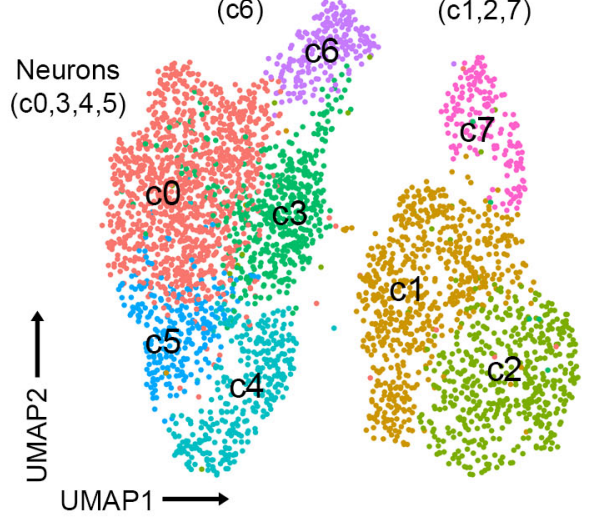

Astrocytes

$(\mathrm{c} 1,2,7)$

$\mathbf{E}$

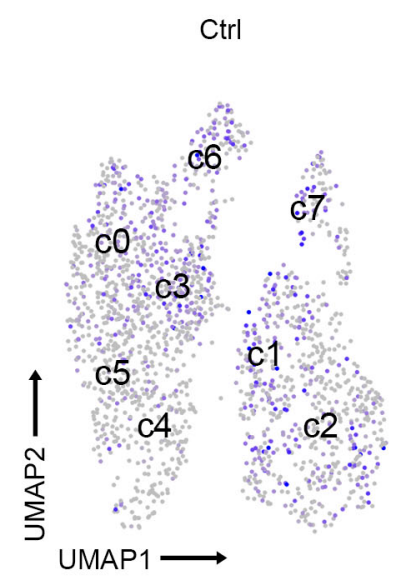

F

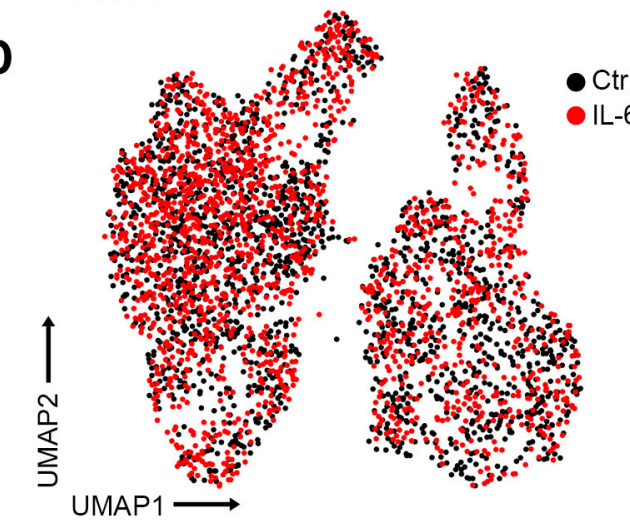

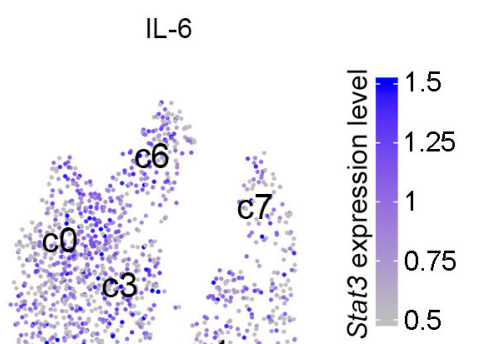

C5 C4

$\mathrm{c4} \quad \mathrm{c} 2$

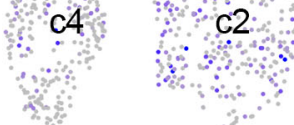

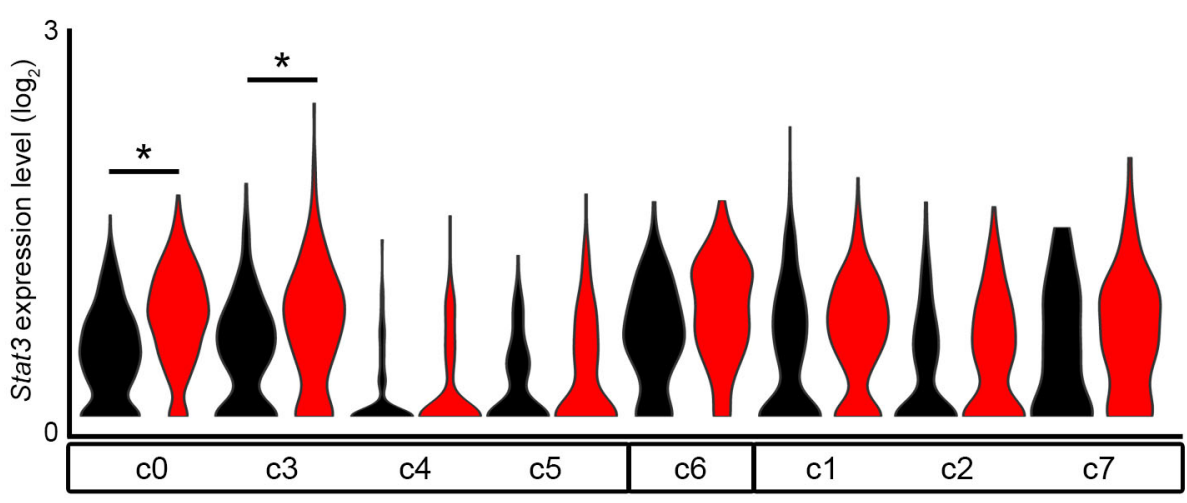

\begin{tabular}{|l|ll|ll|lll|}
\multicolumn{1}{l}{ gene } & $r$ & $p$ value $(r)$ & $\log _{2} \mathrm{FC} c 0$ & $p$ value c0 & $\log _{2} \mathrm{FC}$ c3 & $p$ value c3 \\
\hline Rgs4 & 0.31 & $3.03 \mathrm{E}^{-21}$ & 0.28 & $2.88 \mathrm{E}^{-29}$ & 0.20 & $3.70 \mathrm{E}^{-05}$ \\
Gm10076 & 0.13 & $1.16 \mathrm{E}^{-04}$ & 0.38 & $8.60 \mathrm{E}^{-62}$ & 0.36 & $4.01 \mathrm{E}^{-21}$ \\
Tmsb10 & 0.10 & $2.30 \mathrm{E}^{-03}$ & 0.25 & $4.19 \mathrm{E}^{-35}$ & 0.21 & $5.82 \mathrm{E}^{-16}$ \\
Gm9844 & 0.07 & $3.23 \mathrm{E}^{-02}$ & 0.22 & $2.54 \mathrm{E}^{-23}$ & 0.25 & $1.36 \mathrm{E}^{-10}$ \\
\hline
\end{tabular}

H IL-6
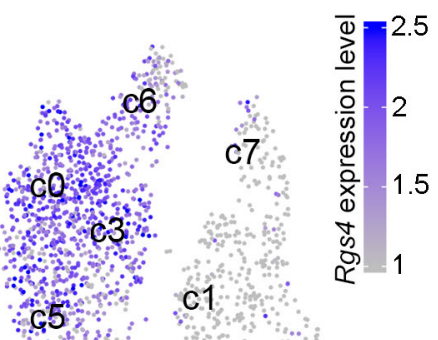

G5
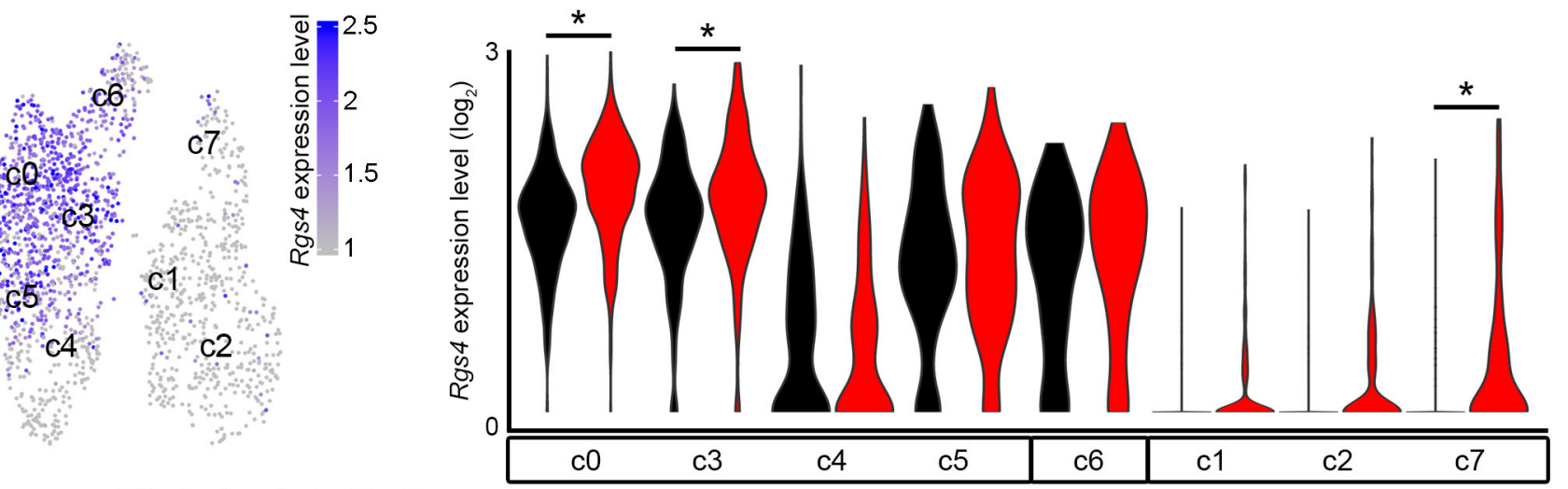

Mirabella et al., Fig 7 
bioRxiv preprint doi: https://doi.org/10.1101/2020.11.02.364356; this version posted November 2, 2020. The copyright holder for this preprint (which was not certified by peer review) is the author/funder, who has granted bioRxiv a license to display the preprint in

A

RGS4 mRNA level

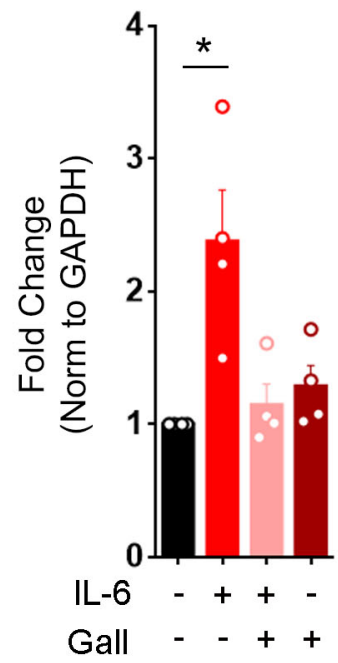

D

\section{Ctrl}

IL-6 + Vehicle

IL-6 + CCG-63802

CCG-63802
B

Transfection:

STAT3 Y705E + GFP

STAT3 Y705F + GFP
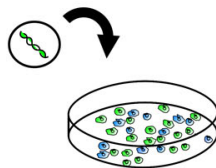

$\mathrm{N} 2 \mathrm{~A}$

cell line

\author{
P
}

$\begin{array}{cc}\text { C } & \text { RGS4 } \\ & \text { mRNA level }\end{array}$

$\mathbf{F}$
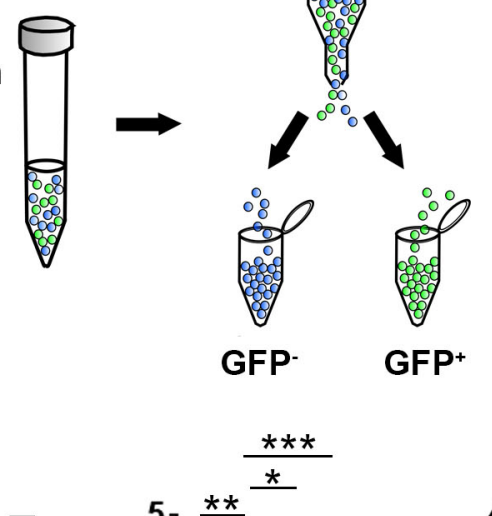

E

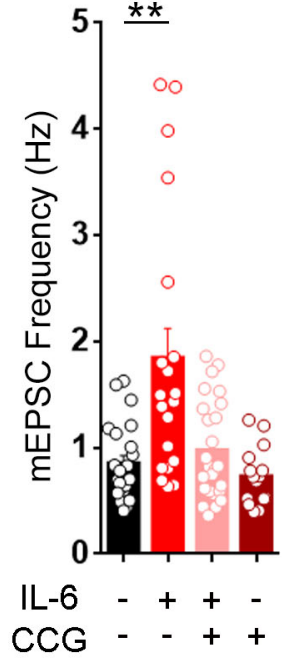

STAT3 mRNA level

FACS Sorting
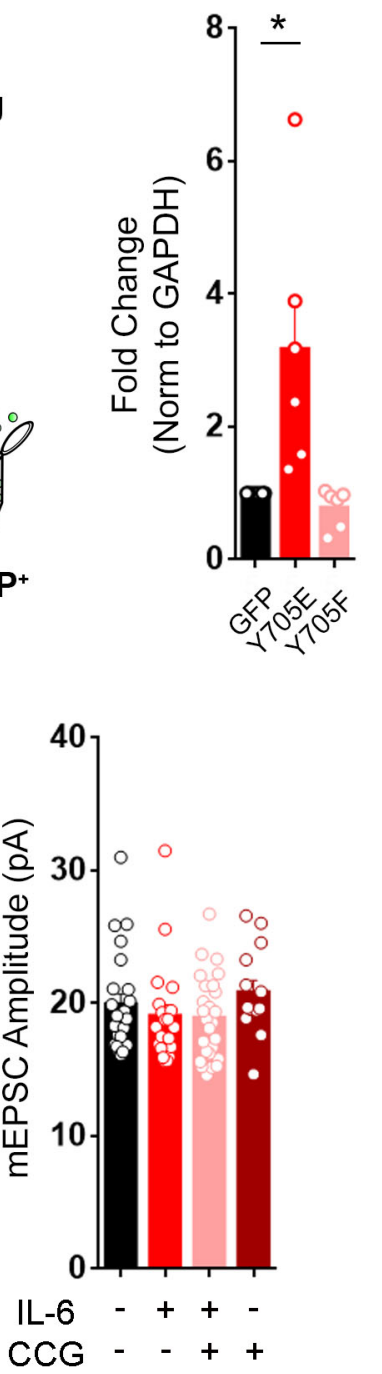

RGS4 mRNA level

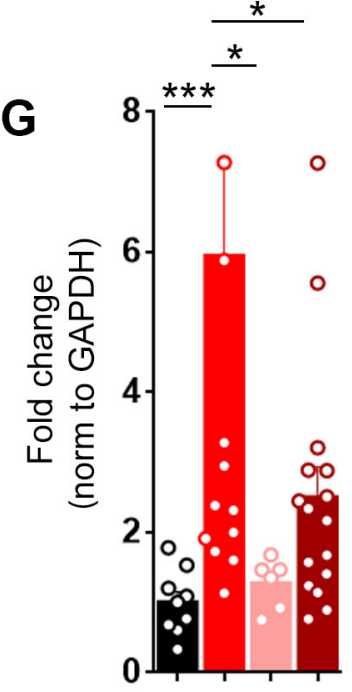

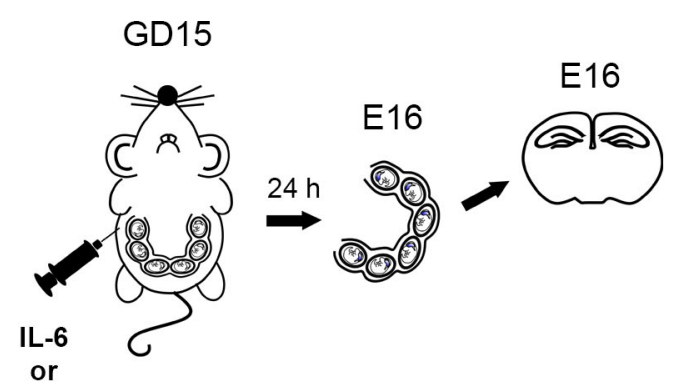

MIA model

(Poly (I:C))

IL-6 - + -

Poly (I:C) - - 220

[mg/kg]

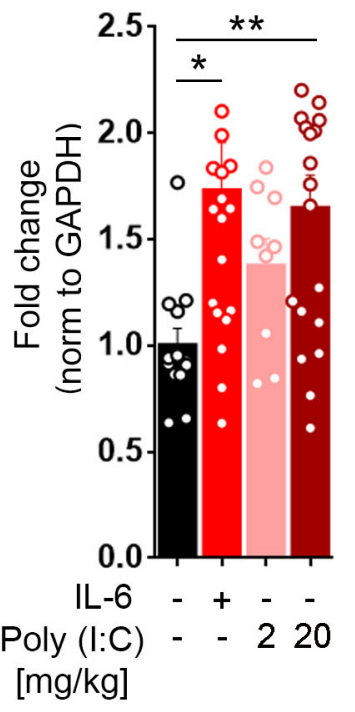

Mirabella et al., Fig 8 